\title{
The role of arginine in human wound healing
}

Citation for published version (APA):

Debats, I. B. J. G. (2011). The role of arginine in human wound healing. [Doctoral Thesis, Maastricht University]. https://doi.org/10.26481/dis.20110923id

Document status and date:

Published: 01/01/2011

DOI:

10.26481/dis.20110923id

Document Version:

Publisher's PDF, also known as Version of record

\section{Please check the document version of this publication:}

- A submitted manuscript is the version of the article upon submission and before peer-review. There can be important differences between the submitted version and the official published version of record.

People interested in the research are advised to contact the author for the final version of the publication, or visit the DOI to the publisher's website.

- The final author version and the galley proof are versions of the publication after peer review.

- The final published version features the final layout of the paper including the volume, issue and page numbers.

Link to publication

\footnotetext{
General rights rights.

- You may freely distribute the URL identifying the publication in the public portal. please follow below link for the End User Agreement:

www.umlib.nl/taverne-license

Take down policy

If you believe that this document breaches copyright please contact us at:

repository@maastrichtuniversity.nl

providing details and we will investigate your claim.
}

Copyright and moral rights for the publications made accessible in the public portal are retained by the authors and/or other copyright owners and it is a condition of accessing publications that users recognise and abide by the legal requirements associated with these

- Users may download and print one copy of any publication from the public portal for the purpose of private study or research.

- You may not further distribute the material or use it for any profit-making activity or commercial gain

If the publication is distributed under the terms of Article $25 \mathrm{fa}$ of the Dutch Copyright Act, indicated by the "Taverne" license above, 


\section{THE ROLE OF ARGININE IN HUMAN WOUND HEALING}


(C) Iris Debats, Maastricht

Layout: Tiny Wouters

Production: Datawyse | Universitaire Pers Maastricht

ISBN: 9789461590763 


\section{THE ROLE OF ARGININE IN}

\section{HUMAN WOUND HEALING}

\section{PROEFSCHRIFT}

Ter verkrijging van de graad van doctor aan de Universiteit Maastricht, op gezag van de Rector Magnificus, Prof. mr. G.P.M.F. Mols,

volgens het besluit van het College van Decanen, in het openbaar te verdedigen op vrijdag 23 september 2011 om 14:00 uur

door

Iris Barbara Johanna Gertruda Debats

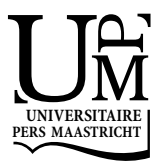


Promotor:

Prof. dr. R.R.W.J. van der Hulst

\section{Beoordelingscommissie:}

Prof. dr. C.H.C. Dejong (voorzitter)

Prof. dr. S.E.R. Hovius

Dr. M.C.G. van de Poll

Prof. dr. P.M. Steijlen

De studies in dit proefschrift kwamen mede tot stand door financiële ondersteuning van het Profileringsfonds academisch ziekenhuis Maastricht en de Nederlandse Brandwonden Stichting (NBS). 



\section{Contents}

Chapter 1 Introduction 9

Chapter 2 Arginine metabolism in human skin; using free vascularized 17 skin flaps as a model

Chapter 3 Role of arginine in superficial wound healing in man 29

Chapter $4 \quad$ Infected chronic wounds show different local and systemic $\quad 51$ arginine conversion compared to acute wounds

Chapter 5 Oral arginine supplementation and the effect on skin graft $\quad 71$ donor sites; a randomized clinical pilot study

Chapter 6 Intravenous arginine and human skin graft donor sites healing; a randomized controlled trial

Chapter 7 Summary and conclusions

Samenvatting

Dankwoord 



\section{Chapter 1}

\section{Introduction}

Vissers YL, Debats IB, Luiking YC, Jalan R, van der Hulst RR, Dejong CH, Deutz NE Partially published in Nutritional Research Reviews, 2004;17:193-210 


\section{Introduction}

The skin is the largest organ of our body, it's surface expands up to 2 square meters in an adult person. Different functions are ascribed to the skin: it provides a physical barrier, which protect us against outside influences (temperature, ultra violet radiation, micro-organisms); the skin warns us if there are changes in temperature, senses pressure and pain. In addition, our skin regulates our internal temperature through perspiration and by vasodilatation. Next to these physiological functions skin also has an important role in social interactions. Man communicates through their skin e.g. skin shows how we feel inside (mental state), we touch others with our skin and visa versa. Moreover, we use our skin to express ourselves (make-up, tattoos, piercings etc.).

The skin has regenerative abilities, needed to restore any disruptions in order to protect us from outside influence. Adequate wound healing is essential for us plastic surgeons. Treatment of wounds has a long history that goes back to the ancient Egypt and Greece. The Ebers Papyrus, circa 1500 BC, detail the use of wound treatments (lint, animal grease, honey) ${ }^{1}$. Hippocrates described the importance of draining pus from a wound and Galen detailed the principle of primary or secondary healing ${ }^{2,3}$. The first research important for wound healing dates from the $19^{\text {th }}$ century, when development of microbiology and cellular pathology occurred, by prominent physicians like Van Leeuwenhoek, Semmelweis, Lister and Virchow ${ }^{4}$. From then on we learned many things about normal wound healing physiology, which even led to therapeutical agents improving wound healing. However, the ultimate therapeutical agent still remains to be discovered. The complexity of wound healing is responsible for this. Normal wound healing is classically divided into three sequential phases: inflammation, proliferation and remodeling phase. During the inflammatory phase neutrophils, macrophages and lymphocytes clean the wound area from foreign material and prevent further bacterial colonization. Proliferation is characterized by multiple reparative cells, mainly fibroblasts. They form the structural proteins for a new matrix. In this phase endothelial and epithelial cell proliferation occur, leading to angiogenesis and epithelialization. During remodeling, the wound contracts to form a mature scar. The newly formed collagen is reorganized, resulting in increasing wound strength.

Different factors such as nutrition, radiation, ischemia, infection, diabetes, and medication influence wound healing. In this thesis we focused on nutrition and more specifically on arginine. The amino acid arginine and one of its metabolites nitric oxide (NO) have gathered broad attention in the last decades. This is related to the fact that arginine is not merely a component of proteins, but also participates in various metabolic processes, and is the direct precursor of NO. As such, arginine has been suggested to have important functions in pathophysiological events, such as sepsis, trauma and wound repair ${ }^{5-9}$. In most mammals, arginine is traditionally considered a conditionally essential amino acid ${ }^{10-13}$, because during growth and metabolic stress the 
endogenous production of arginine can become insufficient ${ }^{14,15}$. Normal daily intake of arginine is about 5-6 grams ${ }^{16,17}$, whilst whole body arginine flux ranges between 15 and 20 grams per day ${ }^{18-20}$. Apart from being an essential component of proteins, arginine plays a key role in several other metabolic pathways ${ }^{21,22}$. It is a precursor in the synthesis of polyamines: putrescine, spermine and spermidine ${ }^{5,23}$. These compounds are important in the growth and differentiation, for example of intestinal mucosal cells $^{23}$. Arginine is also a precursor for urea synthesis in the liver ${ }^{24}$ as well as in the kidney $^{25,26}$, and as such plays an important role as a waste nitrogen carrier in the urea cycle. Besides, arginine is a precursor in the hepatic and renal synthesis of creatine ${ }^{16,17,27}$, an important constituent of skeletal muscle ${ }^{22}$. Moreover, arginine appears to be converted by the enzyme arginine decarboxylase (EC 4.1.1.19) to agmatine, a metabolite that has been suggested to play a role in cell signaling and proliferation $^{22}$.

Via conversion by arginase, arginine is an indirect precursor for collagen formation through ornithine and proline, and as such involved in production of extracellular matrix molecules by fibroblasts ${ }^{28}$, both important in wound healing. Arginine has also been suggested to have immunotrophic effects. It stimulates release of growth hormone and its peripheral mediator IGF-1, stimulates release of prolactin ${ }^{21,23}$ and glucagon ${ }^{16}$ and has the strongest insulinogenic effect of all amino acids ${ }^{5}$. Besides, both arginine and NO are important mediators in T-cell mediated immunity ${ }^{29}$, cytokine induction $^{30}$ and macrophage mediated bacterial toxicity ${ }^{31}$.

Arginine is the sole precursor of nitric oxide (NO) synthesis through the nitric oxide synthase (NOS) pathway (EC 1.14.13.39) ${ }^{19,32}$. Three isoforms of NOS exist: NOS1, NOS2 and NOS3. All isoforms appear to be present in non-stimulated conditions, including NOS2 ${ }^{33,34}$. Microbacterial products and inflammatory cytokines can upregulate NOS2 ${ }^{35}$. NO currently receives considerable attention in view of its widespread effects, especially in the cardiovascular system ${ }^{36,37}$, where it functions as a signal molecule in vasodilatation and angiogenesis ${ }^{38}$. Through the same mechanisms, $\mathrm{NO}$ is involved in wound healing as it provides the wound area with sufficient oxygen and nutrition, which stimulates fibroblasts to synthesize collagen and keratinocytes to proliferate. Therefore NO takes an important part in building up repair-tissue in the wound.

In mice and rats with acute wounds, arginine was shown to be involved in wound healing via two metabolic pathways ${ }^{15-18,39-44}$. The first pathway is mainly active in the first three days and is catalyzed by NOS2, with citrulline and NO as end products. After a few days a shift to the second pathway occurs, catalyzed by arginase, which converts arginine into ornithine and urea. Ornithine is a precursor for collagen synthesis and cell growth. Schaffer and Lee ${ }^{15-18,39,42-44}$ demonstrated consumption of arginine during acute wound healing. In their studies, arginine levels in wound fluid of mice were not detectable, whereas end products of arginine metabolism were increased, thus suggesting local use of arginine in wounds. One of the products of arginine is ornithine, in itself a precursor for collagen synthesis. Studies with NOS2-knock-out mice supplied 
with dietary ornithine show increased wound breaking strength and collagen deposition.

In experimental studies with mice, Witte and Schaffer demonstrated the essential role of NO in wound healing by showing that NOS2-knock-out mice had delayed wound healing ${ }^{8}$ and NO inhibitors diminished wound collagen formation ${ }^{28}$. In tendon healing, Murrell et al. ${ }^{45}$ showed an increase in NOS activity during healing. Furthermore, NOS2 inhibition resulted in decreased tendon healing. Similar results were found concerning $\mathrm{NO}$ and fracture healing ${ }^{46}$. In experiments with NOS3-deficient mice, wound closure was delayed, tensile strength decreased and endothelial cell sprouting reduced ${ }^{38}$. This upregulation of the enzymes involved in the NO-pathway suggest an increased need for arginine in wound healing, as arginine is the sole precursor for NO.

Subsequently the hypothesis that arginine supplementation might be beneficial for wound healing was evaluated in several studies. In rats, $300 \mathrm{mg} / \mathrm{kg}$ of arginine per day enhanced wound tensile strength, hydroxyproline concentrations and collagen accumulation. In addition, it decreased neutrophil counts and adhesivity ${ }^{47}$. In NOS2 knock-out mice, NOS2 was shown to be a mediator in the effects of arginine supplementation on wound breaking strength and hydroxyproline content ${ }^{48}$. Arbbs et al. studied the effects of high arginine levels on early integration of biocompatible mesh grafts in rat abdominal wall. They found enhanced cell accumulation, formation of new vessels, fibroblast proliferation and type III collagen deposition in the argininesupplementation group ${ }^{49}$. In an experimental model for ileitis, ulcer healing was enhanced in rats supplied with diets containing $5 \%$ arginine ${ }^{50}$. Healing of colonic anastomosis in rats on postoperative day 6 was enhanced when rats were fed a perioperatively arginine enriched diet $^{51}$. Arginine supplementation improved wound immune cell function in mice, demonstrated by decreased pro-inflammatory IL-1 $\beta$, IL- 6 and increased anti-inflammatory IL-10 ${ }^{52}$. Arginine supplementation also affected angiogenesis. Angele et al. demonstrated increased microcirculation after arginine supplementation in mice with depressed skin and muscle blood flow after hemorrhage ${ }^{52}$. Arginine supplementation in a rabbit ischemic hind limb stimulated angiogenesis, as shown by marked increase in capillary density and enhanced collateral vessel development ${ }^{53}$. NOS3 was essential for angiogenesis in ischemic tissues in this model.

Diabetes is characterized by a NO deficient state at the wound site. In diabetic rats, arginine supplementation increased wound breaking strength. At the same time, plasma arginine and $\mathrm{NO}_{\mathrm{x}}$ levels were increased, while wound fluid levels of arginine and ornithine remained unaffected ${ }^{54}$. This suggests that the exogenously provided arginine is metabolized to NO by NOS2. In accordance, supplementing the NO donor molsidomine to these rats increased wound breaking strength, hydroxyproline content, urinary NO excretion and MMP-2 activity. It also decreased collagen I and III gene expression and arginase activity ${ }^{55}$.

Only few human studies investigated the effect of arginine as single pharmaconutrient on wound healing. Kirk et al. supplied thirty healthy elderly humans with 
17 grams of arginine per day and found improved serum IGF-1, enhanced hydroxyproline and total protein content deposition in subcutaneously placed catheters $^{56}$. Supplementation however, did not shorten time to complete epithelialization of skin defects of $2 \mathrm{~cm}^{2}$. Barbul et al. ${ }^{5}$ supplied arginine to 36 young healthy humans, divided in three groups, which received either 17 or 25 grams free arginine or placebo for 2 weeks. Both arginine-supplemented groups displayed enhanced hydroxyproline accumulation in subcutaneously placed catheters. Besides, lymphocyte immune reactivity was enhanced. So far, no human studies on the effect of arginine on angiogenesis in wound healing have been published. Moreover, the performed studies address experimental wounds, not relevant in clinical practice.

\section{Aim of the thesis}

Arginine supplementation has found its way into clinical practice. However, conclusions regarding arginine supplementation derive mainly from studies using commercially available nutritional supplements containing, besides arginine, other nutrients such as nucleotides and $\omega-3$ fatty acids (e.g. Impact , Novartis, Minneapolis, Minnesota, USA or Immune-Aid', McGaw, Irvine, California, USA). In general, two major problems exist with this kind of studies: 1) A mixture of nutrients is used: from a scientific point of view, this complicates interpretation of the results, since it is impossible to distil to what nutrient the effects should be contributed; besides, ingredients could interact antagonistically. 2) Control groups are often not present or are not supplied with isonitrogenous and/or isocaloric amounts: this makes it difficult to conclude whether treatments should be attributed to the specific pharmaconutrients or simply to the addition of amino acids and/or calories in general. The overall objective of this thesis is to contribute to a further understanding of:

1. the role of arginine in healing of surgical (acute) wounds (chapter 3)

2. the role of arginine in chronic wounds (chapter 4)

3. arginine metabolism in normal human skin (chapter 2)

4. the effect of arginine, as a monotherapy, on wound healing in a randomized controlled trial (chapter 5 and 6) 


\section{References}

1. Sipos P, Gyõry H, Hagymási K, Ondrejka P, Blázovics A. Special wound healing methods used in ancient egypt and the mythological background. World J Surg 2004;28:211-6.

2. Eming SA, Krieg T, Davidson JM. Inflammation in wound repair: molecular and cellular mechanisms. J Invest Dermatol 2007;127:514-25.

3. Broughton G 2nd, Janis JE, Attinger CE. Wound healing: an overview. Plast Reconstr Surg 2006;117(7 Suppl):1e-S-32e-S.

4. Nicoli Aldini N, Fini M, Giardino R. From Hippocrates to tissue engineering: surgical strategies in wound treatment. World J Surg 2008;32:2114-21.

5. Barbul A, Lazarou SA, Efron DT, Wasserkrug HL, Efron G. Arginine enhances wound healing and lymphocyte immune responses in humans. Surgery 1990;108:331-6; discussion 336-7.

6. Kirk SJ, Barbul A. Role of arginine in trauma, sepsis, and immunity. JPEN J Parenter Enteral Nutr 1990;14(5 Suppl):226S-9S.

7. Kelly E, Morris SM Jr, Billiar TR. Nitric oxide, sepsis, and arginine metabolism. JPEN J Parenter Enteral Nutr 1995;19:234-8.

8. Witte MB, Barbul A. Role of nitric oxide in wound repair. Am J Surg 2002;183:406-12.

9. Tzeng E, Billiar TR. Nitric oxide and the surgical patient. Identifying therapeutic targets. Arch Surg 1997;132:977-82.

10. Rose WC, Haines WJ, Warner DT. The amino acid requirements of man. V. The role of lysine, arginine, and tryptophan. J Biol Chem 1954;206:421-30.

11. Cynober L. OKG, glutamine, arginine and so on: nutrients or drugs? Clin Nutr 1996;15:214-5; author reply 215 .

12. Wakabayashi Y, Yamada E, Yoshida T, Takahashi N. Effect of intestinal resection and arginine-free diet on rat physiology. Am J Physiol 1995;269:G313-8.

13. Yu YM, Sheridan RL, Burke JF, Chapman TE, Tompkins RG, Young VR. Kinetics of plasma arginine and leucine in pediatric burn patients. Am J Clin Nutr 1996;64:60-6.

14. Windmueller HG, Spaeth AE. Source and fate of circulating citrulline. Am J Physiol, 1981;241:E473-80.

15. Newsholme EA, Beis I, Leech AR, Zammit VA. The role of creatine kinase and arginine kinase in muscle. Biochem J 1978;172:533-7.

16. Visek WJ. Arginine needs, physiological state and usual diets. A reevaluation. J Nutr 1986;116:36-46.

17. Heys SD, Gardner E. Nutrients and the surgical patient: current and potential therapeutic applications to clinical practice. J R Coll Surg Edinb 1999;44:283-93.

18. Castillo L, DeRojas-Walker T, Yu YM, Sanchez M, Chapman TE, Shannon D, Tannenbaum S, Burke JF, Young VR. Whole body arginine metabolism and nitric oxide synthesis in newborns with persistent pulmonary hypertension. Pediatr Res 1995;38:17-24.

19. Castillo L, Sánchez M, Vogt J, Chapman TE, DeRojas-Walker TC, Tannenbaum SR, Ajami AM, Young VR. Plasma arginine, citrulline, and ornithine kinetics in adults, with observations on nitric oxide synthesis. Am J Physiol 1995;268:E360-7.

20. Castillo L, Beaumier L, Ajami AM, Young VR. Whole body nitric oxide synthesis in healthy men determined from [15N] arginine-to-[15N]citrulline labeling. Proc Natl Acad Sci U S A 1996;93:11460-5.

21. Heys SD, Walker LG, Smith I, Eremin O. Enteral nutritional supplementation with key nutrients in patients with critical illness and cancer: a meta-analysis of randomized controlled clinical trials. Ann Surg 1999;229:467-77.

22. Wu G, Morris SM Jr. Arginine metabolism: nitric oxide and beyond. Biochem J 1998;336:1-17.

23. Cynober L. Can arginine and ornithine support gut functions? Gut 1994;35(1 Suppl):S42-5.

24. Cynober L, Coudray-Lucas C. Urinary urea nitrogen prediction of total urinary nitrogen. JPEN J Parenter Enteral Nutr 1995;19:174.

25. Bankir L, Bouby N, Trinh-Trang-Tan MM, Ahloulay M, Promeneur D. Direct and indirect cost of urea excretion. Kidney Int 1996;49:1598-607.

26. Morel F, Hus-Citharel A, Levillain O. Biochemical heterogeneity of arginine metabolism along kidney proximal tubules. Kidney Int 1996;49:1608-10.

27. Perez GO, Epstein M, Rietberg B, Loutzenhiser R. Metabolism of arginine by the isolated perfused rat kidney. Am J Physiol 1978;235:F376-80. 
28. Schäffer MR, Tantry U, Thornton FJ, Barbul A. Inhibition of nitric oxide synthesis in wounds: pharmacology and effect on accumulation of collagen in wounds in mice. Eur J Surg 1999;165:262-7.

29. Daly JM, Reynolds J, Thom A, Kinsley L, Dietrick-Gallagher M, Shou J, Ruggieri B. Immune and metabolic effects of arginine in the surgical patient. Ann Surg 1988;208:512-23.

30. Reynolds JV, Daly JM, Shou J, Sigal R, Ziegler MM, Naji A. Immunologic effects of arginine supplementation in tumor-bearing and non-tumor-bearing hosts. Ann Surg 1990;211:202-10.

31. Hibbs JB Jr, Vavrin Z, Taintor RR. L-arginine is required for expression of the activated macrophage effector mechanism causing selective metabolic inhibition in target cells. J Immunol 1987;138:550-65.

32. Roth JD, Rowland NE. Effects of L-arginine on angiotensin II-related water and salt intakes. Physiol Behav 1998;63:729-32.

33. Miller MJ, Grisham MB. Nitric oxide as a mediator of inflammation?-You had better believe it. Mediators Inflamm 1995;4:387-96.

34. Hoffman RA, Zhang G, Nüssler NC, Gleixner SL, Ford HR, Simmons RL, Watkins SC. Constitutive expression of inducible nitric oxide synthase in the mouse ileal mucosa. Am J Physiol 1997;272: G383-92.

35. Morris SM Jr, Billiar TR. New insights into the regulation of inducible nitric oxide synthesis. Am J Physiol 1994;266:E829-39.

36. Hirata Y, Nagata D, Suzuki E, Nishimatsu H, Suzuki J, Nagai R. Diagnosis and treatment of endothelial dysfunction in cardiovascular disease. Int Heart J 2010;51:1-6.

37. Levy AS, Chung JC, Kroetsch JT, Rush JW. Nitric oxide and coronary vascular endothelium adaptations in hypertension. Vasc Health Risk Manag 2009;5:1075-87.

38. Lee PC, Salyapongse AN, Bragdon GA, Shears LL 2nd, Watkins SC, Edington HD, Billiar TR. Impaired wound healing and angiogenesis in eNOS-deficient mice. Am J Physiol 1999;277:H1600-8.

39. Lee RH, Efron D, Tantry U, Barbul A. Nitric oxide in the healing wound: a time-course study. J Surg Res 2001;101:104-8.

40. Albina JE, Mills CD, Henry WL Jr, Caldwell MD. Temporal expression of different pathways of 1-arginine metabolism in healing wounds. J Immunol 1990;144:3877-80.

41. Efron DT, Most D, Barbul A. Role of nitric oxide in wound healing. Curr Opin Clin Nutr Metab Care 2000;3:197-204.

42. Schäffer MR, Tantry U, van Wesep RA, Barbul A. Nitric oxide metabolism in wounds. J Surg Res 1997; 71:25-31.

43. Albina JE, Mills CD, Barbul A, Thirkill CE, Henry WL Jr, Mastrofrancesco B, Caldwell MD. Arginine metabolism in wounds. Am J Physiol 1988;254:E459-67.

44. Efron D, Barbul A. Role of arginine in immunonutrition. J Gastroenterol 2000;35 Suppl 12:20-3.

45. Murrell GA, Szabo C, Hannafin JA, Jang D, Dolan MM, Deng XH, Murrell DF, Warren RF. Modulation of tendon healing by nitric oxide. Inflamm Res 1997;46:19-27.

46. Diwan AD, Wang MX, Jang D, Zhu W, Murrell GA. Nitric oxide modulates fracture healing. J Bone Miner Res 2000;15:342-51.

47. Cantürk NZ, Vural B, Cantürk Z, Esen N, Vural S, Solakoglu S, Kirkal G. The role of L-arginine and neutrophils on incisional wound healing. Eur J Emerg Med 2001;8:311-5.

48. Shi HP, Efron DT, Most D, Tantry US, Barbul A. Supplemental dietary arginine enhances wound healing in normal but not inducible nitric oxide synthase knockout mice. Surgery 2000;128:374-8.

49. Arbśs MA, Ferrando JM, Vidal J, Quiles MT, Huguet P, Castells J, Segarra A, Armengol M, Schwartz S. Early effects of exogenous arginine after the implantation of prosthetic material into the rat abdominal wall. Life Sci 2000;67:2493-512.

50. Sukumar P, Loo A, Magur E, Nandi J, Oler A, Levine RA. Dietary supplementation of nucleotides and arginine promotes healing of small bowel ulcers in experimental ulcerative ileitis. Dig Dis Sci 1997; 42:1530-6.

51. Shashidharan M, Lin KM, Ternent CA, Smyrk TC, Thorson AG, Blatchford GJ, Christensen MA. Influence of arginine dietary supplementation on healing colonic anastomosis in the rat. Dis Colon Rectum 1999;42:1613-7.

52. Angele MK, Nitsch SM, Hatz RA, Angele P, Hernandez-Richter T, Wichmann MW, Chaudry IH, Schildberg FW. L-arginine: a unique amino acid for improving depressed wound immune function following hemorrhage. Eur Surg Res 2002;34:53-60. 
53. Murohara T, Asahara T, Silver M, Bauters C, Masuda H, Kalka C, Kearney M, Chen D, Symes JF, Fishman MC, Huang PL, Isner JM. Nitric oxide synthase modulates angiogenesis in response to tissue ischemia. J Clin Invest 1998;101:2567-78.

54. Witte MB, Kiyama T, Barbul A. Nitric oxide enhances experimental wound healing in diabetes. Br J Surg 2002;89:1594-601.

55. Witte MB, Thornton FJ, Tantry U, Barbul A. L-Arginine supplementation enhances diabetic wound healing: involvement of the nitric oxide synthase and arginase pathways. Metabolism 2002;51: 1269-73.

56. Kirk SJ, Hurson M, Regan MC, Holt DR, Wasserkrug HL, Barbul A. Arginine stimulates wound healing and immune function in elderly human beings. Surgery 1993;114:155-9; discussion 160. 


\section{Chapter 2}

Arginine metabolism in human skin; using free vascularized skin flaps as a model

IBJG Debats, MCG van de Poll, RRWJ van der Hulst, O Bekers, NEP Deutz In submission 


\section{Abstract}

\section{Background}

The skin is the body's largest organ; it protects the body against fluid loss and invasion of microorganisms. When it becomes damaged, arginine supplementation improves its healing in rodents. This is attributed to the local conversion of arginine to its metabolites nitric oxide (NO) and ornithine. However, amino acid metabolism within the skin and definite mechanisms by which arginine supplementation may improve wound healing remain unknown. Aim of this study was to investigate the physiology of amino acid metabolism in human skin.

\section{Methods}

Eleven patients undergoing reconstructive surgery using a free vascularized skin flap received a primed continuous intravenous infusion of ${ }^{15} \mathrm{~N}_{2}$-arginine. Arterial and venous blood was sampled and arteriovenous gradients of unlabeled and labeled amino acids were measured to assess skin uptake, conversion, and release of arginine, citrulline, ornithine and other amino acids.

\section{Results}

Normal human skin showed significant net uptake of ${ }^{15} \mathrm{~N}_{2}$-arginine. This was accompanied by net release of citrulline and ornithine. No net release of ${ }^{15} \mathrm{~N}$-labelled citrulline or urea could be demonstrated. Net release of essential and other protein bound amino acids reflected protein breakdown.

\section{Conclusion}

This is the first study of skin amino acid metabolism in humans. Arginine was taken up by the 'normal' skin, probably to serve as precursor for both NO and ornithine production. These data support the view that arginine metabolism is important in skin physiology and wound healing and provide rationale for further research concerning the role of arginine supplementation in acute and chronic wounds. 


\section{Introduction}

The skin is the largest organ of the human body; it protects the body against fluid loss and invasion of micro-organisms. Disruptions of this barrier are common after trauma, surgical interventions and burns. The response is immediate repair of the skin's \integrity by wound healing. Knowledge of skin nitrogen metabolism is important to understand this complex process of wound healing. Numerous mediators play a role in wound healing. The last decade, the amino acid arginine has received a lot of attention. In normal healthy conditions the human body can generate a substantial amount of arginine endogenously ${ }^{1}$. However during stress situations (sepsis, trauma, cancer), endogenous arginine production may not be sufficient to match the arginine requirements $^{2-5}$. Arginine is therefore considered a conditional essential amino acid. Arginine can be degraded enzymatically by the enzymes arginase or nitric oxide synthase. The enzyme arginase (ASE) converts arginine to urea and ornithine ${ }^{6}$. Ornithine can be metabolized to polyamines, that play an important role in cell growth and proliferation. Alternatively, ornithine can be converted to proline, a collagen precursor, which is essential for wound healing.Two isotypes of ASE exist; ASE-1 is liver arginase, part of urea cycle. ASE-2 is a mitochondrial enzyme in many tissues outside the liver. Nitric oxide synthase (NOS) converts arginine to nitric oxide (NO) and citrulline ${ }^{7,8}$. The short-living molecule $\mathrm{NO}$ is involved in regulating many processes like neurotransmission, angiogenesis and immune response. Previous studies have shown the importance of arginine in experimental wound healing as supplementation with arginine improves wound healing whereas arginine-free diets impair wound healing ${ }^{9-16}$. Changes in plasma and wound fluid concentrations are used as markers for activities of specific arginine metabolic enzymes. A decrease in wound fluid levels of arginine and an increase in ornithine, citrulline and NOx are observed, suggesting arginine conversion by NOS and arginase ${ }^{17-20}$. Human studies have shown that diets enriched with arginine stimulate the immune system and wound healing (using hydroxyproline content in granulation tissue as a marker) ${ }^{16,21-30}$. However, potential mechanisms by which arginine supplementation may affect wound healing remain unclear. The aim of this study was to investigate arginine metabolism in normal human skin. The studies were conducted in patients undergoing free vascularised skin flap transplantation. This enabled us to measure arteriovenous concentration gradients of labelled and unlabelled amino acids across an isolated segment of the human skin.

\section{Materials and methods}

\section{Patients}

A total of 11 patients (all female, median (range) age 43 (39-53), admitted for elective plastic surgery, participated in this study conducted at the department of Plastic 
Surgery, University Hospital Maastricht, the Netherlands. Median weight and BMI were $80(60-87) \mathrm{kg}$ and $29.6(24.0-35.6)$ respectively. All patients underwent reconstructive surgery using a free vascularized DIEP flap (Deep Inferior Epigastric artery Perforator). This is a perforator-based skin flap, consisting of both skin and subcutaneous fat ${ }^{31}$. Table 2.1 shows the patients characteristics.

Patients known with active cancer, liver disease, inborn errors of metabolism, insulindependent diabetes or use of steroids were excluded from the study. On the day of admission routine blood tests were performed. Patients were fully informed about the purpose of the study and the potential risks involved. The study was approved by the Medical Ethical committee of the University Hospital Maastricht and all patients gave written informed consent. Oral intake, except for water, was ceased at 12 am on the day of admission and all patients were transported to the operation theatre at approximately 7:30 am the next day. All surgical procedures were performed under general anesthesia. Skin flaps were dissected using standard operative techniques and performed by the same plastic surgeon.

\begin{tabular}{lc} 
Table 2.1 & Patient characteristics. \\
\hline & $\begin{array}{c}\text { DIEP } \\
\text { Median/range }\end{array}$ \\
\hline Male/Female & $0 / 11^{\mathrm{A}}$ \\
Active cancer & $0^{\mathrm{A}}$ \\
Age (years) & $43(39-53)$ \\
Weight $(\mathrm{kg})$ & $80.0(60.0-87.0)$ \\
BMI $(\mathrm{Kg} / \mathrm{cm} 2)$ & $29.6(24.0-35.6)$ \\
\hline
\end{tabular}

\section{Tracer infusion and blood sampling}

Surgery was performed following an overnight fast, anaesthetic management was according to institutional routines and included placement of two peripheral venous catheters and an arterial line. Anaesthesia was maintained using isoflurane and propofol. After induction of anaesthesia, an additional peripheral venous catheter was placed in an antecubital vein for tracer infusion. This catheter was kept patent with normal saline until the start of the tracer infusion. A baseline blood sample was drawn from the arterial line, followed by the start of a primed continuous intravenous tracer infusion. Patients received priming doses in $45 \mathrm{ml}$ normal saline solution of L-[guanidino- ${ }^{15} \mathrm{~N}_{2}$ ] arginine followed by constant intravenous infusion of L-[guanidino${ }^{15} \mathrm{~N}_{2}$ ] arginine $(3.51 \mu \mathrm{mol} / \mathrm{kg} / \mathrm{h}$ ), for two hours (Cambridge Isotope Labs, Andover, MA, USA). Infusates were prepared from sterile, pyrogen-free powders. Subsequently, blood samples were collected from an arterial line or peripheral venous line at $60 \mathrm{~min}$, $90 \mathrm{~min}, 105 \mathrm{~min}$ and $120 \mathrm{~min}$ after infusion to determine steady state conditions. At $\mathrm{t}=120 \mathrm{~min}$, when the flaps were dissected, arterial and venous blood samples were taken from the vascularized skin flaps. First the draining vein was cannulated and $10 \mathrm{ml}$ 
of blood was collected, no forced suction was used during blood collection, to prevent hemolysis. The time needed to collect this amount of blood was recorded to calculate blood flow through the flap, expressed as $\mathrm{ml} / \mathrm{min}$. Simultaneously, an arterial blood sample was collected from a central arterial line or from the supplying artery of the skin flap through cannulation.

\section{Sample processing and analysis}

Blood was collected in pre-chilled heparinized vacuum tubes (BD Vacutainer, Franklin Lakes, NJ), placed on ice, and processed as described before ${ }^{32}$. Within one hour, blood was centrifuged $\left(10 \mathrm{~min}, 4000 \mathrm{rpm}, 4^{\circ} \mathrm{C}\right.$ ) and $500 \mu \mathrm{l}$ of plasma was added to $80 \mathrm{mg}$ dry sulphosalicylic acid (Across Inc., Geel, Belgium) to precipitate plasma proteins. After vortex mixing deproteinized plasma samples were snap frozen in liquid nitrogen and stored at $-80^{\circ} \mathrm{C}$ until analysis. The skin flap was weighted and the surface measured.

Amino acid concentrations in deproteinized samples and infusates were measured using high performance liquid chromatography as described elsewhere ${ }^{33}$. Urea concentrations were determined by the routine clinical chemistry lab of our hospital. Arginine, citrulline and urea enrichments were measured by liquid chromatographymass spectrometry ${ }^{34}$.

\section{Calculations of amino acid kinetics}

Isotopic enrichment was expressed as tracer-to-tracee ratio (TTR, \%), taking into account the contribution of overlapping isotopomer distributions of the tracee and tracers with lower masses to the measured TTR as described by Vogt et al. ${ }^{35}$. Within 30 minutes isotopic steady state was achieved (data not shown).

Since blood flow data yielded by the applied methods appeared to be unreliable transorgan concentration gradients rather than transorgan fluxes were calculated. The amino acid net balance (NB) was calculated as the difference between arterial ([A]) and venous ([V]) amino acid plasma concentrations:

$\mathrm{NB}=[\mathrm{V}]-[\mathrm{A}]$

Accordingly, a positive balance indicates organ specific net release whereas a negative balance indicates net uptake.

The net balance of labelled amino acids (tracer net balances, tNB) was calculated by multiplying arterial and venous amino acid concentrations with amino acid arterial and venous enrichments $\left(T T R_{A}, T T R_{V}\right)$ :

$\mathrm{tNB}=\left(\left[\mathrm{TTR}_{\mathrm{A}} \times[\mathrm{A}]\right)-\left(\mathrm{TTR}_{\mathrm{V}} \times[\mathrm{V}]\right)\right.$ 
Absolute arginine uptake by the skin flaps was calculated from tracer net balance and ${ }^{15} \mathrm{~N}_{2}$ arginine enrichment of the venous plasma sample:

absolute uptake $=\mathrm{tNB} / \mathrm{TTR}_{\mathrm{V}}$

\section{Statistics}

Because of the small sample size non-parametric analyses were selected. Arteriovenous gradients and tracer net balances were tested versus a theoretical mean of zero using a Wilcoxon signed rank test. Correlations between arteriovenous concentration differences of arginine, citrulline and other amino acids were calculated with the use of the Spearman's test. Results are expressed as median and interquartile ranges (IQR). All statistical calculations were performed using Prism 4.0 for Windows (GraphPad Software Inc. San Diego, CA). A p-value $<0.05$ was considered to indicate statistical significance.

\section{Results}

Experimental studies were completed as scheduled in all 11 patients and no protocol violations occurred. Surgical procedures were successful in all cases, particularly the perfusion of the flaps was maintained intact throughout the infusion of ${ }^{15} \mathrm{~N}_{2}$ arginine. Isotopic steady state was achieved within 30 minutes in all patients and maintained throughout the remainder of the experiments (data not shown). Median (IQR) arterial ${ }^{15} \mathrm{~N}_{2}$ arginine enrichment was $6.0(5.0-8.1) \%$.

\section{Arginine uptake and metabolism}

The DIEP flaps significantly extracted ${ }^{15} \mathrm{~N}_{2}$ arginine from the circulation (Figure 2.1). The arterial arginine concentration was 90 (58-99) $\mu \mathrm{mol} / \mathrm{l}$. The median (interquartile range) absolute arginine uptake by the DIEP flaps was 19.0 (7.2-33.2) $\mu \mathrm{mol} / \mathrm{I}(p=0.007)$. From these numbers, a fractional arginine extraction of 13.5 (2.4-22.3)\% could be calculated. There was however no correlation between arterial arginine supply and arginine uptake in the skin flaps (Figure 2.2).

The human skin flaps significantly released ornithine and citrulline, evidenced by arteriovenous concentration gradients that both significantly differed from zero 8.0 $(5.8-8.8) \mu \mathrm{mol} / \mathrm{l}$ and $1.5(0.5-3.4) \mu \mathrm{mol} / \mathrm{l}$ respectively (both $\mathrm{p}<0.005)$ (Figure 2.1).

Somewhat conflictingly, no significant release of ${ }^{15} \mathrm{~N}$ labeled products of arginine metabolism i.e. ${ }^{15} \mathrm{~N}$ urea, representing arginase activity or ${ }^{15} \mathrm{~N}$ citrulline, representing NOS activity could be observed in the present study. The arteriovenous concentration gradient of nitrite was $-0.07(-0.9-0.04) \mu \mathrm{mol} / \mathrm{l}$, however this gradient failed to reach statistical significance when compared to a theoretical median of zero $(p=0.08)$. 


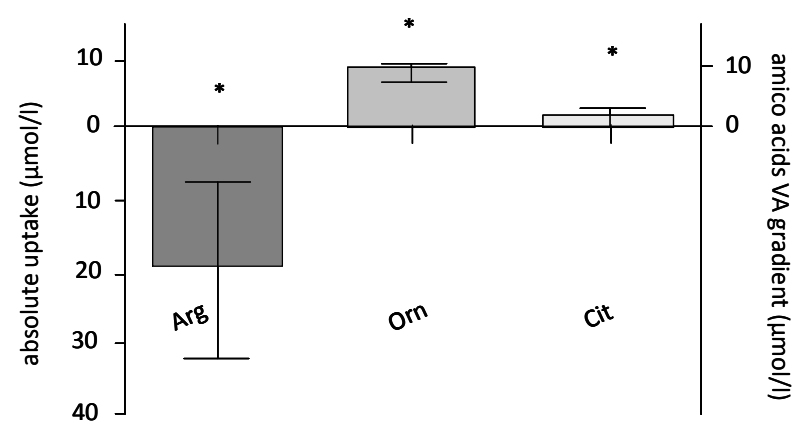

Figure 2.1 Median (interquartile range) absolute uptake of 15N2-arginine is expressed (left Y-axis) and median (interquartile range) amino acid net balance of citrulline and ornithine (right $Y$-axis), both expressed in $\mu \mathrm{mol} / \mathrm{l}, *$ significant difference from zero $\mathrm{p}<0.05$.

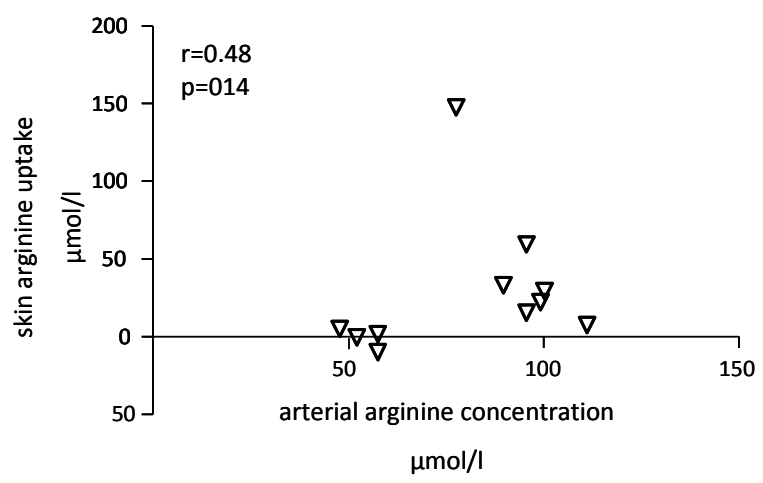

Figure 2.2 Correlation between arterial arginine concentration and uptake of arginine by the human skin. There was no significant correlation, which suggests that arginine uptake by the human skin is not dependent of on its influx. Spearman's test for non-parametric correlations (Spearman's rho $=0.48, p=0.14)$.

\section{Metabolism of other amino acids}

A net release of virtually all amino acids from the skin flaps was observed. Most importantly, net release of essential amino acids was found, which must be ascribed to net protein breakdown. There was net uptake of glutamate. The net arteriovenous gradient of urea was approximately $2 \%$ of the arterial concentration and therefore too small to assess reliably. Table 2.2 summarizes the arterial concentrations and arteriovenous gradients of amino acids and other nitrogenous compounds across the flaps. 
Table 2.2 Arterial [A] concentrations and arteriovenous concentration gradients across human skin flaps $[\mathrm{A}-\mathrm{V}]$ of amino acids and other nitrogenous compounds, expressed as median [range]. Positive gradients indicate uptake, negative gradients release. * arteriovenous gradient significantly different from zero, $p<0.05$.

\begin{tabular}{lcc}
\hline Amino acid & {$[\mathrm{A}](\mu \mathrm{M})$} & {$[\mathrm{A}]-[\mathrm{V}](\mu \mathrm{M})$} \\
\hline Urea & $3600[1800-5500]$ & $2000[-1000-800]$ \\
NO2 & $1.22[1.1-1.38]$ & $-0.07[-0.95-0.04]$ \\
ARG & $89[48-111]$ & $-11[(-25)-4]^{*}$ \\
GLU & $67(38-102)$ & $14(5-39)^{*}$ \\
ASN & $56(34-71)$ & $-11[(-19)-(-3)]^{*}$ \\
SER & $122[89-198]$ & $-18[(-32)-(-10)]^{*}$ \\
GLN & $1028[771-1295]$ & $-175[(-284)-(-100)]^{*}$ \\
HIS & $83[69-156]$ & $-31[(-42)-(-19)]^{*}$ \\
GLY & $312[149-556]$ & $-41[(-88)-(-13)]^{*}$ \\
THR & $169[92-224]$ & $-22\left[(-36)-(-4)^{*}\right.$ \\
ALA & $417[214-718]$ & $-85[(-273)-(-17)]^{*}$ \\
TAU & $47[34-75]$ & $-51[(-86)-(-23)]^{*}$ \\
aAB & $25[12-37]$ & $-2[(-4)-1]^{*}$ \\
TYR & $47[28-76]$ & $-8[(-16)-(-3)]^{*}$ \\
VAL & $197[103-245]$ & $-17[(-23)-7]^{*}$ \\
MET & $27[17-35]$ & $-5[(-8)-(-1)]^{*}$ \\
ILE & $57[17-84]$ & $-4[(-9)-3)^{*}$ \\
PHE & $57[35-77]$ & $-8[(-18)-(-1)]^{*}$ \\
TRP & $23[16-29]$ & $-2[(-7)-1]^{*}$ \\
LEU & $123[50-185]$ & $-10[(-26)-5]^{*}$ \\
LYS & $191[113-241]$ & $-31\left[(-52)-(-11)^{*}\right.$ \\
\hline
\end{tabular}

\section{Discussion}

We have studied arginine metabolism of healthy human skin by using transorgan balances of skin flaps during breast reconstruction procedures. The use of stable isotope techniques enabled us to calculate production and consumption. By labelling arginine with two ${ }^{15} \mathrm{~N}$ isotopes at its guanido group its uptake by the skin tissues and its enzymatic conversion to citrulline (and NO) by NOS and urea (and ornithine) by arginase could be assessed. We found significant uptake of ${ }^{15} \mathrm{~N}_{2}$ arginine, in addition a net release of ornithine and citrulline was observed. Median net arginine uptake was $15.5 \mu \mathrm{mol} / \mathrm{l}$, with a fractional extraction of $13.5 \%$. Ornithine is formed from arginine by ASE, also yielding urea. While citrulline is a product of NOS. Both ornithine and citrulline are no constituent building blocks of protein and therefore their net release by the human skin flaps cannot be ascribed to protein breakdown and must therefore uniquely reflect de novo synthesis by enzymatic conversion of arginine. Degradation of ${ }^{15} \mathrm{~N}_{2}$ arginine would result in production of ${ }^{15} \mathrm{~N}_{2}$ urea and unlabeled ornithine. In addition, NOS would give rise to ${ }^{15} \mathrm{Ncitrulline}$ and ${ }^{15} \mathrm{NO}$. We could not measure such enzymatic conversion this was probably due to the arteriovenous concentration 
differences of labelled citrulline and urea, being too small to be detected by the applied methods.

Furthermore, net amino acid fluxes show that glutamate is taken up by the skin (table 2 ) and essential amino acids like phenylalanine are released. The latter indicates net protein degradation in the skin flaps. Previous experimental studies in a rabbit skin model show similar findings ${ }^{36,37}$. Although tracer data clearly show arginine tracer uptake by the skin, amino acid balance shows net arginine release. In line with the general net release of amino acids this finding can be ascribed to net protein breakdown in these post-absorptive patients. The unique uptake of the amino acid glutamate is remarkable. Glutamate is a precursor for glutamine, which has several important functions: it is a gluconeogenic precursor, a vehicle for interorgan carbon/nitrogen transport, metabolic substrate for cells with high turnover rate (immune cells, enterocytes, renal cells). In addition, it is a precursor for purines/pyrimidines needed for DNA-synthesis and gluthathione an anti-oxidant. In times of catabolic stress glutamine is released into plasma, specifically by muscle, but also by adipose tissue ${ }^{38-40}$. As precursor for proline, glutamate might have a role in collagen formation, essential for wound healing ${ }^{41}$. Glutamate uptake by the legs has been described in several experimental settings, including in multi-catheterized humans ${ }^{37}$. This has invariably been ascribed to conversion to glutamine by skeletal muscle glutamine synthetase-activity. Our data suggest that skin, next to skeletal muscle, may be involved in the conversion of glutamate to glutamine in the extremities. Dermis seems to have an efficient reuse of amino acids, resulting in net protein balance of zero ${ }^{36}$, therefore layer of subcutaneous tissue incorporated in our skin flaps may be responsible for this finding. Which would be in line with in vitro studies showing glutamine metabolism in adipocytes ${ }^{39}$. Next to muscle, fat may be an important producer of glutamine in times of systemic distress ${ }^{38,42}$. Whether this conversion is needed for systemic or local processes, or ammonia detoxification remains unknown.

Most studies implicating the importance of arginine for skin healing, have been performed in rodents. In these studies arginine consumption is shown in wounds, and in addition they show that arginine supplementation improves nitric oxide-mediated wound healing $5,17,20,43,44$

In line with experimental studies we previously observed an up-regulation of arginine metabolizing enzymes in human wounds compared to uninjured skin, suggesting arginine metabolism ${ }^{44}$. However, we could not show a beneficial effect of arginine supplementation on human wound healing in our $\mathrm{RCT}^{\prime} \mathrm{s}^{45,46}$. An explanation might lie in the present study showing no correlation between uptake of arginine by the skin flaps and their arterial arginine supply, indicating that increasing arginine influx does not lead to increased uptake, and therefore suggesting that arginine metabolism in the skin is not a substrate-driven process.

The inaccessibility of afferent and efferent blood vessels of skin was a drawback to measure arteriovenous balances across skin. The rabbit ear model, as introduced by 
Zhang et al. ${ }^{36}$ was the first animal model in which it was possible to measure flow and sample arteriovenous balances across an isolated peace of skin. This model shows net protein breakdown in normal rabbit skin. However, arginine metabolism was not measured. The technique of microsurgical free vascularized skin transplantations used by plastic surgeons since 1975 , allowed us to sample veins and arteries separately. For the first time we used this model successfully in men, making it an unique model for future research.

In conclusion, this is the first study of transorgan measurements of arginine metabolism in human skin. The data support our hypothesis of arginine consumption to produce NO and ornithine in human skin. These findings provide rationale for further research after the role of arginine metabolism in wound healing. 


\section{References}

1. Wu G, Morris SM Jr. Arginine metabolism: nitric oxide and beyond. Biochem J 1998;336:1-17.

2. Kirk SJ, Barbul A. Role of arginine in trauma, sepsis, and immunity. JPEN J Parenter Enteral Nutr, 1990;14(5 Suppl):226S-9S.

3. Wu G, Meininger CJ, Knabe DA, Bazer FW, Rhoads JM. Arginine nutrition in development, health and disease. Curr Opin Clin Nutr Metab Care 2000;3:59-66.

4. Beaumier L, Castillo L, Yu YM, Ajami AM, Young VR. Arginine: new and exciting developments for an "old" amino acid. Biomed Environ Sci, 1996;9:296-315.

5. Hallemeesch MM, Lamers WH, Deutz NE. Reduced arginine availability and nitric oxide production. Clin Nutr 2002;21:273-9.

6. De Bandt JP, Cynober L, Lim SK, Coudray-Lucas C, Poupon R, Giboudeau J. Metabolism of ornithine, alpha-ketoglutarate and arginine in isolated perfused rat liver. Br J Nutr 1995;73:227-39.

7. Anggard E. Nitric oxide: mediator, murderer, and medicine. Lancet 1994;343:1199-206.

8. Tapiero H, Mathé G, Couvreur P, Tew KD. Arginine. Biomed Pharmacother 2002;56:439-45.

9. Shi HP, Most D, Efron DT, Witte MB, Barbul A. Supplemental L-arginine enhances wound healing in diabetic rats. Wound Repair Regen, 2003;11:198-203.

10. Shi HP, Efron DT, Most D, Tantry US, Barbul A. Supplemental dietary arginine enhances wound healing in normal but not inducible nitric oxide synthase knockout mice. Surgery 2000;128:374-8.

11. Shashidharan M, Lin KM, Ternent CA, Smyrk TC, Thorson AG, Blatchford GJ, Christensen MA. Influence of arginine dietary supplementation on healing colonic anastomosis in the rat. Dis Colon Rectum 1999;42:1613-7.

12. Seifter E, Rettura G, Barbul A, Levenson SM. Arginine: an essential amino acid for injured rats. Surgery 1978;84:224-30.

13. Schäffer MR, Tantry U, van Wesep RA, Barbul A. Nitric oxide metabolism in wounds. J Surg Res 1997; 71:25-31.

14. Nirgiotis JG, Hennessey PJ, Andrassy RJ. The effects of an arginine-free enteral diet on wound healing and immune function in the postsurgical rat. J Pediatr Surg 1991;26:936-41.

15. Langkamp-Henken B, Herrlinger-Garcia KA, Stechmiller JK, Nickerson-Troy JA, Lewis B, Moffatt L. Arginine supplementation is well tolerated but does not enhance mitogen-induced lymphocyte proliferation in elderly nursing home residents with pressure ulcers. JPEN J Parenter Enteral Nutr 2000; 24:280-7.

16. Kirk SJ, Hurson M, Regan MC, Holt DR, Wasserkrug HL, Barbul A. Arginine stimulates wound healing and immune function in elderly human beings. Surgery 1993;114:155-9.

17. Efron DT, Most D, Barbul A. Role of nitric oxide in wound healing. Curr Opin Clin Nutr Metab Care 2000;3:197-204.

18. Lee RH, Efron D, Tantry U, Barbul A. Nitric oxide in the healing wound: a time-course study. J Surg Res 2001;101:104-8.

19. Witte MB, Barbul A. Role of nitric oxide in wound repair. Am J Surg 2002;183:406-12.

20. Albina JE, Mills CD, Henry WL Jr, Caldwell MD. Temporal expression of different pathways of 1-arginine metabolism in healing wounds. J Immunol 1990;144:3877-80.

21. Barbul A, Lazarou SA, Efron DT, Wasserkrug HL, Efron G. Arginine enhances wound healing and lymphocyte immune responses in humans. Surgery 1990;108:331-6.

22. Efron D, Barbul A. Role of arginine in immunonutrition. J Gastroenterol 2000;35(Suppl 12):20-3.

23. Bansal V, Ochoa JB. Arginine availability, arginase, and the immune response. Curr Opin Clin Nutr Metab Care 2003;6:223-8.

24. Mühling J, Fuchs M, Fleck C, Sablotzki A, Krüll M, Dehne MG, Gonter J, Weiss S, Engel J, Hempelmann G. Effects of arginine, L-alanyl-L-glutamine or taurine on neutrophil (PMN) free amino acid profiles and immune functions in vitro. Amino Acids 2002;22:39-53.

25. Shang HF, Tsai HJ, Chiu WC, Yeh SL. Effects of dietary arginine supplementation on antibody production and antioxidant enzyme activity in burned mice. Burns 2003;29:43-8.

26. Yan $H$, Peng $X$, Huang $Y$, Zhao $M$, Li F, Wang P. Effects of early enteral arginine supplementation on resuscitation of severe burn patients. Burns 2007;33:179-84. 
27. Mendez C, Jurkovich GJ, Wener MH, Garcia I, Mays M, Maier RV. Effects of supplemental dietary arginine, canola oil, and trace elements on cellular immune function in critically injured patients. Shock 1996;6:7-12.

28. Daly JM, Reynolds J, Thom A, Kinsley L, Dietrick-Gallagher M, Shou J, Ruggieri B. Immune and metabolic effects of arginine in the surgical patient. Ann Surg 1988;208:512-23.

29. Sigal RK, Shou J, Daly JM. Parenteral arginine infusion in humans: nutrient substrate or pharmacologic agent? JPEN J Parenter Enteral Nutr 1992;16:423-8.

30. Riso S, Aluffi P, Brugnani M, Farinetti F, Pia F, D'Andrea F. Postoperative enteral immunonutrition in head and neck cancer patients. Clin Nutr, 2000;19:407-12.

31. Blondeel PN, Boeckx WD. Refinements in free flap breast reconstruction: the free bilateral deep inferior epigastric perforator flap anastomosed to the internal mammary artery. Br J Plast Surg 1994; 47:495-501.

32. van de Poll MC, Siroen MP, van Leeuwen PA, Soeters PB, Melis GC, Boelens PG, Deutz NE, Dejong CH. Interorgan amino acid exchange in humans: consequences for arginine and citrulline metabolism. Am J Clin Nutr 2007;85:167-72.

33. van Eijk HM, Rooyakkers DR, Deutz NE. Rapid routine determination of amino acids in plasma by highperformance liquid chromatography with a 2-3 microns Spherisorb ODS II column. J Chromatogr 1993; 620:143-8.

34. van Eijk HM, Rooyakkers DR, Soeters PB, Deutz NE. Determination of amino acid isotope enrichment using liquid chromatography-mass spectrometry. Anal Biochem 1999;271:8-17.

35. Vogt JA, Chapman TE, Wagner DA, Young VR, Burke JF. Determination of the isotope enrichment of one or a mixture of two stable labelled tracers of the same compound using the complete isotopomer distribution of an ion fragment; theory and application to in vivo human tracer studies. Biol Mass Spectrom 1993;22:600-12.

36. Zhang XJ, Sakurai Y, Wolfe RR. An animal model for measurement of protein metabolism in the skin. Surgery 1996;119:326-32.

37. Biolo G, Gastaldelli A, Zhang XJ, Wolfe RR. Protein synthesis and breakdown in skin and muscle: a leg model of amino acid kinetics. Am J Physiol 1994;267:E467-74.

38. van der Hulst RR, von Meyenfeldt MF, Soeters PB. Glutamine: an essential amino acid for the gut. Nutrition 1996;12(11-12 Suppl):S78-81.

39. Kowalski TJ, Wu G, Watford M. Rat adipose tissue amino acid metabolism in vivo as assessed by microdialysis and arteriovenous techniques. Am J Physiol 1997;273(3 Pt 1):E613-22.

40. Frayn KN, Khan K, Coppack SW, Elia M. Amino acid metabolism in human subcutaneous adipose tissue in vivo. Clin Sci (Lond) 1991;80:471-4.

41. Barbul A. Proline precursors to sustain Mammalian collagen synthesis. J Nutr 2008;138:2021S-4S.

42. Ritchie JW, Baird FE, Christie GR, Stewart A, Low SY, Hundal HS, Taylor PM. Mechanisms of glutamine transport in rat adipocytes and acute regulation by cell swelling. Cell Physiol Biochem 2001;11:259-70.

43. Amadeu TP, Seabra AB, de Oliveira MG, Monte-Alto-Costa A. Nitric oxide donor improves healing if applied on inflammatory and proliferative phase. J Surg Res 2008;149:84-93.

44. Debats IB, Wolfs TG, Gotoh T, Cleutjens JP, Peutz-Kootstra CJ, van der Hulst RR. Role of arginine in superficial wound healing in man. Nitric Oxide 2009;21:175-83.

45. Debats IB, Booi DI, Wehrens KM, Cleutjens J, Deutz NE, van de Hogen E, Bemelmans M, van der Hulst RR. Oral arginine supplementation and the effect on skin graft donor sites: a randomized clinical pilot study. J Burn Care Res 2009;30:417-26.

46. Debats IB, Koeneman MM, Booi DI, Bekers O, van der Hulst RR. Intravenous arginine supplementation and human skin graft donor site healing; a randomized controlled trial. Burns. 2011;37:420-6. 


\section{chapter 3}

\section{Role of arginine in superficial wound healing}

in man

IBJG Debats, TGAM Wolfs, T Gotoh, JPM Cleutjens, CJ Peutz-Kootstra, RRWJ van der Hulst Nitric Oxide 2009;21:175-183 


\section{Abstract}

\section{Backgroud}

Arginine supplementation has been identified as advantageous in experimental wound healing. However, the mechanisms underlying this beneficial effect in tissue repair remain unresolved. Animal studies suggest that the beneficial role of arginine supplementation is mediated, at least in part through NO. The latter component mediates processes involved in tissue repair, including angiogenesis, epithelialization and collagen formation.

\section{Methods}

This prospective study is performed to investigate arginine metabolism in acute surgical wounds in man. Expression of enzymes, known to be involved in arginine metabolism were studied in donorsites of skin grafts of 10 hospitalized patients undergoing skin transplantation. Plasma and wound fluid levels of arginine metabolites (ornithine, citrulline, nitrate and nitrite=NOx) were measured using High Performance Liquid Chromatography. Expression of iNOS, eNOS, arginase-1 and arginase-2 were studied by immunohistochemistry in paraffin sections of skin tissue. Arginase- 1 concentration was measured in plasma and wound fluid using ELISA. Arginase-2 was determined using Western Blot analysis.

\section{Results}

We observed increased levels of citrulline, ornithine, NOx and arginase- 1 in wound fluid when compared with plasma. Arginase- 2 was expressed in both plasma and wound fluid and seemed higher in plasma. iNOS was expressed by neutrophils, macrophages, fibroblasts, keratinocytes and endothelial cells upon wounding, whereas eNOS reactivity was observed in endothelial cells and fibroblasts. Arginase-1 was expressed in neutrophils post-wounding, while arginase- 2 staining was observed in endothelial cells, keratinocytes, fibroblasts, macrophages and neutrophils.

\section{Conclusion}

For the first time, human data support previous animal studies suggesting arginine metabolism for an NO- as well as arginase-mediated reparation of injured skin. 


\section{Introduction}

Wound healing represents a complex process, initiated to restore tissue damage. The amino acid arginine has been identified as an important mediator in this process ${ }^{1}$. Arginine is the sole precursor of nitric oxide (NO), a signal molecule, among others, involved in immune responses, angiogenesis, epithelialisation and formation of granulation tissue, all essential aspects accompanying wound healing ${ }^{2}$.

Nitric Oxide Synthase (NOS) converts arginine to NO and citrulline. Three isoforms of NOS exist: Neuronal NOS (NOS 1) and endothelial NOS (NOS3) are constitutively expressed by neuronal and endothelial cells respectively. Inducible NOS (NOS 2), is expressed in response to inflammatory cytokines and endotoxins, such as seen during wound repair. The beneficial effects of arginine supplementation on wound healing have been attributed to enhanced synthesis of NO by $\mathrm{NOS}^{3-6}$. Former studies with rodents showed that arginine-free diets impair wound healing, with decreased breaking strengths of incisions and collagen deposition in granulation tissue) ${ }^{7,8}$, while supplementation of arginine increased hydroxyproline concentration, a marker of collagen synthesis $^{9-12}$. In addition, to its role as precursor of $\mathrm{NO}$, arginine can be metabolized by arginase ${ }^{13-17}$. Two different isoforms of this enzyme have been identified: arginase-1 (ARG1) and arginase-2 (ARG2). The liver type, ARG1, is the cytosolic isoform. ARG2 is the mitochondrial isoform, located in kidney, prostate, small intestine and the breast. Arginase catalyses the conversion of arginine to ornithine and urea. Ornithine is an essential precursor for collagen and polyamines synthesis ${ }^{18}$, both required for wound healing processes ${ }^{19-25}$. Moreover, arginase seems to influence the immune response, another important contributor involved in tissue repair. Activated macrophages and neutrophils (PMN's) show increased NO-production for their antibacterial function. This NO-production is subsequently down-regulated by arginase through substrate competition ${ }^{26-28}$.

Although arginine supplementation is considered to promote the wound healing process, little is known of its metabolism during normal human wound healing. This study examines the role of arginine during uncompromised human wound healing. To this end, levels of arginine, its metabolites and arginase were measured in wound fluid and plasma of superficial surgical wounds in man. In addition, we evaluated the immunohistochemical distribution of the enzymes arginase, iNOS and eNOS in these wounds on paraffin-embedded tissue sections.

\section{Materials and methods}

A prospective study was performed in ten hospitalised healthy adults undergoing skin transplantation as part of reconstructive surgery at the Department of Plastic Surgery in University Hospital Maastricht. Details of their characteristics are given in Table 3.1. 
Exclusion criteria were: age younger than 18 or older than 70 years, kidney or liver failure, pregnancy, use of steroids or diabetes mellitus.

Patients underwent screening evaluation, including medical history and physical examination. Nutritional assessment was obtained measuring body weight and length and expressed as Body Mass Index ( $=$ weight $/$ lenght $^{2}$ ). Age and sex of the patients were noted. The Maastricht Hospital Medical Ethical Board approved the investigation protocol. Each patient signed informed consent.

\section{Wound protocol}

For the purpose of this study we used the donorsite of a skin graft as a model for an acute surgical wound. Under aseptic conditions and general anaesthesia skin grafts were obtained by using an electric dermatome (Aesculaap ${ }^{\circledR}$ ) with a thickness of 0.3 millimeters. Biopsies of normal skin obtained on day zero (=day of operation) were used as controls. To collect wound fluid donorsites were covered with a layer of Gordasoft $^{\circledR}$, then a polyvinylalcohol (PVA) sponge was applied to the wound (Coldex ${ }^{\circledR}$ ) and on top of that a transparent dressing $\left(\right.$ Tegaderm $\left.^{\circledR}\right)$, as previously described ${ }^{29}$.

\section{Study protocol}

The initial protocol was to sample on day 2, 5 and 10 after surgery. However, on day 10 wound fluid samples could only be harvested in three patients, as in the other patients no wound fluid was present in the sponge. Twenty-four hours before sampling, the dressing was changed by removing the transparent dressing and the PVA-sponge and reapplying a new sponge and transparent dressing. On the day of sampling, biopsies were taken under local anesthesia (1\% lidocaine), using a 3 millimeters punch biopsy from the central part of the wound. The sponge was removed, and immediately stored on ice. Simultaneously a venous blood sample was drawn from a major vein in the cubital fossa and also put on ice. After sampling a new dressing was applied to the wound.

\section{Sample collection, processing and analysis}

Blood was centrifuged at $4^{\circ} \mathrm{C}$ for 10 minutes (4000 rpm) within one hour after sampling. After centrifugation, $500 \mu \mathrm{l}$ of plasma was deproteinized using $20 \mathrm{mg}$ dry sulphosalicylic acid (SSA), vortexed and frozen in liquid nitrogen. Samples were stored at $-80^{\circ} \mathrm{C}$ until analysis. To obtain wound fluid from acute wounds, sponges were centrifuged at $4^{\circ} \mathrm{C}$ for $10 \mathrm{~min}(11.000 \mathrm{rpm})$. After centrifugation, $500 \mu \mathrm{l}$ of wound fluid was treated similar to the plasma. 


\section{Amino acid concentrations}

Plasma and wound fluid amino acids were determined using a fully automated High Performance Liquid Chromatography system (HPLC) as described previously. Nitrate / nitrite concentrations in plasma and wound fluid were also determined using $\mathrm{HPLC}^{6}$.

\section{Nitrate / nitrite (NOx) concentrations}

To study production of NO by NOS we measured nitrite and nitrate concentrations. The sum of both nitrite and nitrate (NOx) is used as an indirect indicator of NO production as described in several studies ${ }^{6,14,30}$. NOx concentrations in plasma and wound fluid were determined using $\mathrm{HPLC}^{6,31}$.

\section{Elisa for arginase-1}

Plasma and wound fluid arginase- 1 levels were measured using sandwich ELISA ${ }^{32}$. Standard, primary and secondary antibodies were kindly provided by HBT (Uden, The Netherlands). In short, a 96-wells plates were coated overnight at $4^{\circ} \mathrm{C}$ with $100 \mu \mathrm{l}$ of the purified anti-human liver-type arginase monoclonal IgG (first antibody; Mo6G3, $5 \mathrm{mg} / \mathrm{l}$ carbonate buffer, $\mathrm{pH}$ 9.5). Plasma samples were prediluted 1:2 in dilution buffer (1x PBS-0.1\% BSA) and wound fluid samples 1:400. Samples were added to the plate. Bound arginase was detected with a second biotinylated antibody (Mo9C5 in dilution buffer 1:200), followed by peroxidase-conjugated streptavidin and TMB.

\section{Western blot arginase-2}

Plasma or wound exudates were centrifuged at $10.000 \mathrm{rpm}$ for $5 \mathrm{~min}$, supernatants were collected and total protein concentrations were determined using the BCA protein assay kit (Pierce Chemical Co., Rockford, IL)

Aliquots with equal amounts of protein were heated at $100^{\circ} \mathrm{C}$ for $5 \mathrm{~min}$ in Laemmli buffer with ß-mercaptoethanol, separated on 10\% SDS-polyacrylamide gels and transferred to polyvinylidene fluoride membranes (Immobilon P; Millipore, Bedford, MA). After incubation with primary antibody, $1 \mu \mathrm{g} / \mathrm{ml}$ anti-human arginase-2 (Santa Cruz Biotechnology, Inc., Santa Cruz, USA.) and washing, membranes were incubated with a horseradish peroxidase-conjugated secondary anti mouse IgG. Positive bands were detected using the chemiluminescent substrate Supersignal West Pico (Pierce Chemical Co) and transferred onto an X-ray film.

\section{Immunohistochemical staining}

The cellular distribution of arginine-metabolising enzymes was studied in man during the process of wound healing. Sequential biopsies were collected in a period of ten days post-wounding. Skin tissue samples were stained with arginase-1, arginase-2, iNOS and eNOS and compared them to normal skin. For immunophenotyping a 
standard staining with haematoxylin and eosin (H\&E), alpha-smooth muscle actin (ASMA), CD31 and CD68 was performed (data not shown).

Biopsies were fixed in $4 \%$ buffered formaldehyde, processed by routine histological procedures and embedded in paraffin. Four micrometer sections were subsequently obtained from each paraffin block. Specimens were initially stained with H\&E. Parallel sections were immunohistochemically stained for ASMA (smooth muscle cell staining, Dako, monoclonal mouse-anti-human, 1:500), CD31 (endothelial cell staining, Dako, monoclonal mouse-anti-human, 1:50, pre-treatment TRIS/EDTA/pH 8.0, blocking 5\% BSA) and CD68 (macrophage staining, DAKO, monoclonal antibody, pre-treatment pepsin 1:100, no blocking). Subsequently sections were stained using polyclonal rabbit anti-human-iNOS antibody (Zymed Laboratories Inc. South San Francisco, USA), polyclonal goat anti-human eNOS antibody (R\&D systems, Las Vegas, USA), rabbit-antiarginase-1 (Sigma-Aldrich, St. Louis, USA)

and rabbit anti-human type-2 Arginase (kindly provided by Tomomi Gotoh, Kumamoto University, Japan). Briefly, slides were dewaxed and rehydrated in decreasing concentrations of alcohol. For arginase-1, slides were pre-heated in citrate buffer. Sections were then incubated for 30 min with iNOS, eNOS, arginase-1 and arginase 2 antibodies (resp. diluted 1:50, 1:10, 1:750, and 1:500 in 1\% BSA/TBS/0.1\% Tween-20 solution). Then slides were treated with biotinylated anti-rabbit (diluted 1:200, Dako) or biotinylated anti-goat (diluted 1:400, Dako) and treated with avidin-biotinperoxidase-complex (Dako). Positive staining was visualized by applying alkaline phosphatase (Vector Laboratories, Inc. Burlingame) and slides were counter-stained with Mayer's haematoxylin. Negative controls were treated in the same manner but with the omission of the primary antibodies. The slides were independently reviewed in a blinded fashion by two observers, by light microscope. For determination of the wound score, slides were rated semi-quantitatively on a score of 0 to 4 for cells with cytoplasmic staining. 0 (negative staining); $1(0-25 \%$ of the cells stained positive); 2 (26-50\% of the cells stained positive), $3(51-75 \%$ of the cells stained positive) and 4 (76-100\% of the cells stained positive).

\section{Statistical analysis}

Data are expressed as mean \pm SEM. Amino acid concentrations were expressed as $\mu \mathrm{M}$. Differences of plasma and wound fluid parameters were analyzed using ANOVA repeat measurements tests from SPSS, this statistical package for social sciences (SPSS) software was used for statistical analysis. In all cases, $p<0.05$ was considered statistically significant. 


\section{Results}

\section{Patient characteristics}

Patient characteristics are shown in Table 3.1. Eight males and two females entered the study, mean age was 47 years. Patients were in a general good condition. Mean body mass index was 26.5 and none of the patients had suffered from weight loss $>10 \%$ of bodyweight prior to our study (data not shown). Patients needed reconstruction of soft tissue defects for different reasons (Table 3.1). Seven patients underwent a free vascularised tissue transfer in combination with skin transplantation, three patients received only skin transplantation. All donor sites healed without complications.

Table $3.1 \quad$ Patient characteristics.

\begin{tabular}{lcccl}
\hline Patient & F/M & Age & BMI $^{2}$ & Diagnosis \\
\hline 1 & $\mathrm{M}$ & 52 & 31.4 & Burn wounds of the thorax \\
2 & $\mathrm{M}$ & 43 & 26.6 & Open fracture leg \\
3 & $\mathrm{M}$ & 32 & 24.7 & Chronic wound ankle \\
4 & $\mathrm{~F}$ & 35 & 19.7 & Defect face after trauma \\
5 & $\mathrm{M}$ & 75 & 24.6 & Sarcoma of the leg \\
6 & $\mathrm{M}$ & 36 & 40.2 & Chronic ulcer leg \\
7 & $\mathrm{M}$ & 70 & 23.5 & SCC leg \\
8 & $\mathrm{~F}$ & 27 & 27.9 & Trauma of the hand \\
9 & $\mathrm{M}$ & 39 & 21.2 & Leg amputation \\
10 & $\mathrm{M}$ & 68 & 25.8 & Defect face after SCC \\
& & & \\
Mean & & 26.5 & \\
SEM & & 1.9 & \\
Min / Max & & $27-75$ & $19.7-40.2$ & \\
\hline
\end{tabular}

1) F/M; female/male 2) BMI; body mass index 3) SCC: squamous cell carcinoma

\section{Plasma and wound fluid amino acid concentrations}

Wound fluid samples were collected on day 2, 5 and 10. At day 10, wound fluid was only harvested from three out of ten patients, and therefore these data were excluded from analysis.

Plasma arginine levels did not differ over time and were similar to healthy humans ${ }^{31}$. Wound fluid arginine levels were lower compared to plasma, however this difference was not significant (Figure 3.1).

Plasma citrulline levels showed no significant difference over time and were similar to healthy humans ${ }^{31}$. In contrast to arginine, wound fluid citrulline levels were significantly higher than plasma levels (Figure 3.2).

Plasma ornithine levels were higher than normal healthy subjects (normal value: $57 \pm 1.0 \mu \mathrm{M}^{33}$ ). Although an incline was observed from day 2 to 5 , no significance was 
reached over time. Wound fluid ornithine levels were higher compared with plasma. A significant difference was seen on day 2 (Figure 3.3).

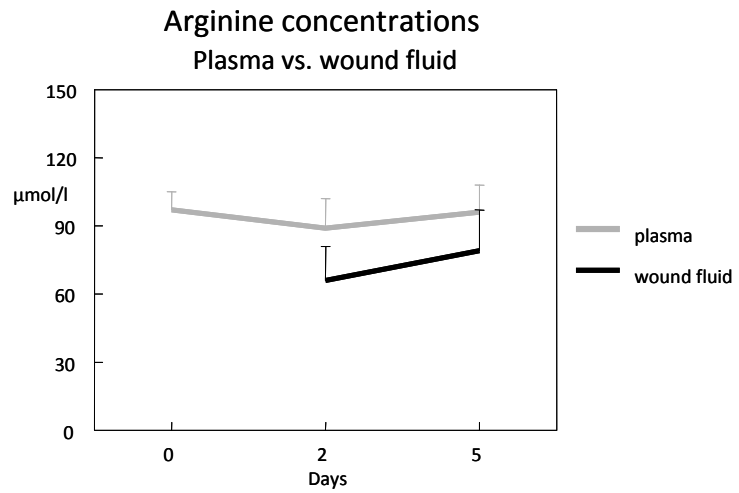

Figure 3.1 Concentrations of arginine in plasma and wound fluid $(\mu \mathrm{M})$. Plasma samples are obtained pre-operatively, and day 2 to 5 post-operative. Wound fluid samples are obtained day 2 to 5 post-operative. Data are expressed as mean $\pm \mathrm{SEM}, \mathrm{n}=10,{ }^{*} \mathrm{p}<0.05$.

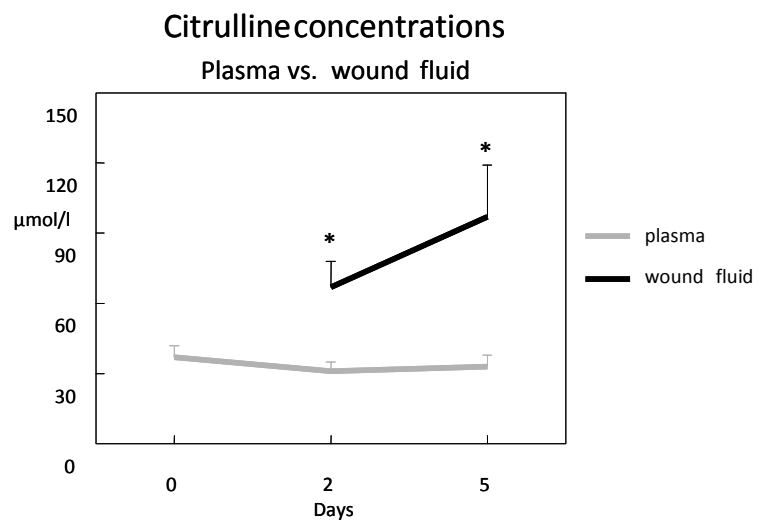

Figure 3.2 Concentrations of citrulline in plasma and wound fluid $(\mu \mathrm{M})$. Plasma samples are obtained pre-operatively, and day 2 to 5 post-operative. Wound fluid samples are obtained day 2 to 5 post-operative. Data are expressed as mean $\pm \mathrm{SEM}, \mathrm{n}=10,{ }^{*} \mathrm{p}<0.05$. 


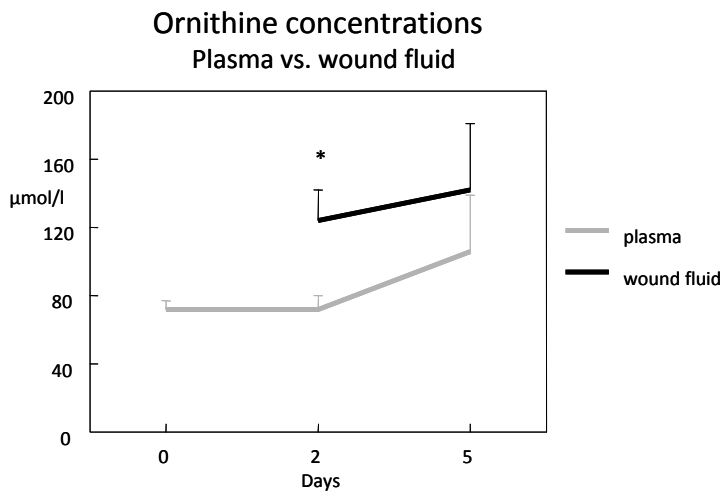

Figure 3.3 Concentrations of ornithine in plasma and wound fluid $(\mu \mathrm{M})$. Plasma samples are obtained pre-operatively, and day 2 to 5 post-operative. Wound fluid samples are obtained day 2 to 5 post-operative. Data are expressed as mean $\pm \mathrm{SEM}, \mathrm{n}=10,{ }^{*} \mathrm{p}<0.05$.

\section{Plasma and wound fluid NOx}

Comparison of plasma and wound fluid nitrite/nitrate levels shows significantly higher NO concentration in wound fluid compared with plasma (Figure 3.4).

\section{Plasma and wound fluid arginase-1}

Comparison of plasma and wound fluid Arginase-1 concentrations revealed significantly higher concentrations in wound fluid compared with plasma (Figure 3.5).

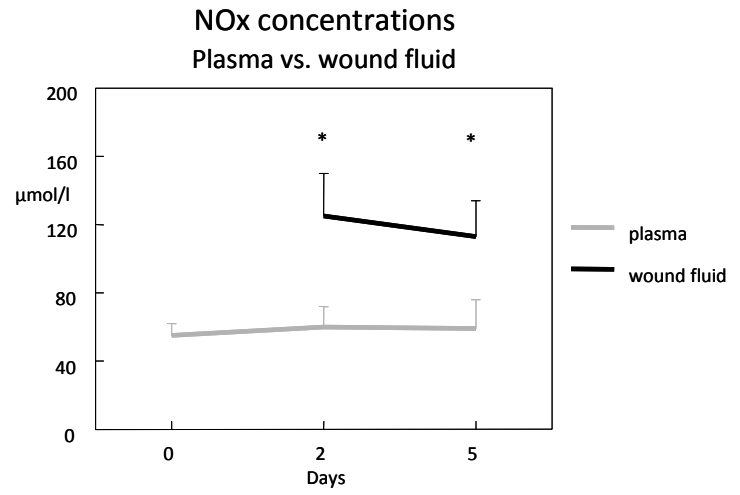

Figure 3.4 Concentrations of NOx (=nitrate+nitrite) in plasma and wound fluid $(\mu \mathrm{M})$. Plasma samples are obtained pre-operatively, and day 2 to 5 post-operative. Wound fluid samples are obtained day 2 to 5 post-operative. Data are expressed as mean \pm SEM, $n=10, * p<0.05$. 


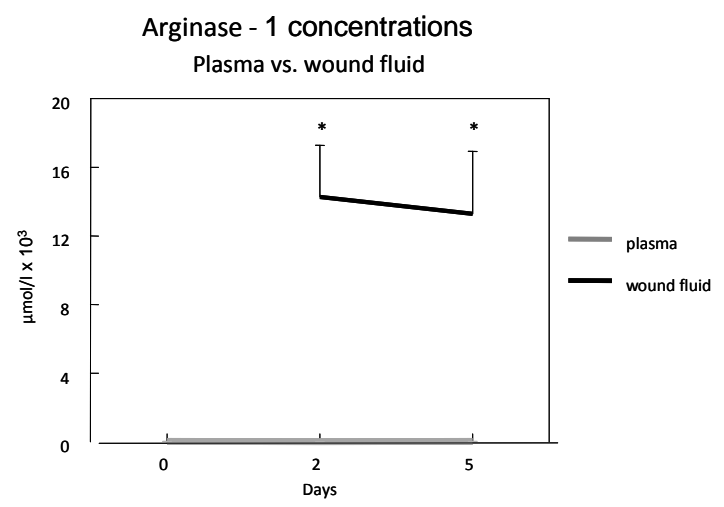

Figure 3.5 Arginase-1 concentrations in plasma and wound fluid $(\mu \mathrm{M})$. Measurements were performed in plasma on the day of operation (day 0), day 2 and 5 post-operatively. Wound fluid samples were only measured on day 2 and 5 post-operatively. Data are expressed as mean \pm SEM, $\mathrm{n}=10, * \mathrm{p}<0.05$.

\section{Plasma and wound fluid arginase-2}

Arginase-2 expression was investigated by Western blot analysis. Using densiometric analysis with LeicaQwin software (Leica Microsystems Switzerland, Ltd.), we could observe increased levels of ARG2 in plasma (Figure 3.6A,B).

\section{Immunohistochemical distribution of iNOS, eNOS and arginase-2 in wounds}

The basic histological pattern was similar for all wound sections. Haematoxylin and eosin-stained wound tissue showed a connective tissue matrix filled with fibrin, inflammatory cells, fibroblasts, glandular cells, vessels, smooth muscle cells.

\section{iNOS}

In unwounded skin, some constitutive expression was detected in epithelial cells, smooth muscle and endothelial cells. This was in contrast with the abundant staining in wounds (Figure 3.7A, magnification $\times 20$ ), where iNOS was additionally expressed by macrophages, fibroblasts and PMN's (Figure 3.7B, magnification x40). Semiquantitative analysis showed significantly more positive cells and cell types in wounds compared to normal skin (Table 3.2). Negative control was negative (Figure 3.7C, magnification $\times 20$ ). 
A

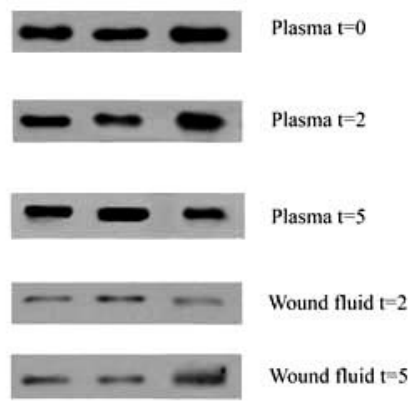

B

\section{Arginase-2}

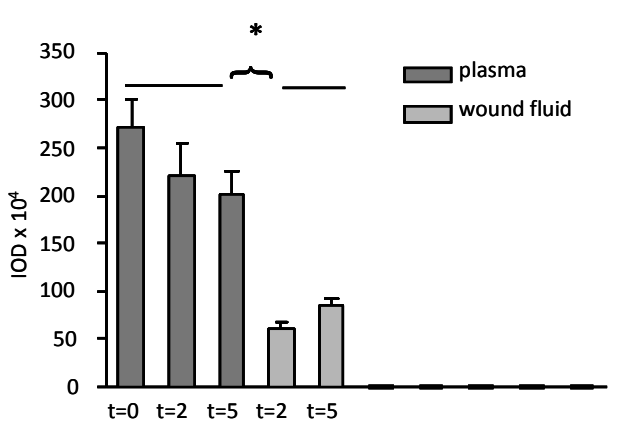

Figure 3.6 Arginase-2 levels in plasma and wound fluid. Enzyme detection by Western Blot (Figure 3.6A). Densiometric quantification of levels, expressed as IOD; mean $\pm \mathrm{SEM}, \mathrm{n}=10, * \mathrm{p}<0.05$ (Figure 3.6B).
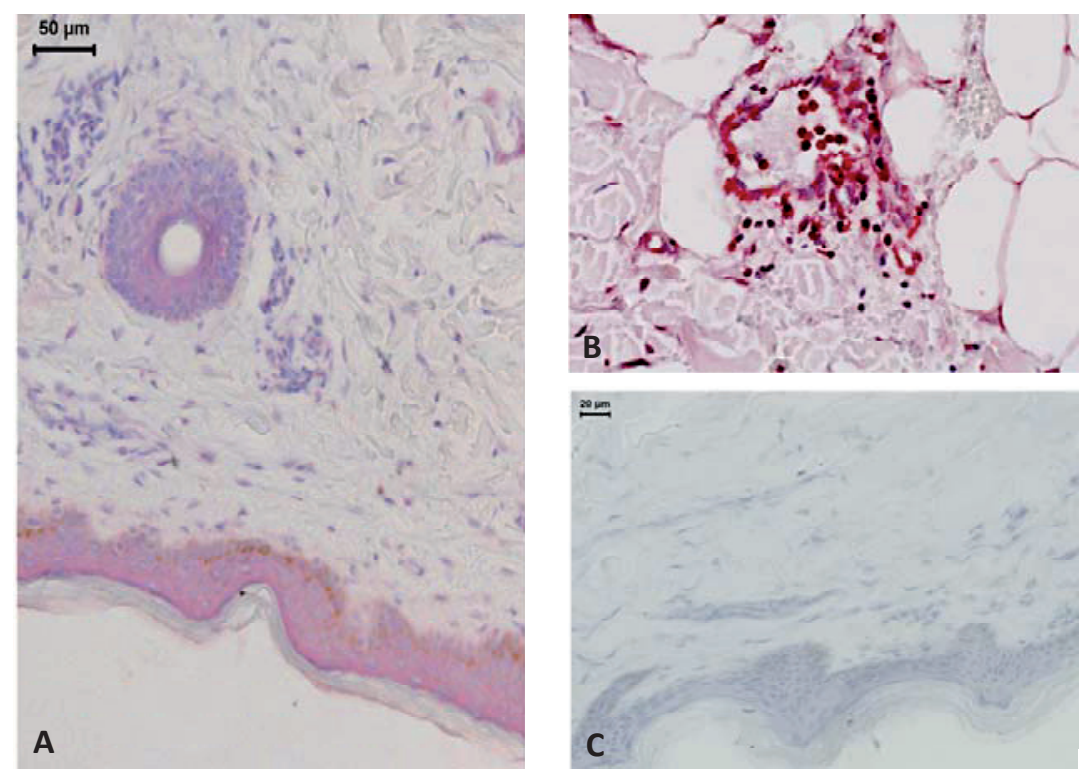

Figure 3.7 iNOS-staining in normal human skin and wounds 10 days post-wounding. Normal skin shows constitutive iNOS-staining in epithelial cells, smooth muscle and endothelial cells (Figure 3.7A; magnification $\times 20$ ). Wounded skin shows similar findings, in addition fibroblasts, PMN's and macrophages stained positive during wound healing (Figure 3.7B magnification $x 40$ ). Negative control (Figure 3.7C; magnification x20). 


\section{eNOS}

In unwounded skin, moderate eNOS expression was observed in some of the endothelial cells. In addition, mild eNOS staining was found in keratinocytes and smooth muscle (Figure 3.8A, magnification x20). Semi-quantitative analysis showed equal expression of eNOS in vessels in wounds at all time points $p<0.05$ (Table 3.2). However, in wounded skin the number of blood vessels was significantly increased from day 5 to 10 compared with normal skin $\left(16.1 \pm 1.7\right.$ to $28.1 \pm 3.8$ vessels $/ \mu \mathrm{m}^{2}$, $\mathrm{p}<0.05$ ) (Figure 3.8B, magnification $\times 40$ ). Negative control was negative (Figure $3.8 \mathrm{C}$, magnification $\times 20)$.
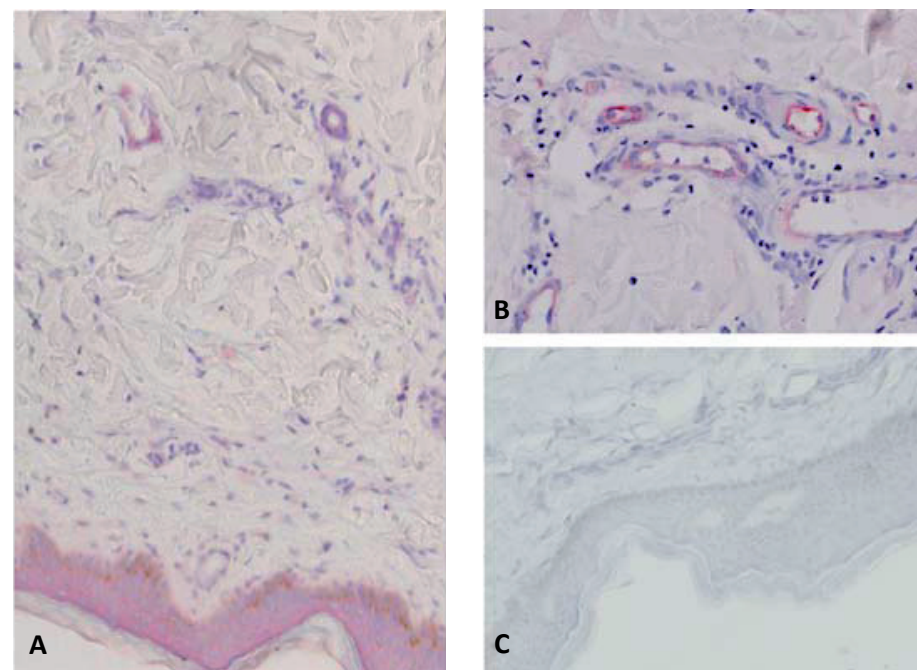

Figure 3.8 eNOS-staining in normal human skin and wounds 10 days post-wounding. Normal skin shows constitutive eNOS-staining in few endothelial cells and keratinocytes (Figure 3.8A; magnification $\times 20$ ). Wound tissue shows positive eNOS-staining predominantly in vessels and some in fibroblasts (Figure 3.8B; magnification x40). Negative control (Figure 3.8C; magnification $\times 20$ ).

\section{Arginase-1}

In unwounded skin no arginase-1 staining is observed (Figure 3.9A, magnification x20). In wounded tissue arginase-1 staining is only seen in PMN's (Figure 3.9B: magnification $\mathrm{x} 40$ ). Macrophages are do not show positive staining. Semi-quantitative scoring shows significant more ARG1 expression in PMN's post-wounding compared to normal skin and equal expression of positive PMN's at different days post-wounding (Table 3.2). Negative control was negative (Figure 3.9C, magnification $\times 20$ ). 
Table 3.2 Cell types expressing iNOS, eNOS, arginase-1 and arginase-2, normal (unwounded) versus wounded skin.

\begin{tabular}{|c|c|c|c|c|}
\hline Cell type & Unwounded & Day 2 & Day 5 & Day 10 \\
\hline \multicolumn{5}{|l|}{ iNOS } \\
\hline Epithelial cells & $0^{\circ}$ & $0.75 \pm 0.35$ & $0.4 \pm 0.5$ & $0.6 \pm 0.3$ \\
\hline Fibroblasts & $0^{\circ}$ & $0.7 \pm 0.3$ & $0.5 \pm 0.3$ & $0.7 \pm 0.4$ \\
\hline PMN's & $0^{\circ}$ & $0.7 \pm 0.2$ & $0.35 \pm 0.1$ & $0.25 \pm 0.0$ \\
\hline Macrophages & $0^{\circ}$ & $0.5 \pm 0.1$ & $0.7 \pm 0.3$ & $0.7 \pm 0.2$ \\
\hline Endothelial cells & $0^{\circ}$ & $0.8 \pm 0.4$ & $0.7 \pm 0.3$ & $0.8 \pm 0.4$ \\
\hline Glandular cells & $0^{\circ}$ & $0.9 \pm 0.2$ & $1.0 \pm 0.0$ & $0.65 \pm 0.5$ \\
\hline \multicolumn{5}{|l|}{ eNOS } \\
\hline Epithelial cells & $1.0 \pm 0.0$ & $1.0 \pm 0$ & $0.5 \pm 0.5$ & $1.0 \pm 0$ \\
\hline Fibroblasts & 0 & $0.3 \pm 0.2$ & $0.2 \pm 0.1$ & $0.3 \pm 0.2$ \\
\hline PMN's & 0 & $0.2 \pm 0.2$ & $0.1 \pm 0.1$ & $0.25 \pm 0.2$ \\
\hline Macrophages & 0 & 0 & 0 & 0 \\
\hline Endothelial cells & $1.0 \pm 0.0$ & $1.0 \pm 0$ & $1.0 \pm 0$ & $1.0 \pm 0$ \\
\hline Glandular cells & 0 & 0 & 0 & 0 \\
\hline \multicolumn{5}{|l|}{ Arg-2 } \\
\hline Epithelial cells & 0 & 0 & 0 & 0 \\
\hline Fibroblasts & 0 & 0 & 0 & 0 \\
\hline PMN's & $0^{\circ}$ & $1.0 \pm 0$ & $1.0 \pm 0$ & $1.0 \pm 0$ \\
\hline Macrophages & 0 & 0 & 0 & 0 \\
\hline Endothelial cells & 0 & 0 & 0 & 0 \\
\hline Glandular cells & 0 & 0 & 0 & 0 \\
\hline
\end{tabular}

PMN's: polymorphonuclear cells; ${ }^{\circ} \mathrm{p}<0.05$ vs. days 2, 5 and 10 post-wounding.

Mean score of enzyme expression on a four point scale; 0: no expression, 1: 1-25\% expression, 2: 26-50\% expression, $3: 51-75 \%$ expression and $4: 76-100 \%$ expression. Mean percentage \pm SD is shown.

\section{Arginase-2}

In unwounded skin constitutive staining was observed in keratinocytes, smooth muscle and endothelial cells (Figure 3.10A: magnification $\times 20$ ). All cells showed milder expression of arginase-2 in unwounded skin. In wounded tissue (Figure 3.10B: magnification $\times 40$ ) additional staining of macrophages, fibroblasts and PMN's was observed when compared to healthy skin. Semi-quantitative analysis showed significant more cells expressing ARG2 compared to normal skin (Table 3.2). No difference in ARG2-expression was observed at sequential time points during healing. Negative control was negative (Figure 3.10C: magnification x20). 

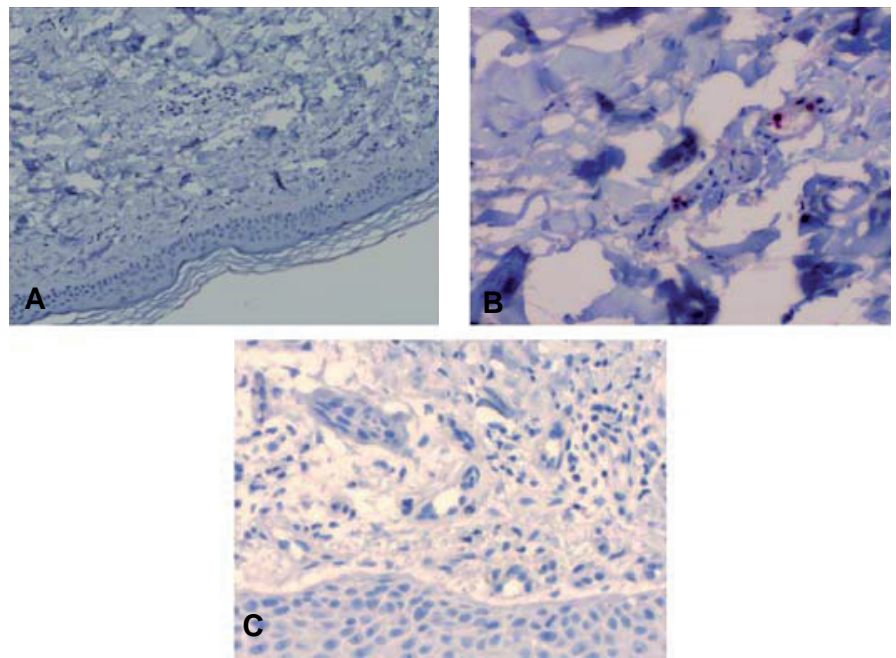

Figure 3.9 Arginase-1 staining in normal skin and wounds 10 days post-wounding. Normal skin shows no arginase-1 staining (Figure 3.9A; magnification $\times 20$ ). In wounded skin arginase-1 staining is only seen in PMN's. Macrophages are not stained (Figure 3.9B; magnification $\mathrm{x} 40$ ). Semiquantitative scoring shows significant more ARG1 positively stained PMN's in wounds compared to normal skin and equal expression of positive PMN's at different days postwounding (Table 3.2). Negative control (Figure 3.9C; magnification x20).
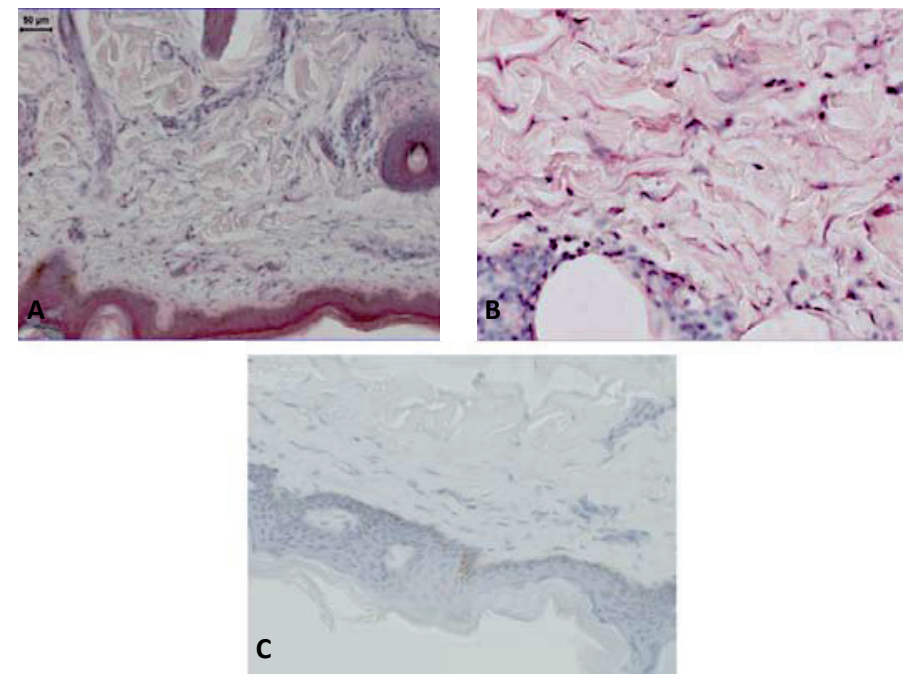

Figure 3.10 Arginase-2-staining in normal human skin and wounds 10 days post- wounding. Constitutive staining was observed in keratinocytes, smooth muscle and endothelial cells of normal skin (Figure 3.10A; magnification $\mathrm{x} 20$ ). In wounds predominantly fibroblasts, macrophages and PMN's stained positive (Figure 3.10B; magnification $\times 40$ ). Negative control was negative (Figure 3.10C: magnification $\times 20$ ). 


\section{Discussion}

Data from animal studies suggested that arginine metabolism occurs during wound healing. In addition, arginine supplementation in animals and humans appears to improve skin repair. However the mechanisms underlying this effect remain unidentified. To our opinion, this is the first study supporting the role of arginine metabolism in normal wound healing in man. It provides insight in the mechanisms by showing expression of arginine-metabolites and arginine-metabolizing enzymes at different time points during normal healing of surgical wounds, compared with normal skin.

The supporting evidence is shown by increased levels of wound fluid citrulline and NOx when compared with plasma, indicating arginine conversion by NOS ${ }^{14,34,35}$. Moreover, a significant rise of ornithine detected in wound fluid compared with plasma suggests that L-arginine is also metabolised by arginase. Since citrulline and ornithine are not released by protein breakdown, these findings are indicative for arginine metabolism both through NOS and arginase-pathways. This suggestion is also supported by levels of ARG1 and ARG2 detected in wound fluid. Although not significant, arginine levels in wound fluid tend to be lower compared to plasma. This is in line with animal studies $^{14,35,36}$, which showed decreased arginine levels in wound fluid when compared with plasma during healing, suggesting arginine consumption at the wound site ${ }^{34,37-39}$. We observed simultaneous increase levels of citrulline and ornithine in wound fluid. Experimental studies show temporal elevation of NOx and ornithine in wound fluid when compared to plasma, suggesting sequential activation of the different arginine metabolic pathways ${ }^{35,39}$. Moreover, others like Finnen et al. suggest a time course requirement for different arginine metabolites, as increased healing upon NOapplication in the early healing phase was observed ${ }^{40,41}$. Since the number of sequential samples was limited, we cannot draw conclusions about the time course activation or requirements of arginine metabolism. Unfortunately, more extensive sampling was not ethical for our patients.

The mechanisms by which arginine stimulates cutaneous wound repair is still not completely understood. In the present study, we observed iNOS expression in macrophages, PMN's, fibroblasts, epithelial and endothelial cells upon wounding. In contrast, these cells did not express iNOS in normal skin, indicating wounding activates arginine metabolism. All these cells have specific functions during the complex process of healing and NO has been implicated as a mediator. PMN's and macrophages are needed to debride the wound area and attract other cells important for wound healing. Human neutrophils generate $\mathrm{NO}^{42-44}$ which modulates their migration ${ }^{45}$. In addition, activated macrophages and neutrophils need arginine for adequate NOsynthesis $^{46-48}$. Moreover, after arginine supplementation, an increased myeloperoxidase-activity in PMN's is observed, that was accompanied by increased NO levels and wound tensile strength ${ }^{49-51}$. Fibroblasts are responsible for collagen formation in granulation tissue, a process essential in tissue repair. In vitro and animal 
studies show that NO regulates collagen synthesis in wound fibroblasts ${ }^{25,38,39,52,53}$. Wang et al. showed that fibroblasts derived from human skin express eNOS and iNOS upon stimulation with LPS and INF- $\gamma^{54,55}$. This is in line with our findings, as eNOS and iNOS were expressed in fibroblasts of wounds at all time points, suggesting NOmediated collagen formation in wound healing in man (Table 3.2). Neovascularisation is of central importance in wound healing. In vitro studies showed that VEGF, the most potent known angiogenic protein, is induced by $\mathrm{NO}^{56,57}$. Inhibition of NO-synthesis impairs VEGF expression and angiogenesis. Moreover, it delays wound healing ${ }^{58-61}$. We observed constitutive expression of eNOS in endothelial cells, which did not alter upon wounding, whereas iNOS was expressed in endothelial cells only after injury. Comparable findings were observed in keratinocytes in present study. They showed a constitutive expression of eNOS and iNOS in normal skin, whereas after injury a more abundant expression of iNOS was noticed. Keratinocytes in normal human skin express all NOS isoforms ${ }^{61}$ and iNOS is induced in proliferating keratinocytes upon cutaneous injury in rodents ${ }^{62}$. As all our wounds healed without complications, we speculate that the up-regulation of iNOS/eNOS as seen in the present study implicates that normal human wound healing is NO-mediated, and therefore arginine is required.

Arginase, the other major L-arginine-consuming enzyme, regulates polyamines and proline synthesis through the production of ornithine ${ }^{1,63}$. In addition, arginase regulates NO-formation through substrate competition ${ }^{64-67}$. Previous animal and in vitro studies showed exclusive up regulation of ARG1 during normal wound healing, which was required for collagen formation ${ }^{25}$. Human studies that addressed the role of arginases during wound healing are limited. They described overexpression of arginase in pathological wound states (e.g. diabetes, psoriasis and venous ulcers) ${ }^{13,16,68}$. We detected ARG1 in both plasma and wound fluid. Surgery and sepsis are known to induce elevated plasma levels of ARG1. It has been suggested that ARG1 is released by inflammatory cells, hepatocytes and erythrocytes in order to decrease T-cell immunity ${ }^{69-72}$. In this study, ARG1 levels were significantly higher wound fluid than in plasma, supporting our hypothesis of arginine metabolism through ARG1 in the wound environment. In contrast, we measured higher plasma ARG2 levels compared with wound fluid (Figure 3.6B). ARG2 has a wide tissue distribution, with the highest expression in kidney, prostate and vasculature. In vessels it appears to be involved in the regulation of vascular tone and atherosclerosis ${ }^{66}$. Only Corraliza et al., measured ARG2 in joint fluid from arthritic joints and suggested that this contributed to the disturbed healing process ${ }^{15}$. At present, we do not have an explanation for the elevated levels of ARG2 in plasma and wound fluid observed in this study.

Interestingly we observed coexpression of ARG1 and ARG2 in PMN's, at all time points post-wounding, while no expression was seen in PMN's of normal skin. Coexpression of ARG1 and ARG2 has not yet been reported in PMN's [Munder, 2006, Blood]. However, it has been observed in endothelial cells, where intracellular ARG1 and ARG2 compete for arginine, leading to decreased NO-production. A specific role for arginase isotypes has been suggested; ARG1: ornithine synthesis and ARG2: polyamines 
production $^{73}$. Jacobsen suggested that the function of release of arginase from PMN's is to reduce NO-formation by macrophages, endothelial and T-cells ${ }^{74}$. All, these previous findings could apply to PMN function in human wound healing, but the complexity of wound healing in vivo warrants more research. Another interesting finding is that we only observed ARG2 expression in macrophages after injury. Arginase expression by macrophages seems to be species and cell specific as murine macrophages express ARG-1 and -2 , rat macrophages $A R G 1^{25,75,76}$ and human myeloid cells express $A R G 1^{27}$. The role of arginase in activated macrophages seems to be down regulation of NO-production through substrate competition which is more pronounced when L-arginine availability is reduced ${ }^{76,77}$. Gotoh et al. suggested early and late arginase expression in macrophages: first ARG2 to produce polyamines for macrophage growth and differentiation and later on ARG1 to produce ornithine for collagen production ${ }^{77}$. It is possible that assessment of ARG in this study was only conducted in the early ARG-expressing phase. Alternatively, different arginase isotypes may play different roles during normal and pathological healing.

Comparable findings were observed in fibroblasts, only expressing ARG2 upon injury. In rats, up-regulation of only ARG1 is detected in fibroblasts after wounding to provide substrate for collagen-synthesis and cell proliferation ${ }^{25,78}$.

Furthermore, our study shows ARG2 expression in endothelial cells. Non human endothelial cells express ARG1. Unstimulated human endothelial cells express some ARG2, which increases upon stimulation ${ }^{79,80}$. Arginase seems to be involved in vascular function $^{65}$. In addition, Hui et al. suggested ARG1 is needed for ornithine and ARG2 for polyamines production by bovine endothelial cells ${ }^{24,73}$. Which makes both pathways important for the formation of new blood vessels, an essential process for wound healing.

Finally, expression of ARG2 in epithelial cells of healthy skin was seen, and increased in wounds. The expression of ARG2 in normal skin was already seen by Wohlrab et al. $2002^{81}$. Present study is the first to show that expression of ARG2 is increased in normal wound healing in man.

In summary, our findings support previous experimental studies suggesting arginine metabolism for an NO-mediated as well as arginase-mediated reparation of injured skin. Our findings suggest a more prominent role of ARG2 in normal healing. As it is known that ARG-1 is more activated in pathological skin healing our finding may have important therapeutic consequences. Inhibition of ARG1 and stimulation of ARG2 during pathological wound healing might be considered in the future. More work remains to be done to translate the needs of injured skin into clinically useful agents. 


\section{References}

1. Curran JN, Winter DC, Bouchier-Hayes D. Biological fate and clinical implications of arginine metabolism in tissue healing. Wound Repair Regen 2006;14:376-86.

2. Witte MB, Barbul A. Role of nitric oxide in wound repair. Am J Surg 2002;183:406-12.

3. Pollock JS, Webb W, Callaway D, Sathyanarayana, O'Brien W, Howdieshell TR. Nitric oxide synthase isoform expression in a porcine model of granulation tissue formation. Surgery 2001;129:341-50.

4. Schaffer MR, Tantry U, van Wesep RA, Barbul A. Nitric oxide metabolism in wounds. J Surg Res 1997;71:25-31.

5. Norris KA, Schrimpf JE, Flynn JL, Morris SM Jr. Enhancement of macrophage microbicidal activity: supplemental arginine and citrulline augment nitric oxide production in murine peritoneal macrophages and promote intracellular killing of Trypanosoma cruzi. Infect Immun 1995;63:2793-6.

6. Bruins MJ, Soeters PB, Lamers WH, Meijer AJ, Deutz NE. L-arginine supplementation in hyperdynamic endotoxemic pigs: effect on nitric oxide synthesis by the different organs. Crit Care Med 2002;30: 508-17.

7. Schaffer MR, Tantry U, Ahrendt GM, Wasserkrug HL, Barbul A. Acute protein-calorie malnutrition impairs wound healing: a possible role of decreased wound nitric oxide synthesis. J Am Coll Surg 1997;18:37-43.

8. Nirgiotis JG, Hennessey PJ, Andrassy RJ. The effects of an arginine-free enteral diet on wound healing and immune function in the postsurgical rat. J Pediatr Surg 1991;26:936-41.

9. Barbul A, Lazarou SA, Efron DT, Wasserkrug HL, Efron G. Arginine enhances wound healing and lymphocyte immune responses in humans. Surgery 1990;108:331-6.

10. Kirk SJ, Hurson M, Regan MC, Holt DR, Wasserkrug HL, Barbul A. Arginine stimulates wound healing and immune function in elderly human beings. Surgery 1993;114:155-9; discussion 160.

11. Shashidharan M, Lin KM, Ternent CA, Smyrk TC, Thorson AG, Blatchford GJ, Christensen MA. Influence of arginine dietary supplementation on healing colonic anastomosis in the rat. Dis Colon Rectum 1999; 42:1613-7.

12. Arbss MA, Ferrando JM, Vidal J, Quiles MT, Huguet P, Castells J, Segarra A, Armengol M, Schwartz S. Early effects of exogenous arginine after the implantation of prosthetic material into the rat abdominal wall. Life Sci 2000;67:2493-512.

13. Abd-El-Aleem SA, Ferguson MW, Appleton I, Kairsingh S, Jude EB, Jones K, McCollum CN, Ireland GW. Expression of nitric oxide synthase isoforms and arginase in normal human skin and chronic venous leg ulcers. J Pathol 2000;191:434-42.

14. Albina JE, Mills CD, Henry WL Jr, Caldwell MD. Temporal expression of different pathways of 1-arginine metabolism in healing wounds. J Immunol 1990;144:3877-80.

15. Corraliza I, Moncada S. Increased expression of arginase II in patients with different forms of arthritis. Implications of the regulation of nitric oxide. J Rheumatol 2002;29:2261-5.

16. Jude EB, Boulton AJ, Ferguson MW, Appleton I. The role of nitric oxide synthase isoforms and arginase in the pathogenesis of diabetic foot ulcers: possible modulatory effects by transforming growth factor beta 1. Diabetologia 1999;42:748-57.

17. Kampfer $\mathrm{H}$, Pfeilschifter J, Frank S. Expression and activity of arginase isoenzymes during normal and diabetes-impaired skin repair. J Invest Dermatol 2003;121:1544-51.

18. Morris SM Jr. Regulation of enzymes of urea and arginine synthesis. Annu Rev Nutr 1992;12:81-101.

19. Adams E, Frank L. Metabolism of proline and the hydroxyprolines. Annu Rev Biochem 1980;49: 1005-61.

20. Albina JE, Abate JA, Mastrofrancesco B. Role of ornithine as a proline precursor in healing wounds. J Surg Res 1993;55:97-102.

21. Dolynchuk KN, Bendor-Samuel R, Bowness JM. Effect of putrescine on tissue transglutaminase activity in wounds: decreased breaking strength and increased matrix fucoprotein solubility. Plast Reconstr Surg 1994;93:567-73.

22. Lesiewicz J, Goldsmith LA. Inhibition of rat skin ornithine decarboxylase by nitrofurazone. Arch Dermatol 1980;116:1225-6. 
23. Maeno $\mathrm{Y}$, Takabe $\mathrm{F}$, Inoue $\mathrm{H}$, Iwasa $\mathrm{M}$. A study on the vital reaction in wounded skin: simultaneous determination of histamine and polyamines in injured rat skin by high-performance liquid chromatography. Forensic Sci Int 1990;46:255-68.

24. Wu G, Morris SM Jr. Arginine metabolism: nitric oxide and beyond. Biochem J 1998;336( Pt 1):1-17.

25. Witte MB, Barbul A, Schick MA, Vogt N, Becker HD. Upregulation of arginase expression in woundderived fibroblasts. J Surg Res 2002;105:35-42.

26. Bansal V, Ochoa JB. Arginine availability, arginase, and the immune response. Curr Opin Clin Nutr Metab Care 2003;6:223-8.

27. Bronte V, Serafini P, Mazzoni A, Segal DM, Zanovello P. L-arginine metabolism in myeloid cells controls T-lymphocyte functions. Trends Immunol 2003;24:302-6.

28. Mori M. Regulation of nitric oxide synthesis and apoptosis by arginase and arginine recycling. J Nutr, 2007;137(6 Suppl 2):1616S-20S.

29. Debats IB, Booi DI, Wehrens KM, Cleutjens J, Deutz NE, van de Hogen E, Bemelmans M, van der Hulst RR. Oral arginine supplementation and the effect on skin graft donor sites: a randomized clinical pilot study. J Burn Care Res 2009;30:417-26.

30. Giovannoni G, Land JM, Keir G, Thompson EJ, Heales SJ. Adaptation of the nitrate reductase and Griess reaction methods for the measurement of serum nitrate plus nitrite levels. Ann Clin Biochem 1997;34 :193-8.

31. van Eijk $\mathrm{HMH}$, Dejong $\mathrm{CH}$, Deutz NE, Soeters PB. Influence of storage conditions on normal plasma amino-acid concentrations. Clinical Nutrition 1994;13:374-80.

32. Ikemoto M, Tsunekawa S, Awane M, Fukuda $Y$, Murayama H, Igarashi M, Nagata A, Kasai $Y$, Totani M. A useful ELISA system for human liver-type arginase, and its utility in diagnosis of liver diseases. Clin Biochem 2001;34:455-61.

33. Williams JZ, Abumrad N, Barbul A. Effect of a specialized amino acid mixture on human collagen deposition. Ann Surg 2002;236:369-74; discussion 374-5.

34. Albina JE, Mills CD, Barbul A, Thirkill CE, Henry WL Jr, Mastrofrancesco B, Caldwell MD. Arginine metabolism in wounds. Am J Physiol 1988;254:E459-67.

35. Lee RH, Efron D, Tantry U, Barbul A. Nitric oxide in the healing wound: a time-course study. J Surg Res 2001;101:104-8.

36. Seifter E, Rettura G, Barbul A, Levenson SM. Arginine: an essential amino acid for injured rats. Surgery 1978;84:224-30.

37. Efron DT, Most D, Shi HP, Tantry US, Barbul A. A novel method of studying wound healing. J Surg Res 2001;98:16-20.

38. Schaffer MR, Tantry U, Gross SS, Wasserburg HL, Barbul A. Nitric oxide regulates wound healing. J Surg Res 1996;63:237-40.

39. Zunić G, Supić G, Magić Z, Drasković B, Vasiljevska M. Increased nitric oxide formation followed by increased arginase activity induces relative lack of arginine at the wound site and alters whole nutritional status in rats almost within the early healing period. Nitric Oxide 2009;20:253-8.

40. Weller R, Finnen MJ. The effects of topical treatment with acidified nitrite on wound healing in normal and diabetic mice. Nitric Oxide 2006;15:395-9.

41. Amadeu TP, Seabra AB, de Oliveira MG, Monte-Alto-Costa A. Nitric oxide donor improves healing if applied on inflammatory and proliferative phase. J Surg Res 2008;149:84-93.

42. Wright CD, Mülsch A, Busse R, Osswald H. Generation of nitric oxide by human neutrophils. Biochem Biophys Res Commun 1989;160:813-9.

43. Markert M, Carnal B, Mauel J, Nitric oxide production by activated human neutrophils exposed to sodium azide and hydroxylamine: the role of oxygen radicals. Biochem Biophys Res Commun 1994;199:1245-9.

44. Jabłońska E, Puzewska W, Marcińczyk M, Grabowska Z, Jabłoński J. iNOS expression and NO production by neutrophils in cancer patients. Arch Immunol Ther Exp (Warsz) 2005;53:175-9.

45. Nolan S, Dixon R, Norman K, Hellewell P, Ridger V. Nitric Oxide Regulates Neutrophil Migration through Microparticle Formation. Am J Pathol 2008;172:265-73.

46. Bronte V, Zanovello P. Regulation of immune responses by L-arginine meabolism. Nat Rev Immunol 2005;5:641-54. 
47. Reichner JS, Meszaros AJ, Louis CA, Henry WL Jr, Mastrofrancesco B, Martin BA, Albina JE. Molecular and metabolic evidence for the restricted expression of inducible nitric oxide synthase in healing wounds. Am J Pathol 1999;154:1097-104.

48. Mullner N, Lazar A, Hrabak A. Enhanced utilization and altered metabolism of arginine in inflammatory macrophages caused by raised nitric oxide synthesis. Int J Biochem Cell Biol 2002;34:1080-90.

49. Moncada S, Palmer RM, Higgs EA. Nitric oxide: physiology, pathophysiology, and pharmacology. Pharmacol Rev 1991;43:109-42.

50. Mühling J, Fuchs M, Fleck C, Sablotzki A, Krüll M, Dehne MG, Gonter J, Weiss S, Engel J, Hempelmann G. Effects of arginine, L-alanyl-L-glutamine or taurine on neutrophil (PMN) free amino acid profiles and immune functions in vitro. Amino Acids 2002;22:39-53.

51. Cantürk NZ, Vural B, Cantürk Z, Esen N, Vural S, Solakoglu S, Kirkal G. The role of L-arginine and neutrophils on incisional wound healing. Eur J Emerg Med 2001;8:311-5.

52. Schäffer MR, Tantry U, Thornton FJ, Barbul A. Inhibition of nitric oxide synthesis in wounds: pharmacology and effect on accumulation of collagen in wounds in mice. Eur J Surg 1999;165:262-7.

53. Thornton FJ, Schäffer MR, Witte MB, Moldawer LL, MacKay SL, Abouhamze A, Tannahill CL, Barbul A. Enhanced collagen accumulation following direct transfection of the inducible nitric oxide synthase gene in cutaneous wounds. Biochem Biophys Res Commun 1998;246:654-9.

54. Shi HP, Most D, Efron DT, Tantry U, Fischel MH, Barbul A. The role of iNOS in wound healing. Surgery 2001;130:225-9.

55. Wang R, Ghahary A, Shen YJ, Scott PG, Tredget EE. Human dermal fibroblasts produce nitric oxide and express both constitutive and inducible nitric oxide synthase isoforms. J Invest Dermatol 1996;106:419-27.

56. Kapoor M, Howard R, Hall I, Appleton I. Effects of epicatechin gallate on wound healing and scar formation in a full thickness incisional wound healing model in rats. Am J Pathol 2004;165:299-307.

57. Fukumura D, Gohongi T, Kadambi A, Izumi Y, Ang J, Yun CO, Buerk DG, Huang PL, Jain RK. Predominant role of endothelial nitric oxide synthase in vascular endothelial growth factor-induced angiogenesis and vascular permeability. Proc Natl Acad Sci U S A 2001;98:2604-9.

58. Noiri E, Lee E, Testa J, Quigley J, Colflesh D, Keese CR, Giaever I, Goligorsky MS. Podokinesis in endothelial cell migration: role of nitric oxide. Am J Physiol 1998;274: C236-44.

59. Goligorsky MS, Abedi H, Noiri E, Takhtajan A, Lense S, Romanov V, Zachary I. Nitric oxide modul

60. Most D, Efron DT, Shi HP, Tantry US, Barbul A. Characterization of incisional wound healing in induci ation of focal adhesions in endothelial cells. Am J Physiol 1999;276:C1271-81. ble nitric oxide synthase knockout mice. Surgery 2002;132:866-76.

61. Shimizu Y, Sakai M, Umemura Y, Ueda H. Immunohistochemical localization of nitric oxide synthase in keratinocytes. J Dermatol 1997;24:80-7.normal human skin: expression of endothelial-type and inducible-type nitric oxide synthase in

62. Frank S, Madlener M, Pfeilschifter J, Werner S. Induction of inducible nitric oxide synthase and its corresponding tetrahydrobiopterin-cofactor-synthesizing enzyme GTP-cyclohydrolase I during cutaneous wound repair. J Invest Dermatol 1998;111:1058-64.

63. Barbul A. Proline precursors to sustain Mammalian collagen synthesis. J Nutr 2008;138:2021S-4S.

64. Chang $\mathrm{Cl}$, Liao JC, Kuo L. Arginase modulates nitric oxide production in activated macrophages. Am J Physiol 1998;274:H342-8.

65. Zhang C, Hein TW, Wang W, Chang Cl, Kuo L. Constitutive expression of arginase in microvascular endothelial cells counteracts nitric oxide-mediated vasodilatory function. Faseb J 2001;15:1264-6.

66. Durante W, Johnson FK, Johnson RA. Arginase: a critical regulator of nitric oxide synthesis and vascular function. Clin Exp Pharmacol Physiol 2007;34:906-11.

67. Holán V, Pindjáková J, Krulová M, Neuwirth A, Fric J, Zajícová A. Production of nitric oxide during graft rejection is regulated by the Th1/Th2 balance, the arginase activity, and L-arginine metabolism. Transplantation 2006;81:1708-15.

68. Bruch-Gerharz D, Schnorr O, Suschek C, Beck KF, Pfeilschifter J, Ruzicka T, Kolb-Bachofen V. Arginase 1 overexpression in psoriasis: limitation of inducible nitric oxide synthase activity as a molecular mechanism for keratinocyte hyperproliferation. Am J Pathol 2003; 162:203-11.

69. Munder M, Schneider H, Luckner C, Giese T, Langhans CD, Fuentes JM, Kropf P, Mueller I, Kolb A, Modolell M, Ho AD. Suppression of T-cell functions by human granulocyte arginase. Blood 2006;108: 1627-34. 
70. Rotondo R, Barisione G, Mastracci L, Grossi F, Orengo AM, Costa R, Truini M, Fabbi M, Ferrini S, Barbieri O. IL-8 induces exocytosis of arginase 1 by neutrophil polymorphonuclears in nonsmall cell lung cancer. Int J Cancer 2009;125:887-93.

71. Tsuei BJ, Bernard AC, Shane MD, Shirley LA, Maley ME, Boulanger BR, Kearney PA, Ochoa JB. Surgery induces human mononuclear cell arginase I expression. J Trauma 2001;51: 497-502.

72. Ochoa JB, Bernard AC, O'Brien WE, Griffen MM, Maley ME, Rockich AK, Tsuei BJ, Boulanger BR, Kearney PA, Morris Jr SM Jr. Arginase I expression and activity in human mononuclear cells after injury. Ann Surg, 2001;233:393-9.

73. Li H, Meininger CJ, Hawker JR Jr, Haynes TE, Kepka-Lenhart D, Mistry SK, Morris SM Jr, Wu G. Regulatory role of arginase I and II in nitric oxide, polyamine, and proline syntheses in endothelial cells. Am J Physiol Endocrinol Metab 2001;280:E75-82.

74. Jacobsen LC, Theilgaard-Mönch K, Christensen EI, Borregaard N. Arginase 1 is expressed in myelocytes/metamyelocytes and localized in gelatinase granules of human neutrophils. Blood 2007;109:3084-7.

75. Kepka-Lenhart D, Mistry SK, Wu G, Morris SM Jr. Arginase I: a limiting factor for nitric oxide and polyamine synthesis by activated macrophages? Am J Physiol Regul Integr Comp Physiol 2000;279:R2237-42.

76. Morris SM Jr, Kepka-Lenhart D, Chen LC. Differential regulation of arginases and inducible nitric oxide synthase in murine macrophage cells. Am J Physiol 1998;275(5 Pt 1):E740-7.

77. Gotoh T, Mori M. Arginase II downregulates nitric oxide (NO) production and prevents NO-mediated apoptosis in murine macrophage-derived RAW 264.7 cells. J Cell Biol 1999;144:427-34.

78. Witte MB, Vogt N, Stuelten C, Gotoh T, Mori M, Becker HD. Arginase acts as an alternative pathway of L-arginine metabolism in experimental colon anastomosis. J Gastrointest Surg 2003;7:378-85.

79. Xu W, Kaneko FT, Zheng S, Comhair SA, Janocha AJ, Goggans T, Thunnissen FB, Farver C, Hazen SL, Jennings C, Dweik RA, Arroliga AC, Erzurum SC. Increased arginase II and decreased NO synthesis in endothelial cells of patients with pulmonary arterial hypertension. Faseb J 2004;18:1746-8.

80. Bachetti T, Comini L, Francolini G, Bastianon D, Valetti B, Cadei M, Grigolato P, Suzuki H, Finazzi D, Albertini A, Curello S, Ferrari R. Arginase pathway in human endothelial cells in pathophysiological conditions. J Mol Cell Cardiol 2004;37:515-23.

81. Wohlrab J, Siemes C, Marsch WC. The influence of L-arginine on the regulation of epidermal arginase. Skin Pharmacol Appl Skin Physiol 2002;15:44-54. 



\section{Chapter 4}

Infected chronic wounds show different local and systemic arginine conversion compared to acute wounds

IBJG Debats, D Booi, NEP Deutz, WA Buurman, WD Boeckx, RRWJ van der Hulst Journal of Surgical Research 2006;134:205-214 


\section{Abstract}

\section{Background}

Several experimental studies have shown the importance of arginine in wound healing. However, little is known about its role in human wound healing. In this study we investigate arginine metabolism in impaired wound healing.

\section{Materials and methods}

Twenty patients with chronic wounds and ten patients with acute wounds were included in a prospective study. Amino acids, nitrate/nitrite and arginase concentrations were determined in plasma and wound fluid using High Performance Liquid Chromatography and ELISA. Chronic wounds were divided into two groups: non-infected chronic wounds $(n=11)$ and infected chronic wounds $(n=9)$, based on quantitative bacterial analysis of wound fluid samples.

\section{Results}

Plasma arginine levels, next to total plasma amino acid levels, were significantly decreased in patients with infected chronic wounds compared with patients having acute or non-infected wounds. Citrulline and ornithine levels were significantly increased in infected chronic wounds and related to decreased nitrate/nitrite levels, while wound fluid arginine levels were similar in all groups. In addition, wound fluid arginase levels of infected chronic wounds were significantly enhanced.

\section{Conclusions}

This study demonstrates that patients with infected chronic wounds have decreased plasma arginine levels, and suggests enhanced arginine conversion in the wound. In contrast to noninfected chronic wounds, arginine seems to be mainly metabolised by arginase in infected chronic wounds. In conclusion, our hypothesis is that impaired wound healing is related to an altered arginine usage. 


\section{Introduction}

Patients with chronic wounds are a major problem in health care. The resulting prolonged hospital stay generates high costs and impairs the well-being of the patient. The high prevalence of chronic wounds leads to a financial burden in health care, for example in the USA 1.5 to 3 million patients are affected by pressure ulcers ${ }^{1,2}$. Although the development of chronic wounds is multifactorial, nutritional factors have an important role in their development ${ }^{3}$. Supplementation of high amounts of proteins and vitamins to malnourished patients with chronic wounds initially improves wound healing, although complete healing is not observed ${ }^{4-6}$.

Recent studies suggest the need of specific amino acids instead of supplementation of high amounts of proteins to stimulate wound healing ${ }^{7-10}$. In this context the amino acids arginine and ornithine are suggested to be of great importance in wound healing ${ }^{10-14}$. The effect of arginine supplementation has been attributed to enhanced synthesis of nitric oxide (NO) $)^{10,12,13,15-18}$. NO is a signal molecule involved in immune responsiveness, angiogenesis, epithelialisation and formation of granulation tissue, and has been shown to be critical for healing ${ }^{19-23}$.

Ornithine is the precursor for proline, an essential amino acid for collagen synthesis ${ }^{24}$ and for polyamines, key components in cell growth and differentiation ${ }^{14,25-29}$. Supplementation of ornithine also has shown to enhance wound healing. The mechanism of action is unclear but it is suggested that that supplementation of ornithine contributes to the synthesis of collagen by increasing the pool of free proline. Different enzymes are involved in the arginine metabolism in wound healing: NOS and arginase. NOS exists in three isoforms, endothelial NOS, neuronal NOS and inducible NOS, which convert arginine into NO. Inducible NOS (iNOS) is expressed in response to different cytokines and endotoxins and had been shown to be crucial in wound healing ${ }^{19}$. Next to NOS there is arginase, which catalyses the hydrolysis of L-arginine to urea and ornithine. Two different isoforms are identified, differing in cellular distribution: arginase I (AI), mainly localised in liver and arginase II (AII), mainly localized extrahepatic tissue ${ }^{30}$. Next to collagen synthesis, arginase influences immune response ${ }^{31-33}$.

From experimental studies it is known that the NOS-pathway dominates the first days of wound healing, whereas the arginase pathway becomes more active after these days $^{34}$. However, little is known of arginine metabolism in acute or chronic wounds in humans. It has been suggested that chronicity in wounds starts with persistent levels of bacteria in the wound tissue, resulting in prolonged elevation of proinflammatory cytokines $^{35,36}$. Although inflammation is part of normal wound healing, an excessive inflammatory response impairs the healing ${ }^{37}$.

Based on the above-mentioned findings, we hypothesize that local arginine metabolism is altered in chronic human wounds compared with acute wounds, leading to disturbed wound healing. In addition, we hypothesize that infection may play a role in these changes. Therefore in this study arginine, its metabolites and metabolising 
enzymes were measured in plasma and wound fluid of patients with acute and chronic non-infected and infected wounds.

\section{Materials and methods}

A prospective study was performed in hospitalised adults having chronic and acute wounds. Patients with chronic wounds were referred to the Chronic Wound Clinic of the Department of Plastic Surgery. Patients underwent screening evaluation, including medical history and physical examination. Nutritional assessment was obtained measuring body weight and length and expressed as Body Mass Index (= weight / lenght ${ }^{2}$ ). Age and sex of the patients and wound parameters were registered. The investigation protocol was approved by the Maastricht Hospital Medical Ethical Board. Each patient signed informed consent.

\section{Acute wounds}

Ten patients with an acute surgical wound were included. Details of their characteristics are given in Table 4.1 and 4.2. They were admitted to the hospital one day before surgery and underwent a skin transplantation as part of reconstructive surgery. The donorsite of the skin graft was studied. Exclusion criteria were: age younger than 18 or older than 70 years, kidney or liver failure, pregnancy, active cancer, use of steroids, diabetes mellitus.

Under aseptic conditions and general anaesthesia skin grafts were obtained by using an electric dermatome (Aesculaap ${ }^{\circledR}$ ) with a thickness of $0.3 \mathrm{~mm}$. To collect wound fluid, donorsites were covered with a layer of Gordasoft $^{\circledR}$, then a polyvinylalcohol (PVA) sponge was applied to the wound (Coldex ${ }^{\circledR}$ ) and on top of that a transparent dressing (Tegaderm ${ }^{\circledR}$ ). The day before wound fluid collection dressing was changed by removing the transparent dressing and the PVA-sponge and reapplying a new sponge and transparent dressing. In this study, wound fluid of acute wounds was collected from the sponge on the second day after surgery. Simultaneously a venous blood sample was drawn from a major vein in the cubital fossa and like the sponge, immediately put on ice.

\section{Chronic wounds}

Twenty patients with chronic wounds were included. Chronic wounds were defined as wounds in which the normal healing process is disturbed. Clinical features are: presence of necrotic/unhealthy tissue, lack of adequate blood supply, absence of healthy granulation tissue, lack of reepithelialisation and recurrent breakdown ${ }^{38}$. In this study chronic wounds existing longer than 4 weeks and fulfilling the above mentioned clinical features were studied. Exclusion criteria were haemodynamic instability, sepsis, diabetes mellitus and age younger than 18 or older than 80 . 
Chronic wounds were treated with Vacuum Assisted Closure ${ }^{\circledR}$ (VAC)-therapy. VACtherapy consists of a polyurethane foam sponge, which is put in the wound and connected to a pump by a tube. A negative topical pressure is then created in the wound. Wound fluid is drained into a canister attached to the pump. If required, necrotic tissue was removed and VAC therapy was applied. In this study twenty-four hours after initiation of VAC therapy, a single wound fluid sample was collected from the chronic wound. It was drawn from the canister and kept on ice immediately after collection. At the same time a venous blood sample was drawn as described above. Patients with chronic wounds were subdivided into two groups on the basis of results of the bacterial analysis of the wound fluid.

Table 4.1 Main diagnosis and treatment of control patients and wound status of chronic wound patients.

\begin{tabular}{|c|c|c|}
\hline Acute wounds & Main Diagnosis & Operation \\
\hline 1 & Cancer of the ear & Reconstruction with free temporal fascia \& SSG \\
\hline 2 & Tibia fracture & $\begin{array}{l}\text { Wound leg: reconstruction ff-gracilis muscle and } \\
\text { SSG }\end{array}$ \\
\hline 3 & Sarcoma of the leg & Reconstruction with ff-ALT/SSG \\
\hline 4 & Nose contraction after cocaine use & Reconstruction with ff-Radial forearm/SSG \\
\hline 5 & Burn wounds back & SSG \\
\hline 6 & Venous ulcer leg & SSG \\
\hline 7 & Marjolin's ulcer, old burn wounds & Ff-temporal fascia with SSG \\
\hline 8 & Crush wound of the hand & Ff-temporal fascia SSG \\
\hline 9 & Fracture maleolus & Ff-temporal fascia with SSG \\
\hline 10 & Trauma, leg amputation & SSG \\
\hline Non-infected & Main Diagnosis & Wound status \\
\hline 1 & Correction epigastric hernia & W. D. abdomen \\
\hline 2 & CABG with Intra Aortic Balloon Pump & W. D. groin \\
\hline 3 & Acute Abdominal Aneurysm & W. D. abdomen \\
\hline 4 & Cancer rectum & W. D. rectum \\
\hline 5 & CABG & W. D. sternum \\
\hline 6 & Abdominoplasty & W. D. abdomen \\
\hline 7 & CABG & W. D. abdomen \\
\hline 8 & CABG & W. D. thorax \\
\hline 9 & Abdominoplasty & W. D. abdomen \\
\hline 10 & Breast reconstruction with free TRAM & W. D. abdomen \\
\hline 11 & CABG & W. D. thorax \\
\hline \multicolumn{3}{|l|}{ Infected } \\
\hline 1 & Decubitus sacrum & W. D. sacrum \\
\hline 2 & Decubitus sacrum & W. D. sacrum \\
\hline 3 & Rectal Cancer & W. D. rectum \\
\hline 4 & CABG & W. D. thorax \\
\hline 5 & Thoracic aneurysm & W. D. abdomen \\
\hline 6 & Breast reconstruction with TRAM & W. D. breast \\
\hline 7 & Calcaneus fracture, removal OSM & W. D. maleolus \\
\hline 8 & Wound infection after fall & W. D. lower leg \\
\hline 9 & CABG & W. D. thorax \\
\hline
\end{tabular}

SSG, split skin graft; Ff, Free flap; CABG, Coronary artery bypass surgery; W.D, wound dehiscence; TRAM, transverse rectus abdominis musculocutaneous flap; OSM, osteosynthesis material. 
Table $4.2 \quad$ Patient characteristics.

\begin{tabular}{|c|c|c|c|c|c|c|c|c|c|c|c|}
\hline \multirow[t]{3}{*}{ Group } & \multirow[t]{3}{*}{$\mathrm{F}: \mathrm{M}$} & \multicolumn{2}{|c|}{ Age } & \multicolumn{2}{|c|}{ BMI } & \multicolumn{2}{|c|}{ Plasma ESR } & \multicolumn{2}{|c|}{ Plasma CRP } & \multicolumn{2}{|c|}{$\begin{array}{l}\text { Plasma } \\
\text { Albumin }\end{array}$} \\
\hline & & \multicolumn{2}{|c|}{$\mathrm{yr}$} & \multicolumn{2}{|c|}{$\mathrm{Kg} / \mathrm{m}^{2}$} & \multicolumn{6}{|c|}{$(\operatorname{Ref} 0-12 \mathrm{~mm})(\operatorname{Ref} 2.0-9.0 \mathrm{mg} / \mathrm{l})(\operatorname{Ref} 35-55 \mathrm{~g} / \mathrm{l})$} \\
\hline & & Mean & SEM & Mean & Min / Max & Mean & SEM & Mean & SEM & Mean & SEM \\
\hline Acute wounds & $2: 8$ & 47.2 & 5.3 & 26.5 & $20-40$ & 12.0 & 3.6 & 70.2 & 17.8 & 37.9 & 5.5 \\
\hline \multicolumn{12}{|l|}{ Chronic wounds } \\
\hline Non-infected & $4: 7$ & 58.3 & 2.7 & 26.4 & 21-41 & $67.8 *$ & 7.5 & 85.6 & 21.2 & $20.8^{*}$ & 1.5 \\
\hline Infected & $6: 3$ & $61.0^{*}$ & 3.8 & 26.3 & $17-38$ & $65.6^{*}$ & 15.0 & 92.2 & 15.5 & $21.5^{*}$ & 1.6 \\
\hline
\end{tabular}

BMI, Body Mass Index; ESR, Erythrocyte Sedimentation Rate; CRP, C-reactive protein. All values are expressed as means \pm SEM, except for BMI which is expressed as mean, min and max values.

$* p<0.05$ compared to the acute wound group.

\section{Bacterial analysis}

Quantitative and specific bacterial analysis were obtained from the wound fluid of acute and chronic wounds. After collection a wound fluid sample was immediately sent to the laboratory of microbiology of our hospital for quantitative and specific bacterial analysis. A negative culture was defined as less than $10^{3} / \mathrm{ml}$ Colony Forming Units (CFU) and a positive culture as more than $10^{3} \mathrm{CFU} / \mathrm{ml}^{39}$.

\section{Sample processing and analysis}

Blood was centrifuged at $4^{\circ} \mathrm{C}$ during 10 minutes at $4000 \mathrm{rpm}$ within one hour after sampling. After centrifugation, $500 \mu \mathrm{l}$ of plasma was deproteinized using $20 \mathrm{mg}$ dry sulphosalicylic acid (SSA), vortexed and frozen in liquid nitrogen. Samples were stored at -80 degrees Celsius until analysis. Wound fluid from chronic wounds was collected from the canister of the VAC-system. To obtain wound fluid from acute wounds, sponges were centrifuged at $4^{\circ} \mathrm{C}$ during $10 \mathrm{~min}$ at $11.000 \mathrm{rpm}$. After centrifugation, $500 \mu \mathrm{l}$ of wound fluid was treated similar to the plasma.

\section{Biochemical analysis}

\section{Amino acid concentrations}

Plasma and wound fluid amino acids were determined using a fully automated HPLC system as described previously ${ }^{40}$. Nitrate / nitrite concentrations in plasma and wound fluid were also determined using HPLC ${ }^{41}$. The total sum of all amino acids was calculated by adding the concentrations of all individual amino acids (SumAA).

\section{Erythrocyte Sedimentation Rate, C-Reactive Protein and albumin}

ESR was measured using the Westergren method $\left(\mathrm{mm} / 1^{\text {st }}\right.$ hour$)$. Albumin was measured with standard laboratory tests and expressed as $\mathrm{g} / \mathrm{I}$. CRP analysis on the Synchron $L X^{\circledR} 20$ System, a routine clinical chemistry analyser from Beckman Coulter, is 
based on immunoturbidimetry, using a polyclonal anti-CRP antibody (Beckman Coulter, Inc. Fullerton, CA, US). The detection limit of the assay is $1.0 \mathrm{mg} / \mathrm{l}$.

\section{Elisa for arginase I}

Plasma and wound fluid arginase levels were measured using sandwich ELISA ${ }^{42}$. Standard, primary and secondary antibodies were kindly provided by HBT (Uden, the Netherlands). In short, a 96-wells plates were coated overnight at $4^{\circ} \mathrm{C}$ with $100 \mu \mathrm{l}$ of the purified anti-human liver-type arginase monoclonal IgG (Mo6G3). Plasma samples were prediluted 1:2 in dilution buffer (1x PBS-0.1\% BSA) and wound fluid samples 1: 400. Bound arginase was detected with a second biotinylated antibody (Mo9C5), followed by peroxidase-conjugated streptavidin and TMB.

\section{Statistical analysis}

A power analysis was performed for this study: Based on previous (pilot) studies we considered a difference of $40 \mathrm{mmol} / \mathrm{l}$ between plasma and wound fluid amino acid levels as relevant. A total number of 20 patients was needed to show a significant difference. Data are expressed as mean \pm SEM. Amino acid concentrations were expressed as $\mu \mathrm{M}$. To compare the plasma values from chronic wounds with plasma values from acute wounds the non-parametric Mann-Whitney test for independent groups was performed. The same was done for wound fluid. To compare plasma with wound fluid within one group a the non-parametric Wilcoxon test for dependent groups was used. In all cases $\mathrm{p}<0.05$ was selected as criterion for statistical significance. The statistical package for social sciences (SPSS) program was used for statistical analysis.

\section{Results}

\section{Patient and wound status}

In Table 4.2 patients nutritional state and disease activity, assessed by BMI, Albumin, ESR, and CRP are shown. There were no differences in BMI and CRP levels between the groups. In contrast ESR and albumin levels differ. ESR was significantly lower in patients with acute wounds and albumin was significantly higher in this group compared with chronic wounds, indicating less disease activity in patients with acute wounds. A small difference in age between the patients with acute wounds and those with chronic infected wounds was observed.

Acute wounds showed no signs of infection and in addition no bacteria were cultured from the wound fluid of these wounds. Eleven chronic wounds showed a negative bacterial culture, further referred to as the non-infected chronic wounds. Nine chronic wounds showed a positive bacterial culture: the infected chronic wounds. More than 
one bacterial strain was found; following species were primarily cultured: Pseudomonas aeruginosa, Staphylococcus aureus, E-coli, Proteus mirabillis.

\section{Amino acid concentrations in plasma and wound fluid}

To identify the specific influence of the presence of different wound types on circulating amino acid levels we measured plasma amino acids levels in all groups. The results revealed significantly decreased plasma arginine levels in patients with infected chronic wounds compared with patients with acute and non-infected wounds (Figure 4.1A). Plasma citrulline and ornithine levels did not differ between the groups. Table 4.3 and 4.4 show the analysed amino acids in plasma and wound fluid. The plasma SumAA (Figure 4.2A), histidine, alanine, valine and methionine concentrations (Table 4.3) were significantly lower in patients with infected chronic wounds compared with patients suffering from acute or non-infected wounds.

Table 4.3 Plasma amino acid concentrations in control patients and patients with chronic wounds.

\begin{tabular}{lrrrrrr}
\hline Plasma & \multicolumn{2}{c}{ Acute wounds } & \multicolumn{2}{c}{ Non-infected wounds } & \multicolumn{2}{c}{ Infected wounds } \\
& Mean & SEM & Mean & SEM & Mean & SEM \\
\hline GLU & 85 & 8 & 84 & 12 & 78 & 8 \\
ASN & 52 & 5 & 47 & 4 & 45 & 3 \\
SER & 122 & 15 & 101 & 6 & 94 & 6 \\
GLN & 683 & 60 & 647 & 30 & 563 & 59 \\
HIS & 75 & 8 & 73 & 4 & $57^{*}$ & 5 \\
GLY & 250 & 35 & 234 & 19 & 217 & 28 \\
THR & 131 & 15 & 128 & 15 & 106 & 9 \\
ALA & 500 & 79 & $349 *$ & 25 & $272^{*}$ & 30 \\
TAU & 70 & 7 & 69 & 10 & 59 & 13 \\
aAB & 19 & 4 & 15 & 2 & 18 & 4 \\
TYR & 59 & 4 & 58 & 6 & 54 & 5 \\
VAL & 240 & 20 & 225 & 24 & $173^{*}$ & 15 \\
MET & 40 & 5 & $24 *$ & 3 & $21^{*}$ & 2 \\
ILE & 87 & 8 & 85 & 9 & 69 & 9 \\
PHE & 67 & 7 & 64 & 4 & 58 & 4 \\
TRP & 42 & 4 & 42 & 4 & 32 & 3 \\
LEU & 144 & 14 & 136 & 16 & 109 & 15 \\
LYS & 199 & 21 & 164 & 21 & 166 & 11 \\
SUM AA & & & & & $2350^{*}$ & 107 \\
\hline
\end{tabular}

All values are means \pm SEM; $A A$, amino acids. * $p<0.05$ significantly different from the controls subjects

To investigate local amino acid metabolism in wounds, we measured wound fluid amino acid levels of each group. Figure 4.1B shows similar wound fluid arginine levels in acute and chronic wounds. Citrulline and ornithine levels in wound fluid of infected wounds were significantly increased compared with acute and non-infected wounds. In addition, SumAA (Figure 4.2B), glutamate, histidine, glycine, alanine, taurine, tyrosine, valine, methionine, isoleucine, phenylalanine, leucine and lysine (Table 4.4) 
were significantly higher in infected chronic wounds compared with acute and noninfected wounds.

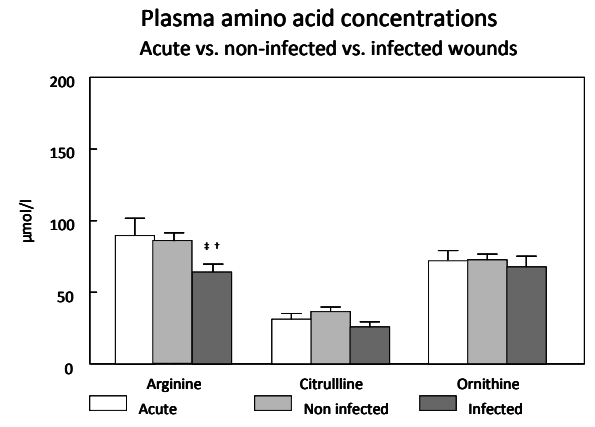

B

Wound fluid amino acid concentrations Acute vs. non-infected vs. infected wounds

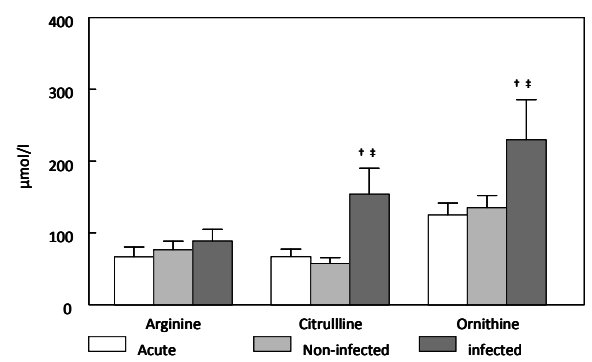

Figure 4.1 Plasma and wound fluid amino acid concentrations of the acute, non-infected and infected chronic wounds are shown. Data represent mean \pm SEM. $+p<0.05$ versus non-infected wounds; $¥ p<0.05$ versus acute wounds.

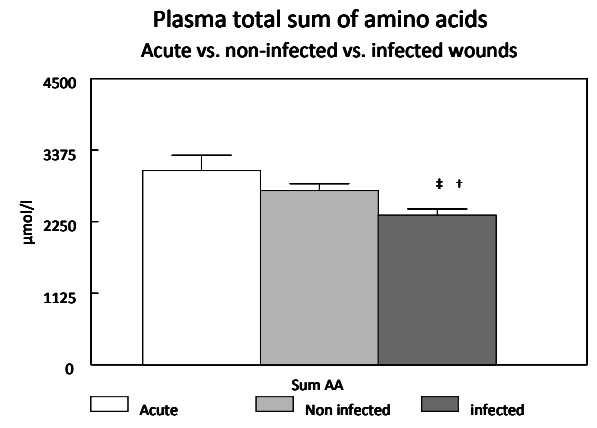

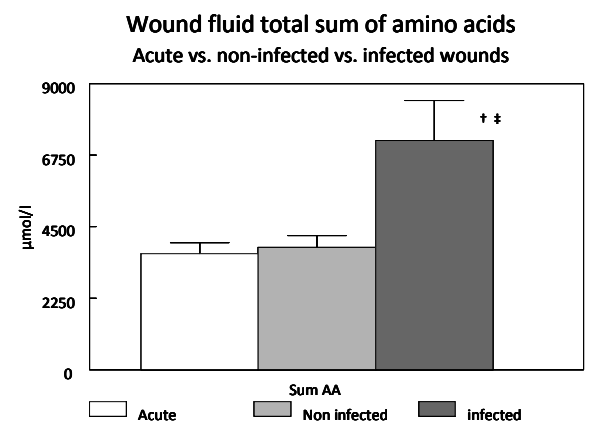

Figure 4.2 Plasma and wound fluid total sum of amino acids (SUM AA) are shown. $+p<0.05$ versus noninfected wounds; $¥ p<0.05$ versus acute wounds. 
Table 4.4 Wound fluid amino acid concentrations in control patients and patients with chronic wounds.

\begin{tabular}{|c|c|c|c|c|c|c|}
\hline \multirow[t]{2}{*}{ Wound fluid } & \multicolumn{2}{|c|}{ Acute wounds } & \multicolumn{2}{|c|}{ Non-infected wounds } & \multicolumn{2}{|c|}{ Infected wounds } \\
\hline & Mean & SEM & Mean & SEM & Mean & SEM \\
\hline$\overline{G L U}$ & 179 & 25 & 206 & 42 & $460 * 0$ & 116 \\
\hline ASN & 51 & 6 & 53 & 9 & 45 & 23 \\
\hline SER & 265 & 39 & 172 & 26 & 317 & 93 \\
\hline GLN & 535 & 61 & 551 & 75 & 589 & 94 \\
\hline HIS & 94 & 13 & 100 & 14 & $167 * 0$ & 36 \\
\hline GLY & 344 & 52 & 393 & 44 & $641 * 0$ & 136 \\
\hline THR & 170 & 19 & 171 & 23 & 291 & 80 \\
\hline ALA & 503 & 44 & 476 & 53 & $786 * 0$ & 155 \\
\hline TAU & 281 & 45 & 212 & 40 & $702 * \underline{0}$ & 229 \\
\hline$A A B$ & 15 & 3 & 30 & 14 & 32 & 9 \\
\hline TYR & 67 & 8 & 91 & 12 & $311 * 0$ & 104 \\
\hline VAL & 233 & 24 & 302 & 38 & $502 * \underline{0}$ & 93 \\
\hline MET & 38 & 6 & 34 & 4 & $77 * 0$ & 18 \\
\hline ILE & 91 & 9 & 126 & 17 & $281 * 0$ & 59 \\
\hline PHE & 91 & 11 & 119 & 16 & $280 * 0$ & 58 \\
\hline TRP & 38 & 4 & 41 & 6 & 64 & 16 \\
\hline LEU & 178 & 19 & 223 & 40 & $561 * 0$ & 122 \\
\hline LYS & 222 & 26 & 276 & 37 & $631 * 0$ & 121 \\
\hline SUM AA & 3653 & 357 & 3848 & 383 & $7208 * 0$ & 1331 \\
\hline
\end{tabular}

All values are means \pm SEM; AA, amino acids. ${ }^{*} p<0.05$ significantly different from the controls subjects; o $p<0.05$ significantly different from the patients with non-infected chronic wounds.

To address wound specific influences on local amino acid metabolism we compared wound fluid amino acid levels with plasma amino acid levels within the groups. Ratio's were calculated by dividing wound fluid by plasma amino acid levels of which a ratio $<1$ indicates lower wound concentrations relative to plasma levels (Figure 4.3). Comparison of arginine ratios revealed no significant differences between the groups. However, lower arginine ratios were observed in wound fluid of acute and noninfected chronic wounds (ratio <1), compared to infected wounds (ratio $>1$ ). Wound fluid citrulline and ornithine ratios, were higher than plasma for all groups. With the most significant increase of wound fluid citrulline in infected chronic wounds.

\section{Nitrate / nitrite concentrations in plasma and wound fluid}

Analysis of the nitrite and nitrate concentrations (NOx), used as an index of NO synthesis, demonstrated significantly decreased NOx levels in wound fluid of infected chronic wounds compared with acute wounds (Figure 4.4B). Comparison of plasma NOx revealed no differences between all groups (Figure 4.4A). 
Ratio's wound/plasma fluid

Acute vs. non-infected vs. infected wounds

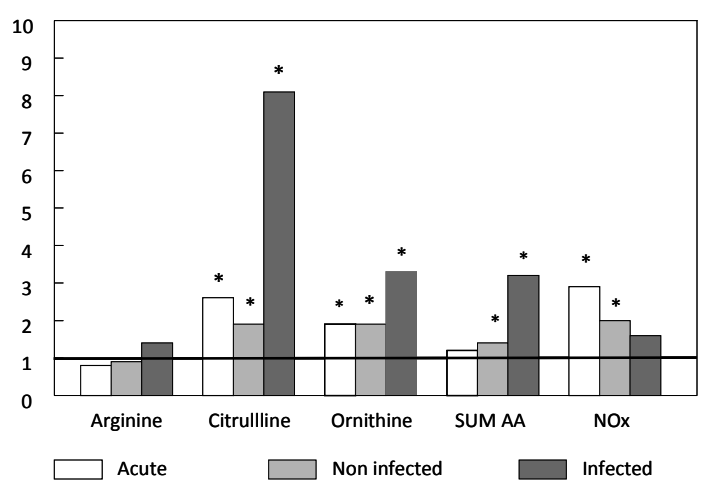

Figure 4.3 Ratio's of plasma and wound fluid arginine, citrulline, ornithine, total SUM of amino acids and sum of nitrite and nitrate (NOx). Wound fluid values are divided by plasma values. * wound fluid/plasma within one group : $p<0.05$.
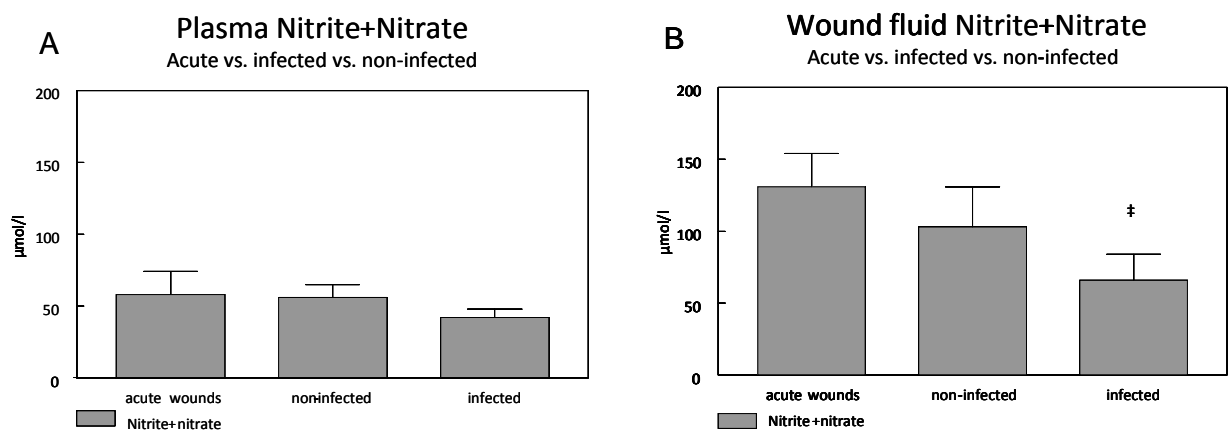

Figure 4.4 Sum of nitrite and nitrate concentrations (NOx) in plasma and wound fluid of the acute, noninfected and infected chronic wounds are shown. Data represent mean \pm SEM. $\ddagger p<0.05$ versus acute wounds.

\section{Arginase-1 levels in plasma and wound fluid}

No differences were observed in plasma arginase levels between the groups (Figure 4.5A). Comparison of wound fluid with plasma levels showed a substantial increase of wound fluid arginase levels of all groups, indicating arginase release locally in the wounds (Figure 4.5B). This finding was most striking in infected chronic wounds. 

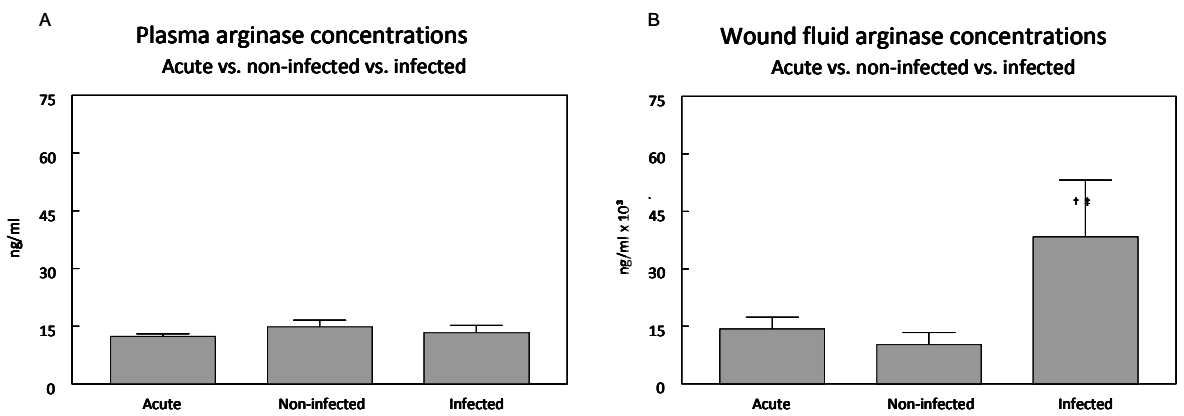

Figure 4.5 Plasma and wound fluid arginase concentrations of the acute, non-infected and infected wounds are shown. Data represent mean \pm SEM.

\section{Discussion}

This study shows that infected chronic wounds have increased citrulline, ornithine and arginase-1 levels and decreased nitrite/nitrate levels compared to acute and noninfected chronic wounds, indicating an altered arginine conversion. In addition, these patients had lowered plasma arginine levels, suggesting enhanced use of arginine.

Previous studies with rodents suggest the local use of arginine by NOS and arginase in acute wound healing ${ }^{34,43}$. Patients in our study, with acute wounds demonstrated decreased wound fluid arginine levels compared with plasma (ratio $<1$ ), indicating the use of arginine. As citrulline and NOx levels were clearly increased in wound fluid compared to plasma, this was indicative for NO synthesis by NOS in acute wounds $s^{43,44}$. Furthermore, our data show increased wound fluid ornithine and arginase-1 levels compared with plasma in acute wounds. Ornithine is the precursor for proline, which is needed for collagen and polyamine synthesis. These findings suggest arginine metabolism via arginase $e^{45,46}$. The acute wounds in this study (donorsites of SSG) all healed within two weeks (data not shown). Therefore these data suggest activation of both pathways of the L-arginine metabolism during normal acute wound healing in humans possibly similar to experimental studies.

Next, arginine conversion was studied in chronic wounds. As infection complicates the course of wound healing and successful closure of wounds is related to a low bacterial count $^{37}$, we studied whether this was related to an altered arginine metabolism. Therefore we subdivided the chronic wounds into two categories: non-infected and infected.

Non-infected chronic wounds show increased levels of wound fluid ornithine and citrulline compared with plasma (Figure 4.3). These increased levels are to be explained by conversion of arginine into its metabolites. Proteolysis, which may be activated in chronic wounds, can not be an explanation for these increased levels 
because ornithine and citrulline are not incorporated in proteins. Therefore these findings suggests activation of both NOS and arginase-pathways in non-infected chronic wounds, as observed in the acute wounds. However, no significant difference between plasma and wound fluid arginine (ratio=1) is observed, suggesting arginine is not used. The use of vacuum therapy in these chronic wounds, contrary to acute wounds, could camouflage arginine metabolism. It is known that vacuum improves wound healing, however the exact mechanism remains unknown ${ }^{47,48}$. The continuous negative pressure created by vacuum causes a flow of extravasated plasma to the wound environment and therefore leads to a constant supply of amino acids from plasma. An equilibrium between plasma and wound fluid amino acid levels is expected if no metabolism would take place. In case of utilization, vacuum may cause equilibration of levels and therefore may explain the comparable arginine plasma and wound levels. However, in case of production vacuum is not able to camouflage increased levels of amino acids in wound fluid. As citrulline and ornithine are increased we therefore think that arginine is utilized in non-infected chronic wounds and that the use of vacuum camouflages decreased arginine levels.

Infected chronic wounds showed some clear differences in amino acid concentrations. First, decreased plasma arginine and SumAA levels are observed $(p<0.05)$ in patients with infected chronic wounds compared with patients with non-infected or acute wounds. Decreased plasma arginine levels have been previously observed in patients with burn wounds, trauma and patients undergoing surgery ${ }^{49-51}$ and were attributed to an increased metabolic demand due to increased systemic inflammatory response. However, our present results show that patients with infected chronic wounds have decreased plasma AA, while no differences in systemic inflammatory response, expressed by ESR, CRP and albumin, are observed compared with patients having noninfected chronic wounds. Also, for other potentially influencing factors such as vascular disease or cancer treatment e.g. radio- or chemotherapy, infected and non-infected groups are comparable. In addition, both groups show BMI's $>20$, indicating normal weight ${ }^{52,53}$. In combination with normal dietary intake, makes chronic malnutrition unlikely (Table 4.2). Therefore these findings suggest that the observed systemic difference in plasma amino acids is due to the infection of the wound, which is also supported by the findings that no plasma amino acid differences are observed between non-infected chronic and acute wounds, both showing no signs of infection in the wounds.

Infected chronic wounds showed a wound/plasma arginine ratio $>1$, suggesting accumulation of arginine locally in the wound instead of use (Figure 4.3). This observation seems to conflict with our hypothesis of utilization of arginine. However, as in non-infected wounds vacuum may camouflage levels of substrates being used as there is a continuous drainage and thus supply of arginine from the plasma pool. Secondly, the higher arginine ratio in infected wounds compared to non-infected wounds may be explained by the higher amount of protein breakdown in the wounds which will result in a general higher level of amino acids included in protein ${ }^{54-56}$. The 
finding of less arginine in wound fluid (arginine ratio $=1.4$ ) compared with other amino acids incorporated in protein, e.g. serine (ratio 3.8), lysine (ratio 3.8) and the SumAA ratio (3.2), supports the hypothesis of use of arginine in these wounds.

Another argument for arginine utilization is the significantly higher wound fluid ornithine and arginase-l levels in infected wounds compared to acute and non-infected wounds (Figure 4.1B + 4.5B). As mentioned earlier, ornithine cannot be released by proteolysis and therefore we think this finding reflects metabolism. Although the synthesis of ornithine is essential and supplementation beneficial to wound healing ${ }^{46,57,58}$, enhanced expression of arginase has been previously related to impaired healing in diabetic and venous ulcers ${ }^{59,60}$. In addition, it has been shown that too much arginase decreases arginine availability for NO production by substrate competition $^{29,61}$.

Finally, wound fluid NOx levels of infected chronic wounds were decreased compared to acute and non-infected wounds, while no difference in plasma NOx were observed between the groups (Figure 4.4A). This indicates decreased NO synthesis in the infected chronic wound. NO is produced by macrophages and elicited polymorphonuclear leucocytes to destruct pathogens. Overproduction of NO may also exert cytotoxic effects on structural elements in wound healing ${ }^{62}$. However, deficient NO production may be responsible for a defective defence barrier. In addition, reduced NO levels could be disadvantageous for wound healing, as NO is needed for numerous processes essential to wound healing ${ }^{63,64}$ like angiogenesis and collagen formation. In line with decreased NOx levels we would expect citrulline to be decreased too. An explanation for the unexpected high citrulline concentration might be the direct conversion of arginine into citrulline by the enzyme arginine deiminase (ADI) expressed by Pseudomonas aeruginosa and E-coli bacteria. These bacteria were cultured in wound fluid of infected wounds and can use arginine to generate ATP ${ }^{65-67}$. Summarizing, we postulate that in infected chronic wounds arginine is increasingly converted into ornithine and that there is decreased NO production. Whether bacterial colonisation is the cause or the effect of the altered arginine metabolism remains speculative.

Although the exact role of the other changes in amino acid levels observed is unknown and literature is scarce some amino acids may be important for wound healing. It is beyond the scope of this article to extensively discuss all these altered amino acid levels. In summary, the most prominent observation is the general increase in amino acids in the infected wounds (Table 4.4) explained as stated earlier by proteolysis. The increased pool of free amino acids may be needed for protein synthesis and other metabolic processes. Glutamate e.g. as a precursor for ornithine and proline synthesis. BCAA's (valine, leucine and isoleucine) as precursors for protein synthesis and as oxidative fuels ${ }^{68-75}$.

Our main aim was to investigate the differences in arginine metabolism in non-infected and infected chronic wounds, as the importance of arginine in wound healing is extensively studied in animal studies. In our study, clear differences are observed in 
infected chronic wounds. This is an interesting finding as these wounds only differ in infection status compared with non-infected and acute wounds. We postulate that enhanced expression of arginase- 1 and the presence of arginine-metabolising bacteria during infection, decrease NO synthesis which could be related to impaired healing of infected chronic wounds. At the moment studies are conducted to investigate arginine metabolism in acute and chronic wounds over time. 


\section{References}

1. Evans JM, Andrews KL, Chutka DS, Fleming KC, Garness SL. Pressure ulcers: prevention and management. Mayo Clin Proc 1995;70:789-99.

2. Smith DM. Pressure ulcers in the nursing home. Ann Intern Med 1995;123:433-42.

3. Schäffer MR, Tantry U, Ahrendt GM, Wasserkrug HL, Barbul A. Acute protein-calorie malnutrition impairs wound healing: a possible role of decreased wound nitric oxide synthesis. J Am Coll Surg 1997;184:37-43.

4. Breslow RA, Hallfrisch J, Guy DG, Crawley B, Goldberg AP. The importance of dietary protein in healing pressure ulcers. J Am Geriatr Soc 1993;41:357-62.

5. Houwing $\mathrm{RH}$, Rozendaal $\mathrm{M}$, Wouters-Wesseling W, Beulens JW, Buskens E, Haalboom JR. A randomised, double-blind assessment of the effect of nutritional supplementation on the prevention of pressure ulcers in hip-fracture patients. Clin Nutr 2003;22:401-5.

6. Thomas DR. Improving outcome of pressure ulcers with nutritional interventions: a review of the evidence. Nutrition 2001;17:121-5.

7. Witte MB, Thornton FJ, Tantry U, Barbul A. L-Arginine supplementation enhances diabetic wound healing: involvement of the nitric oxide synthase and arginase pathways. Metabolism 2002;51: 1269-73.

8. Angele MK, Nitsch SM, Hatz RA, Angele P, Hernandez-Richter T, Wichmann MW, Chaudry IH, Schildberg FW. L-arginine: a unique amino acid for improving depressed wound immune function following hemorrhage. Eur Surg Res 2002;34:53-60.

9. Shi HP, Most D, Efron DT, Witte MB, Barbul A. Supplemental L-arginine enhances wound healing in diabetic rats. Wound Repair Regen 2003;11:198-203.

10. Kirk SJ, Hurson M, Regan MC, Holt DR, Wasserkrug HL, Barbul A. Arginine stimulates wound healing and immune function in elderly human beings. Surgery 1993;114:155-9; discussion 160.

11. Efron D, Barbul A. Role of arginine in immunonutrition. J Gastroenterol 2000;35 Suppl 12:20-3.

12. Barbul A, Lazarou SA, Efron DT, Wasserkrug HL, Efron G. Arginine enhances wound healing and lymphocyte immune responses in humans. Surgery 1990;108:331-6; discussion 336-7.

13. Arbśs MA, Ferrando JM, Vidal J, Quiles MT, Huguet P, Castells J, Segarra A, Armengol M, Schwartz S. Early effects of exogenous arginine after the implantation of prosthetic material into the rat abdominal wall. Life Sci 2000;67:2493-512.

14. Albina JE, Abate JA, Mastrofrancesco B. Role of ornithine as a proline precursor in healing wounds. J Surg Res 1993;55:97-102.

15. Pollock JS, Webb W, Callaway D, Sathyanarayana, O'Brien W, Howdieshell TR. Nitric oxide synthase isoform expression in a porcine model of granulation tissue formation. Surgery 2001;129:341-50.

16. Norris KA, Schrimpf JE, Flynn JL, Morris SM Jr. Enhancement of macrophage microbicidal activity: supplemental arginine and citrulline augment nitric oxide production in murine peritoneal macrophages and promote intracellular killing of Trypanosoma cruzi. Infect Immun 1995;63:2793-6.

17. Shashidharan M, Lin KM, Ternent CA, Smyrk TC, Thorson AG, Blatchford GJ, Christensen MA. Influence of arginine dietary supplementation on healing colonic anastomosis in the rat. Dis Colon Rectum 1999;42:1613-7.

18. Schaffer MR, Tantry U, Gross SS, Wasserburg HL, Barbul A. Nitric oxide regulates wound healing. J Surg Res 1996;63:237-40.

19. Witte MB, Barbul A. Role of nitric oxide in wound repair. Am J Surg 2002;183:406-12.

20. Schäffer MR, Tantry U, Thornton FJ, Barbul A. Inhibition of nitric oxide synthesis in wounds: pharmacology and effect on accumulation of collagen in wounds in mice. Eur J Surg 1999;165:262-7.

21. Yamasaki K, Edington HD, McClosky C, Tzeng E, Lizonova A, Kovesdi I, Steed DL, Billiar TR. Reversal of impaired wound repair in iNOS-deficient mice by topical adenoviral-mediated iNOS gene transfer. J Clin Invest 1998;101:967-71.

22. Thornton FJ, Schäffer MR, Witte MB, Moldawer LL, MacKay SL, Abouhamze A, Tannahill CL, Barbul A. Enhanced collagen accumulation following direct transfection of the inducible nitric oxide synthase gene in cutaneous wounds. Biochem Biophys Res Commun 1998;246:654-9.

23. Shi HP, Efron DT, Most D, Tantry US, Barbul A. Supplemental dietary arginine enhances wound healing in normal but not inducible nitric oxide synthase knockout mice. Surgery 2000;128:374-8. 
24. Morris SM Jr. Regulation of enzymes of urea and arginine synthesis. Annu Rev Nutr 1992;12:81-101.

25. Maeno $\mathrm{Y}$, Takabe F, Inoue H, Iwasa M. A study on the vital reaction in wounded skin: simultaneous determination of histamine and polyamines in injured rat skin by high-performance liquid chromatography. Forensic Sci Int 1990;46:255-68.

26. Lesiewicz J, Goldsmith LA. Inhibition of rat skin ornithine decarboxylase by nitrofurazone. Arch Dermatol 1980;116:1225-6.

27. Dolynchuk KN, Bendor-Samuel R, Bowness JM. Effect of putrescine on tissue transglutaminase activity in wounds: decreased breaking strength and increased matrix fucoprotein solubility. Plast Reconstr Surg 1994;93:567-73.

28. Adams E, Frank L. Metabolism of proline and the hydroxyprolines. Annu Rev Biochem 1980;49: 1005-61.

29. Wu G, Morris SM Jr. Arginine metabolism: nitric oxide and beyond. Biochem J 1998;336:1-17.

30. Yu H, Yoo PK, Aguirre CC, Tsoa RW, Kern RM, Grody WW, Cederbaum SD, Iyer RK. Widespread expression of arginase $\mathrm{I}$ in mouse tissues. Biochemical and physiological implications. J Histochem Cytochem 2003;51:1151-60.

31. Bansal V, Ochoa JB. Arginine availability, arginase, and the immune response. Curr Opin Clin Nutr Metab Care 2003;6:223-8.

32. Bronte V, Serafini P, Mazzoni A, Segal DM, Zanovello P. L-arginine metabolism in myeloid cells controls T-lymphocyte functions. Trends Immunol 2003;24:302-6.

33. Lee J, Ryu H, Ferrante RJ, Morris SM Jr, Ratan RR. Translational control of inducible nitric oxide synthase expression by arginine can explain the arginine paradox. Proc Natl Acad Sci U S A 2003;100:4843-8.

34. Albina JE, Mills CD, Henry WL Jr, Caldwell MD. Temporal expression of different pathways of 1-arginine metabolism in healing wounds. J Immunol 1990;144:3877-80.

35. Thomson PD. Immunology, microbiology, and the recalcitrant wound. Ostomy Wound Manage 2000;46:77S-82S; quiz 83S-84S.

36. Mahoney E, Reichner J, Bostom LR, Mastrofrancesco B, Henry W, Albina J. Bacterial colonization and the expression of inducible nitric oxide synthase in murine wounds. Am J Pathol 2002;161:2143-52.

37. Edwards R, Harding KG. Bacteria and wound healing. Curr Opin Infect Dis 2004;17:91-6.

38. Schultz GS, Sibbald RG, Falanga V, Ayello EA, Dowsett C, Harding K, Romanelli M, Stacey MC, Teot L, Vanscheidt W. Wound bed preparation: a systematic approach to wound management. Wound Repair Regen 2003;11 Suppl 1:S1-S28.

39. Krizek TJ, Robson MC. Evolution of quantitative bacteriology in wound management. Am J Surg 1975;130:579-84.

40. van Eijk HM, Rooyakkers DR, Deutz NE. Rapid routine determination of amino acids in plasma by highperformance liquid chromatography with a 2-3 microns Spherisorb ODS II column. J Chromatogr 1993;620:143-8.

41. Bruins MJ, Soeters PB, Lamers WH, Meijer AJ, Deutz NE. L-arginine supplementation in hyperdynamic endotoxemic pigs: effect on nitric oxide synthesis by the different organs. Crit Care Med 2002;30: 508-17.

42. Ikemoto $M$, Tsunekawa S, Awane M, Fukuda $Y$, Murayama H, Igarashi M, Nagata A, Kasai $Y$, Totani M. A useful ELISA system for human liver-type arginase, and its utility in diagnosis of liver diseases. Clin Biochem 2001;34:455-61.

43. Lee RH, Efron D, Tantry U, Barbul A. Nitric oxide in the healing wound: a time-course study. J Surg Res 2001;101:104-8.

44. Albina JE, Mills CD, Barbul A, Thirkill CE, Henry WL Jr, Mastrofrancesco B, Caldwell MD. Arginine metabolism in wounds. Am J Physiol 1988;254:E459-67.

45. Witte MB, Vogt N, Stuelten C, Gotoh T, Mori M, Becker HD. Arginase acts as an alternative pathway of L-arginine metabolism in experimental colon anastomosis. J Gastrointest Surg 2003;7:378-85.

46. Shi HP, Fishel RS, Efron DT, Williams JZ, Fishel MH, Barbul A. Effect of supplemental ornithine on wound healing. J Surg Res 2002;106:299-302.

47. Chen SZ, Li J, Li XY, Xu LS. Effects of vacuum-assisted closure on wound microcirculation: an experimental study. Asian J Surg 2005;28:211-7. 
48. Saxena V, Hwang CW, Huang S, Eichbaum Q, Ingber D, Orgill DP. Vacuum-assisted closure: microdeformations of wounds and cell proliferation. Plast Reconstr Surg 2004;114:1086-96; discussion 1097-8.

49. Nijveldt RJ, Prins HA, Siroen MP, Rauwerda JA, Teerlink T, van Leeuwen PA. Low arginine plasma levels in patients after thoracoabdominal aortic surgery. Eur J Clin Nutr 2000;54:615-7.

50. Yu YM, Ryan CM, Castillo L, Lu XM, Beaumier L, Tompkins RG, Young VR. Arginine and ornithine kinetics in severely burned patients: increased rate of arginine disposal. Am J Physiol Endocrinol Metab 2001;280:E509-17.

51. Ochoa JB, Bernard AC, O'Brien WE, Griffen MM, Maley ME, Rockich AK, Tsuei BJ, Boulanger BR, Kearney PA, Morris Jr SM Jr. Arginase I expression and activity in human mononuclear cells after injury. Ann Surg 2001;233:393-9.

52. Kondrup J, Rasmussen HH, Hamberg O, Stanga Z; Ad Hoc ESPEN Working Group. Nutritional risk screening (NRS 2002): a new method based on an analysis of controlled clinical trials. Clin Nutr 2003;22:321-36.

53. Kondrup J, Allison SP, Elia M, Vellas B, Plauth M; Educational and Clinical Practice Committee, European Society of Parenteral and Enteral Nutrition (ESPEN). ESPEN guidelines for nutrition screening 2002. Clin Nutr 2003;22:415-21.

54. Visse R, Nagase H. Matrix metalloproteinases and tissue inhibitors of metalloproteinases: structure, function, and biochemistry. Circ Res 2003;92:827-39.

55. Bini A, Itoh Y, Kudryk BJ, Nagase H. Degradation of cross-linked fibrin by matrix metalloproteinase 3 (stromelysin 1): hydrolysis of the gamma Gly 404-Ala 405 peptide bond. Biochemistry 1996;35: 13056-63.

56. Schmidtchen A, Frick IM, Andersson E, Tapper H, Björck L. Proteinases of common pathogenic bacteria degrade and inactivate the antibacterial peptide LL-37. Mol Microbiol 2002;46:157-68.

57. Urdiales JL, Medina MA, Sanchez-Jimenez F. Polyamine metabolism revisited. Eur J Gastroenterol Hepatol 2001;13:1015-9.

58. Bachrach U, Wang YC, Tabib A. Polyamines: new cues in cellular signal transduction. News Physiol Sci 2001;16:106-9.

59. Abd-El-Aleem SA, Ferguson MW, Appleton I, Kairsingh S, Jude EB, Jones K, McCollum CN, Ireland GW. Expression of nitric oxide synthase isoforms and arginase in normal human skin and chronic venous leg ulcers. J Pathol 2000;191:434-42.

60. Jude EB, Boulton AJ, Ferguson MW, Appleton I. The role of nitric oxide synthase isoforms and arginase in the pathogenesis of diabetic foot ulcers: possible modulatory effects by transforming growth factor beta 1. Diabetologia 1999;42:748-57.

61. Gotoh T, Mori M. Arginase II downregulates nitric oxide (NO) production and prevents NO-mediated apoptosis in murine macrophage-derived RAW 264.7 cells. J Cell Biol 1999;144:427-34.

62. Anggard E. Nitric oxide: mediator, murderer, and medicine. Lancet 1994;343:1199-206.

63. Stallmeyer B, Kämpfer $\mathrm{H}$, Kolb N, Pfeilschifter J, Frank S. The function of nitric oxide in wound repair: inhibition of inducible nitric oxide-synthase severely impairs wound reepithelialization. J Invest Dermatol 1999;113:1090-8.

64. Lee PC, Salyapongse AN, Bragdon GA, Shears LL 2nd, Watkins SC, Edington HD, Billiar TR. Impaired wound healing and angiogenesis in eNOS-deficient mice. Am J Physiol 1999;277:H1600-8.

65. Lu CD, Winteler $H$, Abdelal A, Haas D. The ArgR regulatory protein, a helper to the anaerobic regulator ANR during transcriptional activation of the arcD promoter in Pseudomonas aeruginosa. J Bacteriol 1999;181:2459-64.

66. Theil EC, Forsyth GW, Jones EE. Expression of the arginine regulon of Escherichia coli W: evidence for a second regulatory gene. J Bacteriol 1969;99:269-73.

67. Galkin A, Kulakova L, Sarikaya E, Lim K, Howard A, Herzberg O. Structural insight into arginine degradation by arginine deiminase, an antibacterial and parasite drug target. J Biol Chem 2004;279:14001-8.

68. Roberts PR, Black KW, Santamauro JT, Zaloga GP. Dietary peptides improve wound healing following surgery. Nutrition 1998;14:266-9.

69. Sarantos P, Abouhamze A, Abcouwer S, Chakrabarti R, Copeland EM, Souba WW. Cytokines decrease glutaminase expression in human fibroblasts. Surgery 116:276-83; discussion 1994;283-4.

70. Fitzpatrick DW, Fisher H. Carnosine, histidine, and wound healing. Surgery 1982;91:56-60. 
71. Collins N. Glutamine and wound healing. Adv Skin Wound Care 2002;15:233-4.

72. Caldwell MD. Local glutamine metabolism in wounds and inflammation. Metabolism 1989;38:34-9.

73. Soeters PB, van de Poll MC, van Gemert WG, Dejong $\mathrm{CH}$. Amino acid adequacy in pathophysiological states. J Nutr 2004;134:1575S-82S.

74. Cetiner M, Sener G, Sehirli AO, Ekşioğlu-Demiralp E, Ercan F, Sirvanci S, Gedik N, Akpulat S, Tecimer T, Yeğen BC. Taurine protects against methotrexate-induced toxicity and inhibits leukocyte death. Toxicol Appl Pharmacol 2005;209:39-50.

75. Cynober LA. Metabolic and therapeutic aspects of amino acids in clinical nutrition (ed Second), CRC press, 2004. 

Chapter 5

Oral arginine supplementation and the effect on skin graft donor sites; a randomized clinical pilot study

IBJG Debats, DI Booi, KME Wehrens, J Cleutjens, NEP Deutz, E van de Hogen, M Bemelmans, RRWJ van der Hulst

J Burn Care Res 2009;30:417-426 


\section{Abstract}

\section{Background \& Aims}

Although arginine has been shown to improve healing in rodents and in small induced wounds in healthy volunteers, little is known about the effects of arginine supplementation on healing of clinically relevant surgical wounds.

\section{Methods}

We studied 18 patients in a double blind randomized pilot study (12 males, 6 females), who underwent skin transplantation as part of reconstructive surgery. Patients were randomly assigned to receive arginine $(n=8)$ or placebo $(n=10)$ supplementation as an enteral dose of 36.2 grams of L-arginine- $\mathrm{HCl}$ or an isocaloric amount of placebo (51.2 grams alanine), respectively. Wound healing was evaluated at the donor sites of skin grafts by measuring angiogenesis, reepithelialization and neutrophil count. Arginine metabolism was studied by measuring plasma and wound fluid amino acid concentrations.

\section{Results}

Our results show that none of these parameters were significantly different between the oral arginine supplementation group and the placebo group.

\section{Conclusion}

In conclusion, enteral arginine supplementation does not improve wound healing of skin donor sites. 


\section{Introduction}

Although nutrition is an extrinsic factor regulating wound healing, nutritional supplementation for the modulation wound healing remains experimental ${ }^{1,2}$. Until now no studies investigated the effect of supplementation of pharmaconutrients to relatively healthy patients with clinically relevant surgical wounds. This is of great importance in e.g. burn wound treatment; speeding up donor site healing can result in shorter hospital stay leading to increased well-being of the patient and lower costs of healthcare.

Arginine has been shown to have an important role in experimental wound healing. Excluding arginine from the diet leads to decreased wound healing ${ }^{3}$ while supplementation of arginine increases wound collagen accumulation, wound breaking strength and reepithelialization in rodents ${ }^{4-8}$. Beneficial effects of arginine supplementation are attributed to enhanced local nitric oxide (NO) production, a signal molecule needed to mediate processes essential for wound healing (e.g. vascular relaxation, platelet aggregation, neurotransmission and non-specific host defense $)^{9-13}$. Although the exact role of NO remains unclear ${ }^{14,15}$, different studies show arginine is a potent immunomodulator; it improves on patient's immune state: improvement of mitogen-stimulated lymphocyte proliferation in burned children ${ }^{16}$, nitrogen retention, decreased hospital stay and wound infection rates ${ }^{17-19}$. Furthermore, NO is a key mediator in angiogenesis; iNOS-derived (induced nitric oxide synthetase) NO induces VEGF (vascular endothelial growth factor), the most potent known angiogenic protein $^{20-22}$. In addition, Noiri et al. observed that inhibition of NO synthesis blunted VEGF-stimulated cell migration. Comparable results were published by Most et al., showing that i-or eNOS knockout mice exhibited impaired VEGF expression and delayed wound healing ${ }^{23}$.

Arginine has been evaluated using nutritional formulas containing other nutrients like glutamine, nucleotides and $\omega-3$ fatty acids. From these studies, it was not possible to attribute the positive effects of these nutritional formulas strictly to arginine ${ }^{24-26}$. Only Van Bokhorst et al. studied the isolated role of peri-operative arginine supplementation as pharmaconutrient ${ }^{18}$. Moreover, this study only evaluated postoperative morbidity as parameter of wound healing. Although, oral arginine supplementation was studied in healthy volunteers with experimental wounds, showing increased wound collagen synthesis, so far, no clinical studies have investigated the effect of arginine supplementation on clinically relevant wound healing. These prior results prompted us to conduct a pilot study that investigates the effects of arginine supplementation on the healing of skin graft donor sites in wellnourished patients. In addition we tried to clarify the way arginine supplementation affects conversion of arginine in wounds. 


\section{Materials and methods}

\section{Subjects}

Eighteen patients (12 males, 6 females) undergoing skin transplantation as part of reconstructive surgery participated in this double-blind randomized study. Age ranged from 25 to 70 years (mean \pm SEM: $46 \pm 17$ ). Mean body mass index and weight loss within six months prior to surgery was measured to determine clinical depletion according to the Espen guidelines ${ }^{27}$. Exclusion criteria were age younger than 18 or older than 70 years, kidney or liver failure, pregnancy, use of steroids, immune deficiency diseases, and diabetes mellitus. The study protocol was approved by the Ethics Committee of Maastricht University Hospital, and informed consent was obtained for each subject.

Patients were randomly assigned to arginine $(n=8)$ or placebo treatment $(n=10)$, by an independent dietician, using numbered envelopes. Based on literature at the initiation of the study, the highest tolerable amount of arginine was administered ${ }^{4,5}$. Supplementation was given during five days peri-operatively to evaluate the different processes during the initial phases of wound healing (inflammatory and proliferative phase). Patients received either 36.2 grams of L-arginine- $\mathrm{HCl}$ (26 grams of free arginine) or an isocaloric amount of placebo (51.2 grams alanine). We chose isocaloric, because we were not able to make solutions that were isocaloric and isonitrogenous without compromising the study design. To make the solutions isocaloric and isonitrogenous, they would not be isovolumetric and this would make a double blind study impossible. L-arginine- $\mathrm{HCl}$ or alanine was dissolved in $600 \mathrm{ml}$ of commercially available sugar-free lemonade (Slimpie ${ }^{\circledR}$ ) to ameliorate the taste. Patients drank three doses of $200 \mathrm{ml}$ per day for 5 days, in the presence of the investigator. Arginine or placebo (Bufa, Uitgeest, The Netherlands) supplementation was started the day before the skin graft was harvested and continued until the fourth day after surgery. No arginine/placebo drink was administered on the day of operation. Oral food intake was allowed as desired. Samples were collected prior to supplement ingestion.

\section{Wound model}

All clinical wound procedures were performed in the Department of Plastic Surgery, University Hospital Maastricht, The Netherlands. Under general anesthesia and aseptic conditions, split skin grafts were obtained using an electric dermatome (Aesculaap ${ }^{\circledR}$ ) with a thickness of $0.3 \mathrm{~mm}$. The donor sites were used to evaluate wound healing. Wound fluid was collected from these donor sites by covering it with a layer of Gordasoft $^{\circledR}$, followed by a polyvinyl alcohol sponge $\left(\right.$ Coldex $^{\circledR}$ ) and a transparent dressing $\left(\right.$ Tegaderm $^{\circledR}$ ) on top.

Twenty-four hours before sampling the dressing was changed by removing the transparent dressing and the sponge, followed by reapplying a new sponge and transparent dressing. From each patient wound samples were taken on day 2, 5 and 
10. After the sponge was removed, it was immediately put on ice. From the central part of the donor site 3-mm punch biopsies were taken. Before the excision of the biopsies, lidocaine was locally injected. Subsequently a venous blood sample was drawn from a major vein in the cubital fossa. The surfaces of all donor sites were measured.

\section{Sample processing and analysis}

Heparinized blood was centrifuged at $4^{\circ} \mathrm{C}$ for 10 minutes at $4000 \mathrm{rpm}$ within one hour after sampling. After centrifugation, $500 \mu \mathrm{l}$ of plasma was deproteinized using $20 \mathrm{mg}$ dry sulphosalicylic acid (SSA), vortexed and frozen in liquid nitrogen. Samples were stored at -80 degrees Celsius until analysis. Wound fluid from acute wounds was obtained by centrifuging the sponges for $10 \mathrm{~min}$ at $4^{\circ} \mathrm{C}(11.000 \mathrm{rpm})$. After centrifugation, $500 \mu \mathrm{l}$ of wound fluid was treated similar to the plasma. The recovery of fluid from the sponges was validated and found to be constant.

\section{Evaluation of wound healing}

In order to study the wound healing, donor site biopsies were obtained at identical time points: day 2, 5 and 10. These time points were chosen to reflect the inflammatory phase at day 2 , the proliferative phase at day 5 and reepithelialization on day 10 . Biopsies were fixed in $4 \%$ formaldehyde, processed by routine histological procedures and embedded in paraffin. Four $\mu \mathrm{m}$ sections were subsequently obtained from each paraffin block.

\section{Immunohistochemical assessment of neutrophils and angiogenesis}

Sections were initially stained with haematoxylin and eosin. Polymorphonuclear neutrophils (PMN's ) were counted in wound biopsies of day 2, 5 and 10 post-surgery in sections as a marker of inflammation.

We objectified angiogenesis by micro vessel density (MVD), as described previously by Hillen et al. and Baeten et al. ${ }^{28,29}$ in wound of day 2, 5 and 10 post-surgery. Immunolabeling of mouse-anti-human alpha smooth muscle actin (ASMA; Dako Laboratories, Carpinteria, CA, USA) and mouse-anti-human CD31 (Dako Laboratories Carpinteria, CA, USA) was used to stain vessels on separate days. The assessments were performed by two separate blinded investigators.

\section{Reepithelialization}

Standardized photographs of the donor sites with measuring scales were taken on days 5 and 10 (Canon EOS 300 with macro lens, 1:1). Two blinded independent observers measured the surface of reepithelialized skin by planimetry using the morphometric program ImageJ $^{30}$ (W. Bailer, Hagenberg, Austria). The area with reepithelialized skin 
was expressed as a percentage of the total wound area (central part). These type of wounds usually heal within 10 days, i.e. reepithelialization percentages of approximately $80 \%{ }^{31,32}$. A quantitative bacterial analysis was performed of wound fluid samples, expressed as colony forming units (CFU).

\section{Biochemical analysis}

\section{Amino acids measurement in plasma and wound fluid}

Arginine, citrulline and ornithine concentrations were measured in plasma and wound fluids of all patients. Plasma and wound fluid amino acids were determined using a fully automated HPLC system as described previously ${ }^{33}$.

\section{Nitrite/nitrate determination in plasma and wound fluid}

To study production of NO by Nitric Oxide Synthetase (NOS) we measured the concentration of the indicators of NO production (nitrite and nitrate) and expressed these results as NOx (=sum of nitrite and nitrate). NOx concentrations in plasma and wound fluid were also determined using $\mathrm{HPLC}^{33,34}$.

\section{Arginase-1 concentrations in plasma and wound fluid}

Arginase-1 concentrations were determined in plasma and wound fluid samples of all patients to objectify the involvement of this arginine-metabolizing enzyme. A sandwich ELISA method was used to measure arginase levels ${ }^{35}$. Standard, primary and secondary antibodies were kindly provided by HBT (Uden, The Netherlands). In short, a 96-wells plate was coated overnight at $4^{\circ} \mathrm{C}$ with $100 \mu$ of the purified anti-human liver-type arginase monoclonal IgG antibody (Mo6G3). Plasma samples were prediluted 1:2 in dilution buffer (1x PBS-0.1\% BSA) and wound fluid samples 1: 400. Samples were added to the wells. Bound arginase was detected with a second biotinylated antibody (Mo9C5), followed by peroxidase-conjugated streptavidin and TMB.

\section{Statistical analysis}

Data were expressed as means \pm SEM. Amino acid concentrations were expressed in $\mu \mathrm{mol} / \mathrm{l}$. Repeat-measure ANOVA was used to compare both groups. A 95\% confidence interval was used to determine significance. The statistical package for social sciences (SPSS) program was used for statistical analysis. 


\section{Results}

\section{Patient characteristics}

Patient characteristics are shown in Table 5.1 and 5.2.

Table $5.1 \quad$ Patient characteristics (gender, age, BMI).

\begin{tabular}{lccccc}
\hline Group & F:M & \multicolumn{2}{c}{$\begin{array}{c}\text { Age } \\
\text { yr }\end{array}$} & \multicolumn{2}{c}{ BMI } \\
& & Mean & SEM & Mean & Min/max \\
\hline Controls & $8: 2$ & 47 & 6 & 26.5 & $20 / 40$ \\
Suppletion & $4: 4$ & 49 & 6 & 27.6 & $20 / 35$ \\
\hline
\end{tabular}

$\mathrm{BMI}$, Body Mass Index. All values are expressed as means \pm SEM, except for BMI which is expressed as mean, min and max values.

Table $5.2 \quad$ Patient characteristics (diagnosis, operation).

\begin{tabular}{lll}
\hline Controls & Main Diagnosis & Operation \\
\hline 1 & Cancer of the ear & Reconstruction with free temporal fascia \& \\
& SSG & Open wound leg: reconstruction with ff- \\
2 & Tibia fracture & Gracilis muscle and SSG \\
& & Reconstruction with ff-ALT and SSG \\
3 & Sarcoma of the leg & Reconstruction with ff-Radial forearm / SSG \\
4 & Nose contraction after cocaine use & SSG \\
5 & Burn wounds back & SSG \\
6 & Venous ulcer leg & Ff-temporal fascia with SSG \\
7 & Marjolin's ulcer, old burn wounds & Ff-temporal fascia SSG \\
8 & Crush wound of the hand & Ff-temporal fascia with SSG \\
9 & Fracture maleolus & SSG \\
10 & Trauma, leg amputation & \\
& & \\
Suppletion & Main Diagnosis & SSG \\
1 & Scar formation after burn wounds & Ff-Gracilis + SSG \\
2 & Open wound after fracture of tibia & SSG \\
3 & Burn wounds thorax & Free Rectus Abdominis + SSG \\
4 & Open wound after fracture of the femur & SSG \\
5 & Open wound after rupture Achilles' tendon & SSG \\
6 & Open wound after fracture ankle + OSM & SSG \\
7 & Chronic open wound under foot & SSG \\
8 & Deglovement thumb &
\end{tabular}

SSG, split skin graft; Ff, Free flap; OSM, osteosynthesis material.

No differences were observed in age or nutritional status as expressed by Body Mass Index (BMI) between the different groups. BMI values of all patients were $>20$, and none of the patients suffered from weight loss $>10 \%$ total body weight in the period of 6 months before inclusion in the study protocol. All burn wounds were $<5 \%$ of total body surface, and all patients were metabolically stable. There were no differences in 
donor site surface area comparing the placebo group (mean \pm SEM): $83.6 \pm 17.9 \mathrm{~cm}^{2}$ and arginine-treated group $67.5 \pm 13.7 \mathrm{~cm}^{2}$. During the study we experienced that most of the patients had difficulties drinking the amino acid solution because of the bad taste. Nausea and diarrhea occurred in two patients in the supplementation group during drinking of the solution on the first or second postoperative day. Vomiting in one patient, on the first post-operative day, but overall this patient drank $78 \%$ of the solution. Two patients in the supplementation group discontinued the study before the end because of this reason. These patients refused to participate in the follow up procedures (donation of blood and tissue samples) due to logistics reasons. In the placebo group similar tolerance was observed, two patients suffered from nausea. One patient did vomit on the second day postoperative, but overall intake was $87 \%$. However, in the rest of the study subjects, all amino acid drinks were completely finished. No further adverse events were noticed. No clinical signs of infection of the donor sites were observed. In addition there were no quantitative bacterial cultures of the donor site $>10^{3}$ CFU observed in either group (data not shown).

\section{Plasma amino acids}

In the supplementation group a higher wound fluid arginine level was observed (Figure 5.1B). Significant higher citrulline levels were observed in wound fluid compared to plasma in both groups, indicating NO-production. However, no additional effect of arginine supplementation was observed on wound fluid citrulline concentrations showed no significant differences between groups (Figure 5.2B). Data showed no significant differences in wound fluid ornithine concentrations comparing both groups. Although, results show a tendency towards higher wound fluid ornithine levels in the supplementation group (Figure 5.3B).
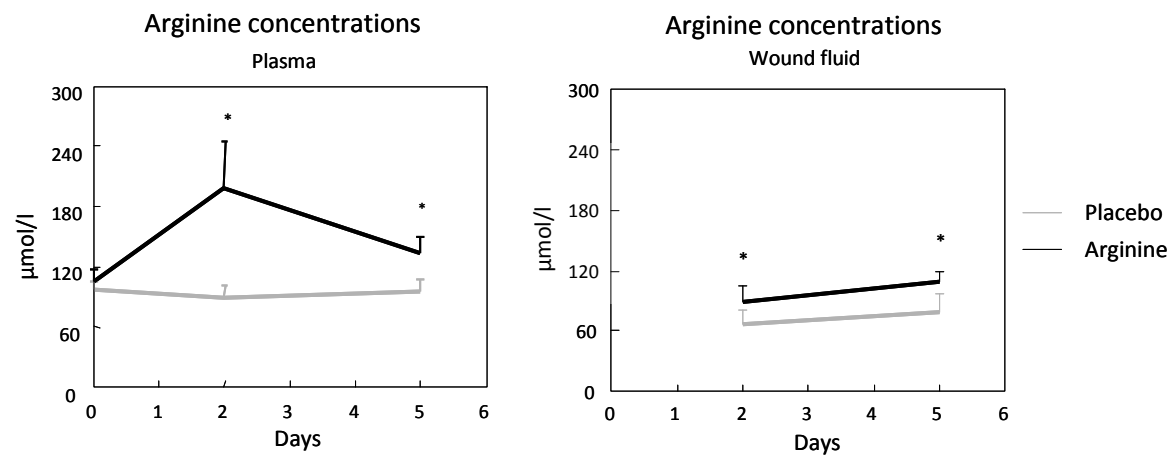

Figure 5.1 A and B: plasma and wound fluid arginine concentrations ( $\mu \mathrm{mol} / \mathrm{l})$ : placebo vs. suppletion. Data are expressed as means \pm SEM, $* p<0.05$. 
A

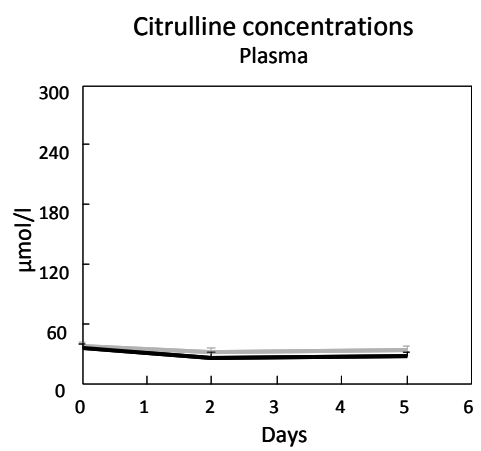

B

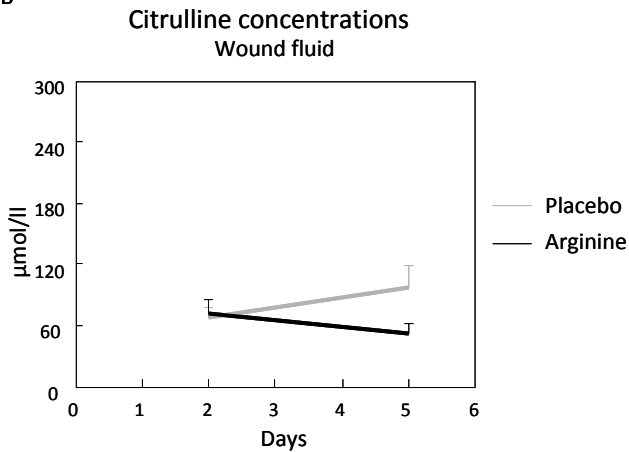

Figure 5.2 A and B plasma and wound fluid Citrulline concentrations ( $\mu \mathrm{mol} / \mathrm{l}$ ); placebo vs. suppletion. Data are expressed as means \pm SEM, $* p<0.05$.

A

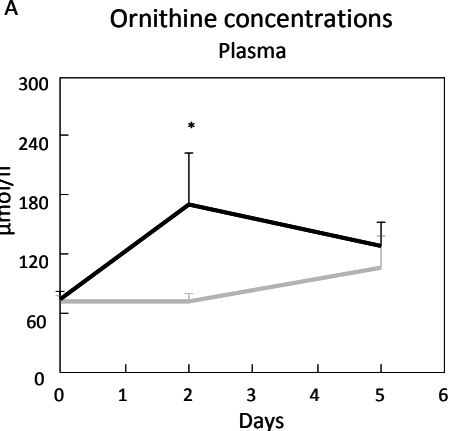

B Ornithine concentrations

Wound fluid

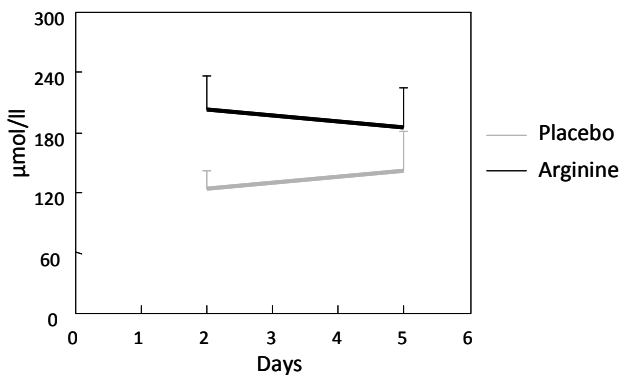

Figure 5.3 A and B: plasma and wound fluid ornithine concentrations ( $\mu \mathrm{mol} / \mathrm{l})$; placebo vs. supplementation. Data are expressed as means \pm SEM, ${ }^{*} p<0.05$.

\section{Plasma NOx and wound fluid NOx}

Data showed no differences in plasma NOx between the groups and no differences were observed in wound fluid NOx between both groups (Figure 5.4A, B).

\section{Plasma and wound arginase-1}

No significant differences were observed in plasma or wound fluid arginase levels between the control and supplementation group (Figure 5.5A, B). 
A

NOx concentrations

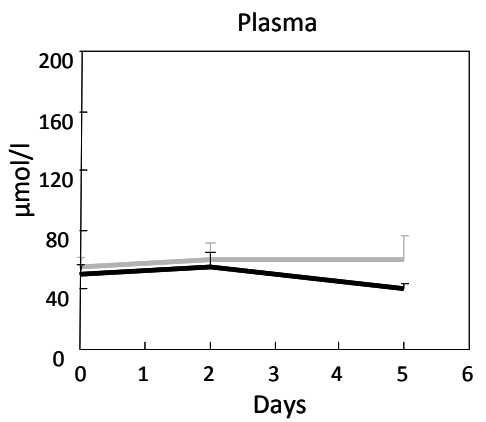

B

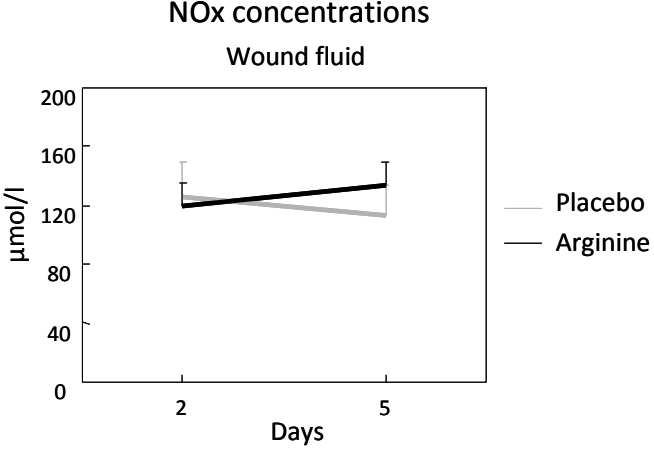

Figure 5.4 A and B: plasma and wound fluid NOx (sum of nitrate and nitrite) concentrations ( $\mu \mathrm{mol} / \mathrm{I}$ ): placebo vs. supplementation. Data are expressed as means $\pm \mathrm{SEM},{ }^{*} \mathrm{p}<0.05$.
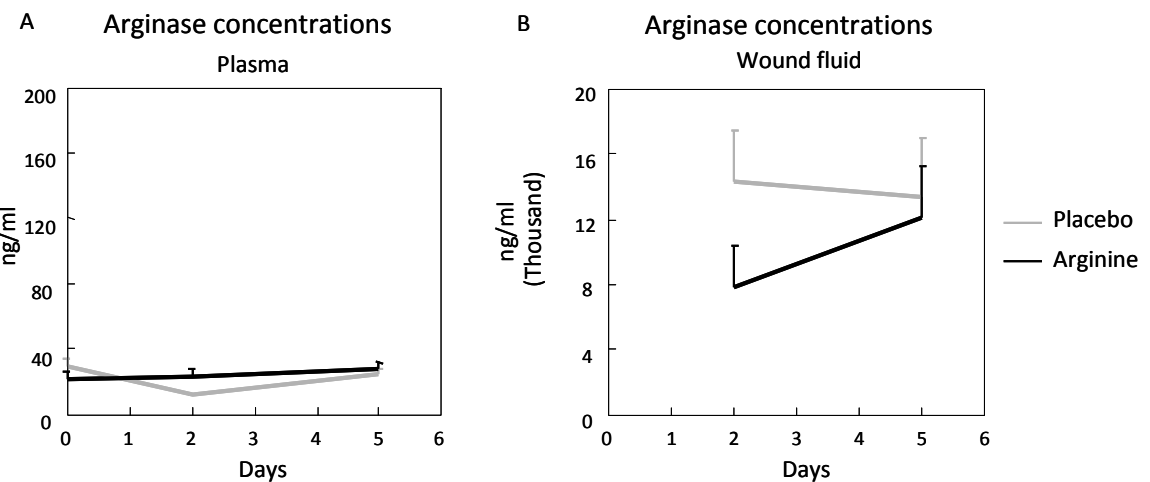

Figure 5.5 A and B: plasma and wound fluid arginase concentrations (ng/ml); placebo vs. supplementation. Data are expressed as means \pm SEM, ${ }^{*} p<0.05$.

\section{Evaluation of wound healing}

\section{PMN-count, angiogenesis and reepithelialization}

Quantification of neutrophils, angiogenesis and reepithelialization, by blind histological investigation (kappa $=0.81 ; 0.72 ; 0.56$ ), showed no differences comparing both groups (Figures. 5.6, 5.7, and 5.8). 


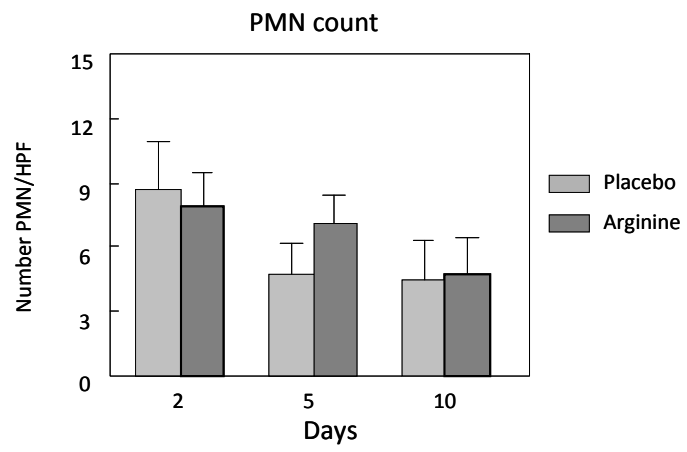

Figure 5.6 Polymorphonuclear neutrophils; number of PMN/HPF.

Data are expressed as means \pm SEM.

\section{Angiogenesis}

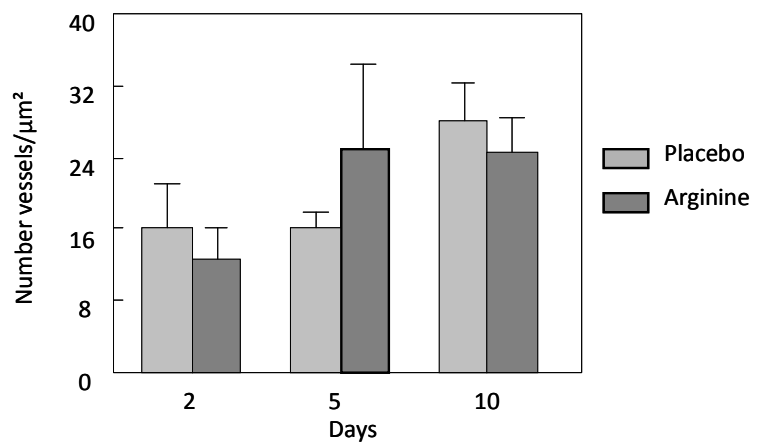

Figure 5.7 Angiogenesis; number of vessels $/ \mu \mathrm{m}$.

Data are expressed as means \pm SEM. 


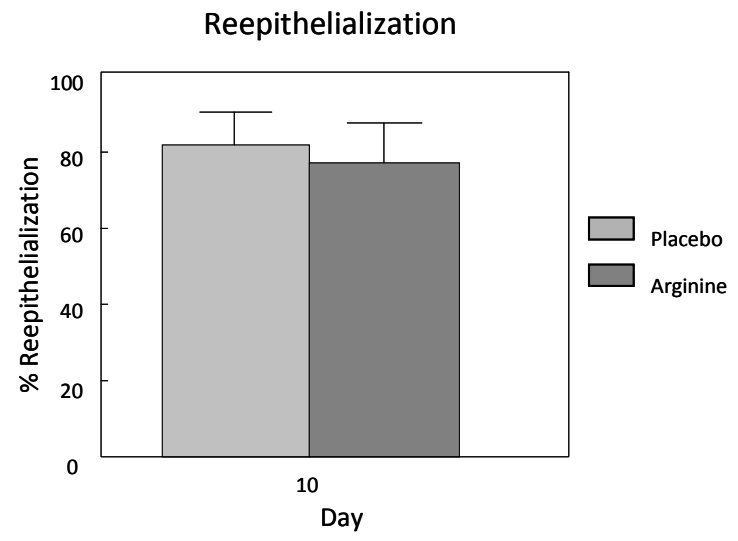

Figure 5.8 Reepithelialization; expressed as percentage of the total wound area. Data are expressed as means \pm SEM.

\section{Discussion}

This pilot study was initiated to investigate the effects of oral arginine supplementation, as a single nutrient, on wound healing of clinical relevant surgical wounds in patients. Our study showed that oral arginine supplementation does not enhance reepithelialization of skin graft donor sites in relatively healthy patients. In addition, no effects were observed on arginine conversion in the wound environment comparing arginine-group to control group.

Oral arginine supplementation increased plasma arginine and ornithine levels, as well as local wound arginine and ornithine levels, the latter however not significant. This finding is comparable to prior studies ${ }^{11,13}$ and can be explained by the fact that a large portion of L-arginine is passing through the gastrointestinal tract to the liver and is catabolized by arginase to ornithine and urea. The observed elevated wound fluid ornithine, could be a reflexion of these elevated plasma levels. However, previous studies show up regulation of arginase in wounded tissue (macrophages, fibroblasts etc), needed to generate substrates for collagen formation and cell proliferation ${ }^{37-42}$. This is confirmed by our findings as arginase- 1 in wound fluid was much higher than plasma values. Although, arginase-1 is the predominant isoform in the liver and arginase- 2 is found predominantly in extrahepatic tissues, with regard to wound healing, most studies show consistent increased expression of arginase-1 upon wounding ${ }^{40-43}$. Few show co-expression of arginase- 1 and $-2^{39,44}$. But the role of arginase-2 is not clear. Comparing our results to other human studies is difficult as no specific arginase- 1 or 2 antibodies were used in their stainings ${ }^{45,46}$. Some show 
increased expression of arginase in relation to impaired healing (chronic wounds and diabetic ulcers) and pathological skin conditions ${ }^{47}$. Only Corraliza et al., did measure arginase-2 in synovial fluid of arthritis patients using RT-PCR, and showed up regulation. They suggested that this up regulation deregulates the healing process in arthritis $^{48}$. In the face of these previous results, our working hypothesis was that arginase- 1 is the main pathway during human wound healing. In addition, no arginase2 antibody for ELISA was available at the time of our experiments. Therefore, we chose to measure arginase- 1 expression in plasma and wound fluid.

In the control group as well as in the supplemented group we observed NOS and arginase activity in the wound environment, as citrulline, NOx and ornithine levels were higher in wound fluid compared to plasma, this is in line with a well established experimental wound model ${ }^{12,49}$. However, our results show no additional effect in the conversion of arginine in the wound environment after supplementation. Although, not easy to compare to other studies as they not always evaluate plasma and wound fluid, our results are comparable ${ }^{7,13,50}$. In human studies, plasma arginine and ornithine are elevated after arginine supplementation ${ }^{4,5}$. The question rises why elevated arginine levels in wound fluid do not lead to increased NOS/arginase activity? Our wound model is an acute wound model in relatively healthy patients. As there was no clinical or histological difference in reepithelialization compared to controls, it is likely that NOS and arginase expression was maximally normal. In addition, enzyme-activity depends on substrate availability, and both our study groups showed no signs of arginine depletion in plasma or wound fluid.

PMN's are the first cells to arrive at the wound site; they degrade cell debris and extracellular matrix (ECM), decontaminate bacteria and produce cytokines to attract the more important macrophages ${ }^{51}$. In vitro studies showed that human neutrophils generate $\mathrm{NO}^{52,53}$ and express $\mathrm{NOS}^{54}$. NOS peaks within 24-72 hours after wounding, inflammatory cells being the predominant source ${ }^{12}$. Different studies show beneficial effect of arginine supplementation on immune state $e^{8,55}$ and decreased infection rate is observed upon arginine supplementation ${ }^{17,18}$. Moreover, Canturk et al. related an increased number and function of PMN's to increased in wound tensile strength, upon arginine supplementation ${ }^{56}$. Therefore, we evaluated the PMN-influx and quantitative bacterial analysis of the wound fluid. Furthermore, PMN's also regulate angiogenesis $^{57,58}$. In vitro studies already showed the importance of NO in angiogenesis; iNOS-derived NO induces VEGF, the most potent known angiogenic protein $^{20-22}$. In addition, Noiri et al. observed that inhibition of NO synthesis blunted VEGF-stimulated cell migration ${ }^{59}$. Most et al., showed that iNOS or eNOS (endothelial nitric oxide synthetase) knockout mice exhibited impaired VEGF expression and delayed wound healing ${ }^{60}$. Our results show no differences in PMN influx, infection or angiogenesis upon arginine supplementation. This could be explained by the fact that we studied acute wounds, in patients with a clinical good condition and clinically normal wound healing. Factors influencing enzyme expression, like diabetes were excluded from our study. Therefore, it is likely to assume that eNOS expression was 
maximally normal. In addition, enzyme-activity depends on substrate availability, and both our study groups showed no signs of arginine depletion. Another possibility might be that specific immunomodulating effects of arginine only concern lymphocytes ${ }^{4,5,37,61}$.

No differences in reepithelialization upon arginine supplementation were observed. Reepithelialization is NO-mediated as shown by several studies; proliferating keratinocytes of wound margins strongly express iNOS ${ }^{51,62}$. Inhibition of iNOS or eNOS impair epithelial proliferation ${ }^{23,6,64}$. In addition, there is a correlation between the availability of $\mathrm{NO}$ and keratinocytes proliferation ${ }^{65}$. Arginine supplementation in rats improved reepithelialization ${ }^{16}$. In the only human study evaluating arginine on reepithelialization of small experimental wounds in volunteers, no effect was observed $^{5}$. The exact mechanism of action remains unclear. The proposed mechanisms of action of arginine supplementation on wound healing based on prior research are: 1) stimulation of adrenal and pituitary secretion of hormones, 2) arginine as biologic precursor for NO / arginase and 3) arginine as pharmaconutriënt. With regard to stimulation of adrenal and pituitary secretion of hormones there is controversy in literature. Some studies show increase of insulin-like-growth factor and growth hormone upon arginine supplementation in humans, while others refute this ${ }^{66-68}$. Arginine is the biologic precursor for NO / arginase, limited arginine availability is known to regulate iNOS and arginase activity. In our study no arginine depletion was observed in plasma or wound fluid, which might explain why there was no effect on reepithelialization. If there might be a depletion in the microenvironment which we could not observe, endogenous production of NO might be sufficient during normal wound healing. We did not measure hydroxyproline (OHP), so we cannot draw conclusions concerning collagen deposition, but with regard to comparable studies we might assume a same increasing effect. What is the reason for a potential effect on collagen deposition and not on reepithelialization? The role of arginine in collagen metabolism became clear after the finding that arginine becomes semi-essential after surgery ${ }^{6}$. Later on, several animal and human studies showed arginine supplementation improved OHP and wound breaking strength and that collagen synthesis is NO-mediated ${ }^{69-72}$. Others, suggested collagen-formation is more depending on arginine as precursor for OHP, which is an actual substrate for collagen building. The process of re-epithelialization is also closely controlled by growth factors, this process consists of multiple integrated networks of cell-matrix-cytokine interactions; it is possible that NO is only important in the early migration of keratinocytes, as Noiri et al. suggested ${ }^{59}$. And thereafter other factors like VEGF mediate the process ${ }^{51,73}$. Another explanation for the effect of arginine on collagen production might be the effect of ornithine. If supplemented as a single nutrient it also stimulates wound healing. Shi et al. showed that this effect was independent of NO and suggested that the available proline pool determines the rate of collagen synthesis ${ }^{74}$. In our study, we observed increased arginine as well as ornithine levels in plasma and wound fluid. It is possible that these amino acids are responsible for the difference in collagen- 
formation vs. reepithelialization. The mechanisms of wound healing are complex, and dependent on temporally and spatially restricted NO expression. Therefore more research has to be done. Arginine as pharmaconutriënt: as arginine improves wound healing in animals, is a potent immunomodulator in humans and the role of NO is obvious in the different aspects of wound healing, we hypothesized that arginine might have the same influence on reepithelialization. However, we have to conclude from our results that arginine as a pharmaconutrient has no effect on reepithelialization in clinically relevant, but normal healing wounds. A restriction of this study may be the route of administration. Drinking the solution was sometimes difficult, causing nausea and vomiting. Two patients quit the study because of bad taste of the solution and were not included for analysis, the others completed the study and drunk the whole solution. Although this issue is important for future studies, it does not explain the negative results of our study. As this is a pilot study with small study groups, this could result in lack of statistical power. Most likely our wound model, which mainly examines reepithelialization, has restrictions in studying the effect of pharmaconutrients. Although epithelialization is important in wound healing and especially in burn wound treatment, a potential beneficial effect of arginine might be expected more in other types of wounds. Finally, our patients were relatively healthy; which might have contributed to the small differences found. It is likely that arginine supplementation in relatively healthy patients has not the same effect as compared to some animal species. The effect of arginine supplementation might be expected more in less healthy patients with an arginine depleted state like malnutrition, sepsis or cardiovascular disease. In conclusion, our results demonstrate that oral arginine as a pharmaconutrient has no effect on reepithelialization in clinically relevant, but normal healing wounds. Studies addressing our specific short comings might be initiated in the future. 


\section{References}

1. Yan H, Peng X, Huang Y, Zhao M, Li F, Wang P. Effects of early enteral arginine supplementation on resuscitation of severe burn patients. Burns 2007;33:179-84.

2. Sacks GS, Genton L, Kudsk KA. Controversy of immunonutrition for surgical critical-illness patients. Curr Opin Crit Care 2003;9:300-5.

3. Nirgiotis JG, Hennessey PJ, Andrassy RJ. The effects of an arginine-free enteral diet on wound healing and immune function in the postsurgical rat. J Pediatr Surg 1991;26:936-41.

4. Barbul A, Lazarou SA, Efron DT, Wasserkrug HL, Efron G. Arginine enhances wound healing and lymphocyte immune responses in humans. Surgery 1990;108:331-6.

5. Kirk SJ, Hurson M, Regan MC, Holt DR, Wasserkrug HL, Barbul A. Arginine stimulates wound healing and immune function in elderly human beings. Surgery 1993;114:155-9.

6. Seifter E, Rettura G, Barbul A, Levenson SM. Arginine: an essential amino acid for injured rats. Surgery 1978;84:224-30.

7. Witte MB, Thornton FJ, Tantry U, Barbul A. L-Arginine supplementation enhances diabetic wound healing: involvement of the nitric oxide synthase and arginase pathways. Metabolism 2002;51: 1269-73.

8. Angele MK, Nitsch SM, Hatz RA, Angele P, Hernandez-Richter T, Wichmann MW, Chaudry IH, Schildberg FW. L-arginine: a unique amino acid for improving depressed wound immune function following hemorrhage. Eur Surg Res 2002;34:53-60.

9. Morbidelli L, Donnini S, Ziche M. Role of nitric oxide in the modulation of angiogenesis. Curr Pharm Des 2003;9:521-30.

10. Bruch-Gerharz D, Ruzicka T, Kolb-Bachofen V. Nitric oxide and its implications in skin homeostasis and disease - a review. Arch Dermatol Res 1998;290:643-51.

11. Witte MB, Kiyama T, Barbul A. Nitric oxide enhances experimental wound healing in diabetes. Br J Surg 2002;89:1594-601.

12. Lee RH, Efron D, Tantry U, Barbul A. Nitric oxide in the healing wound: a time-course study. J Surg Res 2001;101:104-8.

13. Shi HP, Efron DT, Most D, Tantry US, Barbul A. Supplemental dietary arginine enhances wound healing in normal but not inducible nitric oxide synthase knockout mice. Surgery 2000;128:374-8.

14. Parlesak A, Negrier I, Neveux N, Bode C, Cynober L. Arginine does not exacerbate markers of inflammation in cocultures of human enterocytes and leukocytes. J Nutr 2007;137:106-11.

15. Moncada S, Palmer RM, HiggsEA. Nitric oxide: physiology, pathophysiology, and pharmacology. Pharmacol Rev 1991;43:109-42.

16. Chen X, Li Y, Cai X, Xu W, Lu S, Shi J. Dose-effect of dietary L-arginine supplementation on burn wound healing in rats. Chin Med J (Engl) 1999;112:828-31.

17. Braga M, Gianotti L, Vignali A, Carlo VD. Preoperative oral arginine and n-3 fatty acid supplementation improves the immunometabolic host response and outcome after colorectal resection for cancer. Surgery 2002; 132:805-14.

18. van Bokhorst-De Van Der Schueren MA, Quak JJ, von Blomberg-van der Flier BM, Kuik DJ, Langendoen SI, Snow GB, Green CJ, van Leeuwen PA. Effect of perioperative nutrition, with and without arginine supplementation, on nutritional status, immune function, postoperative morbidity, and survival in severely malnourished head and neck cancer patients. Am J Clin Nutr 2001;73:323-32.

19. Zheng $Y$, Li F, Qi B, Luo B, Sun H, Liu S, Wu X. Application of perioperative immunonutrition for gastrointestinal surgery: a meta-analysis of randomized controlled trials. Asia Pac J Clin Nutr 2007;16 Suppl 1:253-7.

20. Kapoor M, Howard R, Hall I, Appleton I. Effects of epicatechin gallate on wound healing and scar formation in a full thickness incisional wound healing model in rats. Am J Pathol 2004;165:299-307.

21. Fukumura D, Gohongi T, Kadambi A, Izumi Y, Ang J, Yun CO, Buerk DG, Huang PL, Jain RK. Predominant role of endothelial nitric oxide synthase in vascular endothelial growth factor-induced angiogenesis and vascular permeability. Proc Natl Acad Sci U S A 2001;98: 2604-9.

22. Suzuki J. L-arginine supplementation causes additional effects on exercise-induced angiogenesis and VEGF expression in the heart and hind-leg muscles of middle-aged rats. J Physiol Sci 2006;56:39-44. 
23. Lee PC, Salyapongse AN, Bragdon GA, Shears LL 2nd, Watkins SC, Edington HD, Billiar TR. Impaired wound healing and angiogenesis in eNOS-deficient mice. Am J Physiol 1999; 277:H1600-8.

24. Schilling J, Vranjes N, Fierz W, Joller H, Gyurech D, Ludwig E, Marathias K, Geroulanos S. Clinical outcome and immunology of postoperative arginine, omega-3 fatty acids, and nucleotide-enriched enteral feeding: a randomized prospective comparison with standard enteral and low calorie/low fat i.v. solutions. Nutrition 1996;12:423-9.

25. Bower RH, Cerra FB, Bershadsky B, Licari JJ, Hoyt DB, Jensen GL, Van Buren CT, Rothkopf MM, Daly JM, Adelsberg BR. Early enteral administration of a formula (Impact) supplemented with arginine, nucleotides, and fish oil in intensive care unit patients: results of a multicenter, prospective, randomized, clinical trial. Crit Care Med 1995;23:436-49.

26. Kemen M, Senkal M, Homann HH, Mumme A, Dauphin AK, Baier J, Windeler J, Neumann H, Zumtobel V. Early postoperative enteral nutrition with arginine-omega-3 fatty acids and ribonucleic acidsupplemented diet versus placebo in cancer patients: an immunologic evaluation of Impact. Crit Care Med 1995;23:652-9.

27. Lochs H, Allison SP, Meier R, Pirlich M, Kondrup J, Schneider S, van den Berghe G, Pichard C. Introductory to the ESPEN Guidelines on Enteral Nutrition: Terminology, definitions and general topics. Clin Nutr 2006;25:180-6.

28. Baeten $\mathrm{Cl}$, Wagstaff J, Verhoeven IC, Hillen HF, Griffioen AW. Flow cytometric quantification of tumour endothelial cells; an objective alternative for microvessel density assessment. Br J Cancer 2002;87:3447.

29. Hillen HF, Hak LE, Joosten-Achjanie SR, Arends JW. Microvessel density in unknown primary tumors. Int J Cancer 1997;74:81-5.

30. Girish V, Vijayalakshmi A. Affordable image analysis using NIH Image/ImageJ. Indian J Cancer 2004;41: 47.

31. Malpass KG, Snelling CF, Tron V. Comparison of donor-site healing under Xeroform and Jelonet dressings: unexpected findings. Plast Reconstr Surg 2003;112:430-9.

32. Kilinç H, Sensöz O, Ozdemir R, Unlü RE, Baran C. Which dressing for split-thickness skin graft donor sites? Ann Plast Surg 2001;46:409-14.

33. Van Eijk HM, Dejong $\mathrm{CH}$, Deutz NE, Soeters PB. Influence of storage conditions on normal plasma amino-acid concentrations. Clinical Nutrition 1994;13:374-380.

34. Bruins MJ, Soeters PB, Lamers WH, Meijer AJ, Deutz NE. L-arginine supplementation in hyperdynamic endotoxemic pigs: effect on nitric oxide synthesis by the different organs. Crit Care Med 2002;30: 508-17.

35. Ikemoto $M$, Tsunekawa S, Awane $M$, Fukuda $Y$, Murayama H, Igarashi $M$, Nagata A, Kasai $Y$, Totani M. A useful ELISA system for human liver-type arginase, and its utility in diagnosis of liver diseases. Clin Biochem 2001;34:455-61.

36. Vissers YL, Dejong CH, Luiking YC, Fearon KC, von Meyenfeldt MF, Deutz NE. Plasma arginine concentrations are reduced in cancer patients: evidence for arginine deficiency? Am J Clin Nutr 2005;81:1142-6.

37. Bronte V, Serafini P, Mazzoni A, Segal DM, Zanovello P. L-arginine metabolism in myeloid cells controls T-lymphocyte functions. Trends Immunol 2003;24:302-6.

38. Corraliza IM, Soler G, Eichmann K, Modolell M. Arginase induction by suppressors of nitric oxide synthesis (IL-4, IL-10 and PGE2) in murine bone-marrow-derived macrophages. Biochem Biophys Res Commun 1995;206:667-73.

39. Kampfer H, Pfeilschifter J, Frank S. Expression and activity of arginase isoenzymes during normal and diabetes-impaired skin repair. J Invest Dermatol 2003;121:1544-51.

40. Ochoa JB, Bernard AC, O'Brien WE, Griffen MM, Maley ME, Rockich AK, Tsuei BJ, Boulanger BR, Kearney PA, Morris Jr SM Jr. Arginase I expression and activity in human mononuclear cells after injury. Ann Surg 2001;233:393-9.

41. Witte MB, Barbul A, Schick MA, Vogt N, Becker HD. Upregulation of arginase expression in woundderived fibroblasts. J Surg Res 2002; 105:35-42.

42. Witte MB, Vogt N, Stuelten C, Gotoh T, Mori M, Becker HD. Arginase acts as an alternative pathway of L-arginine metabolism in experimental colon anastomosis. J Gastrointest Surg 2003;7:378-85. 
43. Wessagowit V, Mallipeddi R, McGrath JA, South AP. Altered expression of L-arginine metabolism pathway genes in chronic wounds in recessive dystrophic epidermolysis bullosa. Clin Exp Dermatol 2004;29:664-8.

44. Salimuddin, Upadhyaya KC, Baquer NZ. Effects of vanadate on expression of liver arginase in experimental diabetic rats. IUBMB Life 1999;48:237-40.

45. Jude EB, Boulton AJ, Ferguson MW, Appleton I. The role of nitric oxide synthase isoforms and arginase in the pathogenesis of diabetic foot ulcers: possible modulatory effects by transforming growth factor beta 1. Diabetologia 1999;42: 748-57.

46. Abd-El-Aleem SA, Ferguson MW, Appleton I, Kairsingh S, Jude EB, Jones K, McCollum CN, Ireland GW. Expression of nitric oxide synthase isoforms and arginase in normal human skin and chronic venous leg ulcers. J Pathol 2000;191:434-42.

47. Bruch-Gerharz D, Schnorr O, Suschek C, Beck KF, Pfeilschifter J, Ruzicka T, Kolb-Bachofen V. Arginase 1 overexpression in psoriasis: limitation of inducible nitric oxide synthase activity as a molecular mechanism for keratinocyte hyperproliferation. Am J Pathol 2003;162: 203-11.

48. Corraliza I, Moncada S. Increased expression of arginase II in patients with different forms of arthritis. Implications of the regulation of nitric oxide. J Rheumatol 2002;29:2261-5.

49. Albina JE, Mills CD, Henry WL Jr, Caldwell MD. Temporal expression of different pathways of 1-arginine metabolism in healing wounds. J Immunol 1990;144:3877-80.

50. Shi HP, Most D, Efron DT, Witte MB, Barbul A. Supplemental L-arginine enhances wound healing in diabetic rats. Wound Repair Regen 2003;11:198-203.

51. Frank S, Kämpfer $\mathrm{H}$, Wetzler $\mathrm{C}$, Pfeilschifter J. Nitric oxide drives skin repair: novel functions of an established mediator. Kidney Int 2002;61:882-8.

52. Wright CD, Mülsch A, Busse R, Osswald H. Generation of nitric oxide by human neutrophils. Biochem Biophys Res Commun, 1989;160:813-9.

53. Markert M, Carnal B, Mauel J. Nitric oxide production by activated human neutrophils exposed to sodium azide and hydroxylamine: the role of oxygen radicals. Biochem Biophys Res Commun 1994;. 199:1245-9.

54. Jabłońska E, Puzewska W, Marcińczyk M, Grabowska Z, Jabłoński J. iNOS expression and NO production by neutrophils in cancer patients. Arch Immunol Ther Exp (Warsz) 2005;53:175-9.

55. Marin VB, Rodriguez-Osiac L, Schlessinger L, Villegas J, Lopez M, Castillo-Duran C. Controlled study of enteral arginine supplementation in burned children: impact on immunologic and metabolic status. Nutrition 2006;22:705-12.

56. Cantürk NZ, Vural B, Cantürk Z, Esen N, Vural S, Solakoglu S, Kirkal G. The role of L-arginine and neutrophils on incisional wound healing. Eur J Emerg Med 2001;8:311-5.

57. Yasuda M, Shimizu S, Tokuyama S, Watanabe T, Kiuchi Y, Yamamoto T. A novel effect of polymorphonuclear leukocytes in the facilitation of angiogenesis. Life Sci 2000;66:2113-21.

58. Schruefer R, Lutze N, Schymeinsky J, Walzog B. Human neutrophils promote angiogenesis by a paracrine feedforward mechanism involving endothelial interleukin-8. Am J Physiol Heart Circ Physiol 2005;288:H1186-92.

59. Noiri E, Lee E, Testa J, Quigley J, Colflesh D, Keese CR, Giaever I, Goligorsky MS. Podokinesis in endothelial cell migration: role of nitric oxide. Am J Physiol 1998;274:C236-44.

60. Most D, Efron DT, Shi HP, Tantry US, Barbul A. Characterization of incisional wound healing in inducible nitric oxide synthase knockout mice. Surgery 2002;132:866-76.

61. Bansal V, Ochoa JB. Arginine availability, arginase, and the immune response. Curr Opin Clin Nutr Metab Care 2003;6:223-8

62. Frank S, Kämpfer H, Wetzler C, Stallmeyer B, Pfeilschifter J. Large induction of the chemotactic cytokine RANTES during cutaneous wound repair: a regulatory role for nitric oxide in keratinocytederived RANTES expression. Biochem J 2000;347:265-73.

63. Benrath J, Zimmermann M, Gillardon F. Substance $P$ and nitric oxide mediate would healing of ultraviolet photodamaged rat skin: evidence for an effect of nitric oxide on keratinocyte proliferation. Neurosci Lett 1995;200:17-20.

64. Akçay MN, Ozcan O, Gündoğdu C, Akçay G, Balik A, Köse K, Oren D. Effect of nitric oxide synthase inhibitor on experimentally induced burn wounds. J Trauma 2000;49:327-30. 
65. Stallmeyer B, Kämpfer H, Kolb N, Pfeilschifter J, Frank S. The function of nitric oxide in wound repair: inhibition of inducible nitric oxide-synthase severely impairs wound reepithelialization. J Invest Dermatol 1999;113:1090-8.

66. Fayh AP, Friedman R, Sapata KB, Oliveira AR. Effect of L-arginine supplementation on secretion of human growth hormone and insulin-like growth factor in adults. Arq Bras Endocrinol Metabol 2007;51:587-92.

67. Hurson M, Regan MC, Kirk SJ, Wasserkrug HL, Barbul A. Metabolic effects of arginine in a healthy elderly population. JPEN J Parenter Enteral Nutr 1995;19:227-30.

68. Fligger JM, Gibson CA, Sordillo LM, Baumrucker CR. Arginine supplementation increases weight gain, depresses antibody production, and alters circulating leukocyte profiles in preruminant calves without affecting plasma growth hormone concentrations. J Anim Sci 1997;75:3019-25.

69. Xia W, Szomor Z, Wang Y, Murrell GA. Nitric oxide enhances collagen synthesis in cultured human tendon cells. J Orthop Res 2006;24:159-72.

70. Obayashi K, Akamatsu H, Okano Y, Matsunaga K, Masaki H. Exogenous nitric oxide enhances the synthesis of type I collagen and heat shock protein 47 by normal human dermal fibroblasts. J Dermatol Sci 2006;41:121-6.

71. Pollock JS, Webb W, Callaway D, Sathyanarayana, O'Brien W, Howdieshell TR. Nitric oxide synthase isoform expression in a porcine model of granulation tissue formation. Surgery 2001;129:341-50.

72. Shukla A, Rasik AM, Shankar R. Nitric oxide inhibits wounds collagen synthesis. Mol Cell Biochem 1999;200:27-33.

73. Frank S, Madlener M, Pfeilschifter J, Werner S. Induction of inducible nitric oxide synthase and its corresponding tetrahydrobiopterin-cofactor-synthesizing enzyme GTP-cyclohydrolase I during cutaneous wound repair. J Invest Dermatol 1998;111:1058-64.

74. Shi HP, Fishel RS, Efron DT, Williams JZ, Fishel MH, Barbul A. Effect of supplemental ornithine on wound healing. J Surg Res 2002;106:299-302. 



\section{Chapter 6}

Intravenous arginine and human skin graft donor sites healing; a randomized controlled trial 


\section{Abstract}

\section{Background \& Aims}

Studies evaluating the effect of arginine supplementation in human wound healing are inhomogeneous and show conflicting results. This study aims to clarify the role of arginine supplementation in the healing of human skin graft donor sites.

\section{Methods}

35 subjects undergoing skin autografting were randomly assigned to receive intravenous arginine $(n=16)$ or placebo $(n=19)$ for 5 days in a dose of $30 \mathrm{~g}$ of arginine or an isovolumetric amount of placebo (25,2 $\mathrm{g}$ of alanine). Wound healing was evaluated at the donor sites by objectifying angiogenesis, reepithelialization and neutrophil influx. Plasma amino acid concentrations were measured to evaluate our intervention.

\section{Results}

The two groups were comparable in age, morbidity and nutritional, metabolic and inflammatory state. Plasma arginine and alanine levels increased significantly upon supplementation in the two groups, respectively. No differences were found between the arginine supplementation group and the placebo group in the studied parameters. Placebo vs. arginine; mean $\pm \mathrm{SD}$ : neutrophil influx on day $2: 6.67 \pm 3.0$ vs. $6.57 \pm 3.3, p=0.66$; angiogenesis on day 10 : $8.0 \pm 2.8$ vs. $8.9 \pm 3.1$; reepithelialization in $\%$ on day $10: 81 \pm 8.5$ vs. $85 \pm 7.1$.

\section{Conclusion}

Intravenous arginine supplementation does not improve angiogenesis, reepithelialization or neutrophil influx in healing of human skin graft donor sites. 


\section{Introduction}

The effect of arginine supplementation on wound healing has been extensively studied in animals and has shown beneficial effects. A dietary lack of arginine leads to impaired wound healing in rodents ${ }^{1,2}$, whereas arginine supplementation leads to increased wound collagen synthesis, wound breaking strength and reepithelialization ${ }^{3-7}$. While human studies are relatively scarce and show methodological flaws, data led to the production commercially available oral nutritional supplements, enriched with arginine, to increase wound healing. Until today however, the effect of arginine supplementation on the clinical outcome of wound healing in man remains to be clarified. In general, the effect of nutrition on wound healing, is well established ${ }^{8}$. In contrast, the role of immunonutrition and its specific ingredients to enhance wound healing is less established ${ }^{9}$. Human studies concerning the use of arginine as immunonutrition show conflicting results. While some studies show no beneficial effect of arginine supplementation on clinical or biochemical parameters in injured and post surgical patients ${ }^{10-12}$, others indicate improved healing of diabetic ulcers ${ }^{13}$, enhanced immune function, reduced postoperative infections, reduced postoperative wound complications and length of hospital stay in post surgical patients ${ }^{14-22}$. Experimental studies evaluating specific parameters of wound healing and arginine supplementation, such as collagen deposition and epithelialization, closest to our study objective, indicate enhanced wound healing ${ }^{23,24}$. Furthermore, most other studies have focused on patients in depleted state, suffering from malignancy, diabetes, pressure ulcers and severe trauma. These studies are often limited in size or express wound healing in terms of infection. Moreover, studies addressing the effect of arginine supplementation in wound healing often use combinations of arginine and other immunonutrients, which makes the interpretation of the single effect of arginine supplementation impossible ${ }^{25-32}$. Skin grafts are frequently used in reconstructive and burn wound surgery. Knowledge of possible means to enhance wound healing is particularly relevant in the treatment of burn wounds, as regrafting of a donorsite is often required ${ }^{33}$. In addition, a donor site is a very homogenous wound healing model. Therefore, the effect of oral arginine supplementation on healing of skin graft donor sites in relatively healthy humans was studied in a pilot study previously conducted at our department. No beneficial effects of arginine supplementation were found, on angiogenesis, reepithelialization and leukocyte influx as parameters of wound healing in patients undergoing skin autografting ${ }^{34}$. The beneficial effects, as suggested by previous literature prompted us to conduct a study that overcomes the possible shortcomings of our previous pilot study. In this double blinded, randomized controlled trial we included a larger study population and administrated arginine intravenously, in order to rule out any influence on study results due to intake problems. Wound healing was objectively evaluated as primary end point, using angiogenesis, reepithelialization and neutrophil influx as key parameters. 


\section{Materials and methods}

\section{Design and subjects}

Between July 2006 and July 2009 a randomized double blind, placebo-controlled study was performed at our department. The Medical Ethical Committee of Maastricht University Hospital approved the study protocol, and informed consent was obtained for each subject. The sample size for this study was calculated based on mean total healing time of donor sites of 10 days, with $80 \%$ confidence and accepting an $\alpha$ of $5 \%$. In order to detect a increased healing of 15\%, 25 subjects per group would have to be included. All subjects received skin autografting as part of reconstructive surgery. Body mass index and weight loss within six months prior to surgery was measured to determine clinical nutritional status according to the Espen guidelines. Exclusion criteria were age younger than 16 or older than 75 years, kidney or liver failure, pregnancy, use of steroids, immune deficiency diseases, and diabetes mellitus. Before operation subjects were randomly assigned to arginine $(n=16)$ or placebo treatment $(n=19)$, by an independent clinical pharmacist, using numbered envelopes. A block randomization was chosen to equally divide subjects in both groups. Based on literature at the initiation of the study, the highest tolerable amount of arginine was administered. Subjects received intravenous supplementation of arginine or placebo (Bufa, Uitgeest, The Netherlands) during five days, starting during surgery, in order to evaluate the different processes during the initial phases of wound healing (inflammatory and proliferative phase). Intravenous supplementation consisted of either a daily dose of 30 grams of arginine, dissolved in $1000 \mathrm{ml} 0.9 \% \mathrm{NaCl}$ and adjusted to $\mathrm{pH} \mathrm{7,2} \mathrm{using} 10 \% \mathrm{HCL}$ (net nitrogen intake $45,7 \mathrm{mmol} / \mathrm{l}$ ) or a placebo treatment consisting of a daily dose of 25,2 grams of alanine, dissolved in $1000 \mathrm{ml}$ $0,9 \% \mathrm{NaCl}$ (net nitrogen intake $44 \mathrm{mmol} / \mathrm{l}$ ). To be able to perform a double blinded study the infusions were made isovolumetric and isonitrogenous. Although it was not possible to make them isocaloric, the arginine infusion accounted for $120 \mathrm{kcal}$ and the placebo infusion for $100.8 \mathrm{kcal}$. However, in a metabolic stress situation, these small differences are often neglected. Patients received a daily infusion of $1000 \mathrm{ml}$ in two doses of $500 \mathrm{ml}$ equally divided over the day. Oral food intake was allowed as desired, in order to maintain the clinical applicability of arginine as a potential immunonutrient treatment.

\section{Wound model}

All clinical wound procedures were performed at the Department of Plastic Surgery, University Hospital Maastricht, The Netherlands. Under general anesthesia and aseptic conditions, split skin grafts were obtained using an electric dermatome (Aesculaap ${ }^{\circledR}$ ) with a thickness of $0.3 \mathrm{~mm}$. The donor sites were used to evaluate wound healing. Wound fluid was collected from these donor sites by covering it with a layer of Gordasoft $^{\circledR}$ (homemade sterilized polyester fabric), followed by a polyvinyl alcohol 
sponge (Coldex ${ }^{\circledast}$, Taureon, Rijswijk, The Netherlands) and a transparent dressing (Tegaderm ${ }^{\circledR}, 3 \mathrm{M}$ Nederland B.V., Zoeterwoude, The Netherlands) on top as previously described.

The surfaces of all donor sites were measured. Twenty-four hours before wound fluid collection the wound dressing was changed by removing the transparent dressing and the sponge, followed by reapplying a new sponge and transparent dressing. After twenty-four hours the sponge was removed, and stored on ice until further processing. Using this protocol a twenty-four hour wound fluid sample was used each time for analysis. From each patient wound fluid samples were taken using this method on day 2, 5 and 10. From the central part of the donor site 3-mm punch biopsies were taken. Before the excision of the biopsies, lidocaine was locally injected. Subsequently a venous blood sample was drawn from a major vein in the cubital fossa.

\section{Sample processing and analysis}

Heparinized blood was centrifuged at $4^{\circ} \mathrm{C}$ for 10 minutes at $4000 \mathrm{rpm}$ within one hour after sampling. After centrifugation, $500 \mu \mathrm{l}$ of plasma was deproteinized using $20 \mathrm{mg}$ dry sulphosalicylic acid (SSA), vortexed and frozen in liquid nitrogen. Samples were stored at -80 degrees Celsius until analysis. Wound fluid was obtained by centrifuging the sponges for $10 \mathrm{~min}$ at $4^{\circ} \mathrm{C}(11.000 \mathrm{rpm})$. After centrifugation, $500 \mu \mathrm{l}$ of wound fluid was treated similar to the plasma. The recovery of fluid from the sponges was validated and found to be constant.

\section{Evaluation of wound healing}

In order to study the different phases of wound healing, donor site biopsies were obtained at identical time points: post-operative day 2, 5 and 10 . These time points were chosen to reflect the inflammatory phase at day 2 , the proliferative phase at day 5 and reepithelialization on day 10 . Biopsies were fixed in $4 \%$ formaldehyde, processed by routine histological procedures and embedded in paraffin. Four $\mu \mathrm{m}$ sections were subsequently obtained from each paraffin block.

\section{Immunohistochemical assessment of neutrophil-influx and angiogenesis}

Sections were initially stained with haematoxylin and eosin. Polymorphonuclear neutrophils (PMN's) were counted per high power field (HPF) at a magnification of 40 in wound biopsies sections of day 2, 5 and 10 post-surgery. We objectified angiogenesis by micro vessel density (MVD), as described by Hillen et al and Baeten et al. in wound biopsies of day 2, 5 and 10 post-surgery ${ }^{35,36}$. Immunolabeling of mouseanti-human alpha smooth muscle actin (ASMA; Dako Laboratories, Carpinteria, CA, USA) and mouse-anti-human CD31 (Dako Laboratories Carpinteria, CA, USA) were used to stain vessels in the sections. Two separate blinded investigators performed the assessments using a microscope. 


\section{Reepithelialization}

Standardized photographs of the donor sites with measuring scales were taken on days 5 and 10 (Canon EOS 300 with macro lens, 1:1). Two blinded independent observers measured the surface of reepithelialized skin by planimetry using the morphometric program ImageJ (W. Bailer, Hagenberg, Austria). The area with reepithelialized skin was expressed as a percentage of the total wound area (central part). A quantitative bacterial analysis was performed of wound fluid samples, expressed as colony forming units (CFU).

\section{Biochemical analysis}

\section{Amino acids measurement in plasma}

Arginine, citrulline and ornithine concentrations were measured in plasma of all patients. Levels were determined using a fully automated HPLC system as described previously ${ }^{37}$.

\section{Statistical Analysis}

Data were expressed as means \pm SEM. Amino acid concentrations were expressed in $\mu \mathrm{mol} / \mathrm{l}$. Repeated-measures ANOVA was used to compare both groups. A $95 \%$ confidence interval was used to determine significance. The statistical package for social sciences (SPSS) program was used for statistical analysis.

\section{Results}

Forty patients complied with the selection criteria and were included in the study. Twenty subjects were randomly allocated to receive placebo and 20 subject to receive arginine. In the placebo group one patient discontinued the study and in the arginine supplementation group four patients discontinued after one day. All subjects discontinued for the same reason: after dislocation of the intravenous needle refusing a new needle only for study purposes. Therefore thirty-five patients were analyzed. Both formulas were well tolerated and both groups consumed $100 \%$. Table 6.1 shows patient characteristics. Age ranged from 17 to 74 years (mean \pm SEM: 44 \pm 17 ). No statistical difference was observed between the two groups in age. Both groups had a comparable nutritional and metabolic status as expressed by BMI (all patients were $>19,7)$, total protein and albumin. With regard to weight loss 6 months prior to the study, as an indication of nutritional depletion, 3 patients suffered from $>10 \%$ loss of their weight. Two patients were in the arginine group (11\% in 1,5 month; $25 \%$ in 9 months) and one in the placebo group (12\% in 3 months). No adverse effects like vomiting, diarrhea were observed. Infection parameters as expressed by CRP were low 
and not statistically different in both groups. Details on performed operations can be found in Table 6.2 .

Table 6.1 Patient characteristics.

\begin{tabular}{lcc}
\hline & Control group & Arginine group \\
Parameter & Mean (SEM) & $11: 5^{\mathrm{A}}$ \\
\hline Male/Female & $9: 10^{\mathrm{A}}$ & $42,3(4,2)$ \\
Age (years) & $44,6(4)$ & $77,4(4)$ \\
Weight (kg) & $82,9(5,6)$ & $25,1(1,0)$ \\
BMI (kg/cm $\left.{ }^{2}\right)$ & $27,2(1,7)$ & $10,8(3,1)$ \\
CRP (mg/l) & $13,3(3,3)$ & $33,4(1,5)$ \\
Albumine (g/l) & $30,7(1,1)$ & $68,8(2,9)$ \\
Total plasma protein (g/l) & $62,4(2,6)$ & \\
\hline
\end{tabular}

A absolute numbers

Table $6.2 \quad$ Operations.

\begin{tabular}{lcc}
\hline & $\begin{array}{c}\text { Control group } \\
(n=19)\end{array}$ & $\begin{array}{c}\text { Arginine group } \\
(n=16)\end{array}$ \\
\hline Reason for operation & 2 & 3 \\
Burns & 9 & 7 \\
Trauma & 4 & 1 \\
Malignancy & 4 & 5 \\
Other & & \\
Type of operation & & 7 \\
SSG* & 13 & 1 \\
Muscle transposition + SSG & 1 & 8 \\
Free muscle transfer + SSG & 5 & \\
\hline
\end{tabular}

* SSG = split skin graft

\section{Plasma amino acids}

Plasma arginine and ornithine levels increased significantly on post-operative days 2 and 5, indicating adequate supplementation (Figure 6.1 and 6.2). The increased plasma ornithine levels can be explained as a conversion of the supplemented arginine by liver arginase. We observed no changes in plasma citrulline levels (Figure 6.3), nor plasma sum of amino acids (sumAA) (Figure 6.4). The later indicates that both groups have comparable catabolic state. In Figure 6.5 levels of plasma alanine are shown, increased levels were observed on day 2-5 in the control group, which normalized at day 10, suggesting adequate intake. 


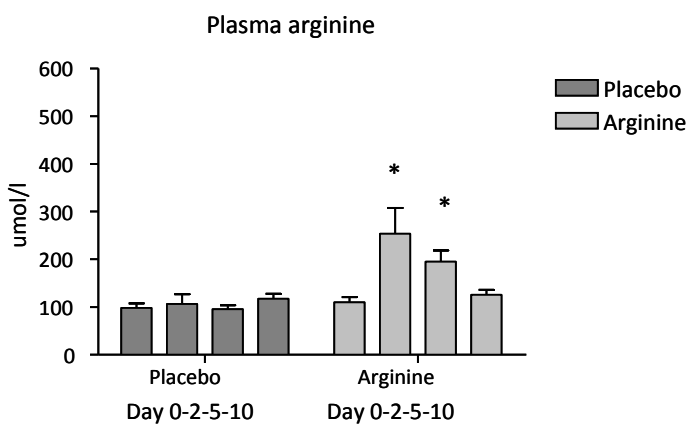

Figure 6.1 Plasma arginine concentrations ( $\mu \mathrm{mol} / \mathrm{I})$ : placebo vs. suppletion. Data are expressed as means $\pm \mathrm{SEM},{ }^{*} \mathrm{p}<0.05$. Adequate rise of plasma arginine is observed upon supplementation.

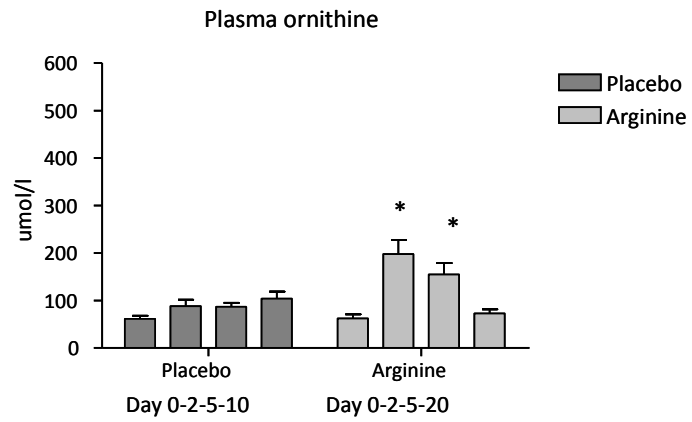

Figure 6.2 Plasma ornithine concentrations ( $\mu \mathrm{mol} / \mathrm{l})$; placebo vs. suppletion.

Data are expressed as means \pm SEM, ${ }^{*} p<0.05$. Upon arginine supplementation, significantly increased plasma ornithine levels are observed, indicating arginase activity.

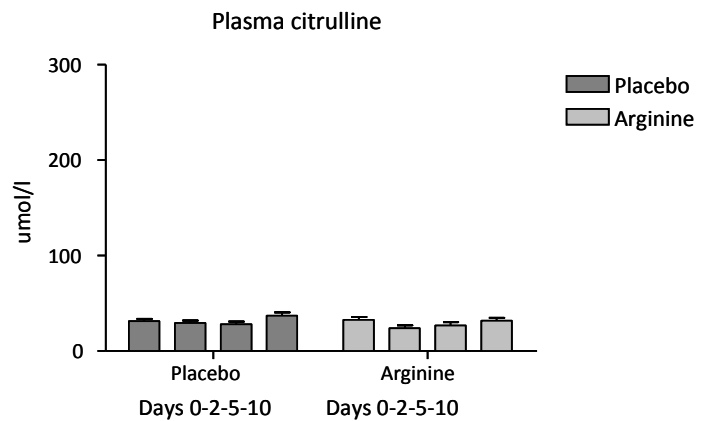

Figure 6.3 Plasma citrulline concentrations ( $\mu \mathrm{mol} / \mathrm{l}$ ); placebo vs. suppletion.

Data are expressed as means $\pm \mathrm{SEM},{ }^{*} p<0.05$. Arginine supplementation does not affect the NOS-pathway. 


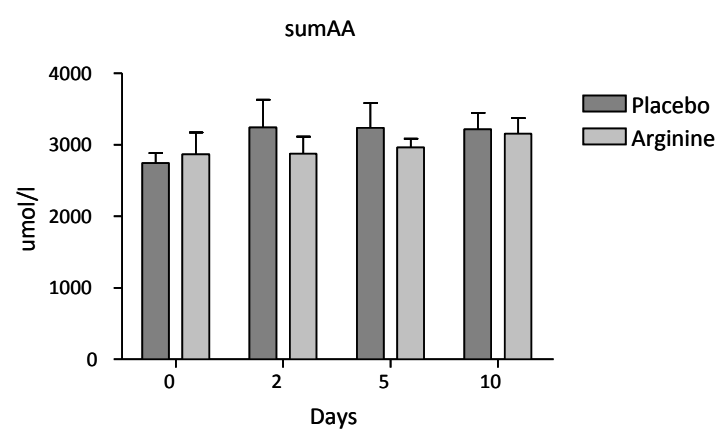

Figure 6.4 Plasma sumAA concentrations ( $\mu \mathrm{mol} / \mathrm{l})$; placebo vs. suppletion.

Data are expressed as means \pm SEM, ${ }^{*} p<0.05$. We observed no changes in plasma sum of amino acids, suggesting that both groups have comparable catabolic state.

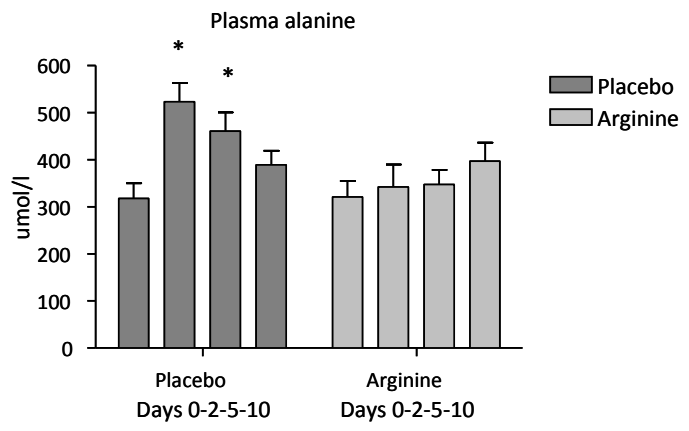

Figure 6.5 Plasma alanine concentrations ( $\mu \mathrm{mol} / \mathrm{l})$; placebo vs. suppletion.

Data are expressed as means $\pm \mathrm{SEM},{ }^{*} p<0.05$. The placebo group showed adequate rise of plasma alanine levels.

\section{Evaluation of wound healing}

\section{PMN-count, angiogenesis and reepithelialization}

No statistical differences were found between the two groups in quantification of neutrophils, angiogenesis and reepithelialization (Figures 6.6, 6.7 and 6.8). Intra- and interobserver variability being respectively 0,98 and 0,73 for quantification of neutrophils and 0,97 and 0,83 for quantification of angiogenesis.

Wound neutrophils (Figure 6.6) decreased significantly in both groups between day 2 and day 10 ( $p=0,008$ for both groups) and day 5 and day 10 ( $p=0,049$ for control group and $p=0,019$ for arginine supplementation group). There was no significant difference in decrease on subsequent days between the two groups. 


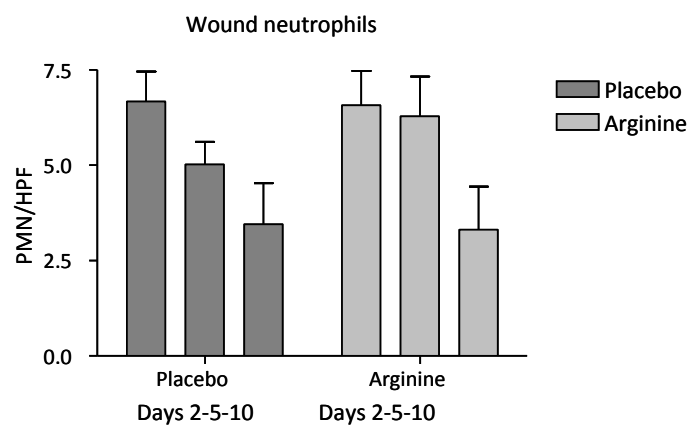

Figure 6.6 Polymorphonuclear neutrophils; number of PMN/HPF.

Data are expressed as means \pm SEM. PMN's as a measure of immuunrespons were not affected by arginine supplementation.

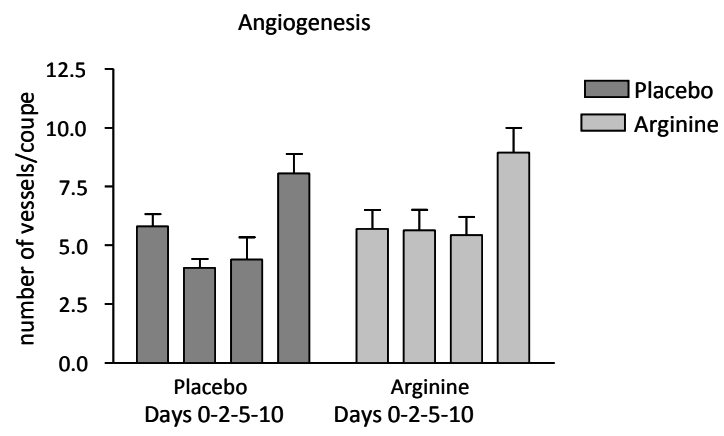

Figure 6.7 Angiogenesis; number of vessels/ $\mu \mathrm{m}$.

Data are expressed as means \pm SEM. Although a tendency was seen toward increased neovascularization on day 10 , no differences were observed between both intervention groups.

Angiogenesis (Figure 6.7) expressed as the number of vessels in wound tissue per high power field show significantly increased vessel count in both the control group and the arginine suppletion group between day 0,2 and day 10 (respectively $p=0,007$ and $p<0,001)$. No significant differences were found for the number of vessels on the subsequent days between both groups.

The amount of wound reepithelialization, expressed as percentage of the total wound surface (Figure 6.8), was similar for both groups on day 5 and day 10 post-surgery. 


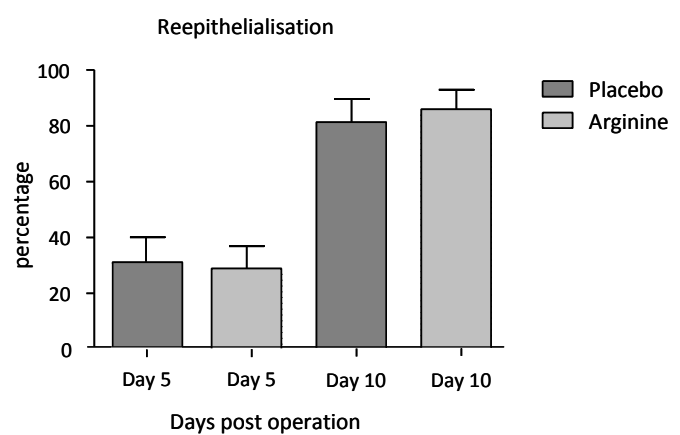

Figure 6.8 Reepithelialization; expressed as percentage of the total wound area. Data are expressed as means \pm SEM. No differences were observed between both groups on post-wounding days 5 and 10 .

\section{Discussion}

The aim of our study was to evaluate the effect of arginine on wound healing in relatively healthy humans with clinically significant wounds. To overcome possible compliance problems with oral intake, we used intravenous arginine administration. No differences were found between the two groups on evaluation of reepithelialization, angiogenesis and wound neutrophil influx as parameters of wound healing.

Plasma amino acids were studied in order to evaluate the effect of administration of arginine on blood arginine concentration. Both plasma arginine and ornithine increased significantly in the supplementation group on day 2 and day 5 and normalized by day 10 . Increased ornithine levels are explained by the conversion of arginine to ornithine by the hepatic enzyme arginase. Despite the high activity of hepatic arginase, arginine levels raise significantly, showing an effective administration and hence biological availability. When arginine is metabolized by nitric oxide synthase (NOS), producing NO, citrulline is produced in equivalent amounts. Despite the coupled production of NO and citrulline, plasma citrulline cannot be used as marker of systemic NO-synthesis as it is converted back to arginine. This de novo arginine synthesis mainly takes place in the kidneys, but has also been described in endothelial cells and macrophages in vitro ${ }^{38,39}$. In the wound environment, however, citrulline and nitrite/nitrate levels are used as NO-synthesis markers. Rodents show a simultaneous increase of both NO and citrulline levels at the wound site in the first 48 hours after wounding ${ }^{40,41}$. Similar findings were observed in humans in our previous study ${ }^{34}$. However, no additional effect was observed after arginine supplementation. Present study reveals lack of differences in plasma citrulline between the two groups, which is 
in line with the previous pilot study. These findings can either be explained by the conversion of systemic citrulline back to arginine or by an unchanged NO production despite the relatively high arginine supplementation. Similar findings were recently published by Lo et al, showing that a pharmacological dose of parenteral arginine did not cause augmentation of the NO production in sub-acute inflammation in peritonitic rats $^{42}$. These findings might be explained by enzyme kinetics. Several factors influence the catalytic reaction, such as temperature, $\mathrm{pH}$, the amount of enzyme, the amount of substrate and the presence of inhibitors. After arginine supplementation, serum levels rise above the $\mathrm{Km}$ value of $\operatorname{NOS}(2-20 \mu \mathrm{M})^{43,44}$. This indicates that the amount of substrate arginine is more than enough to activate NOS, and thus producing NO. Moreover, present study shows that elevated substrate levels do not increase arginine conversion. This might explain why arginine supplementation is not effective.

Plasma alanine was significantly increased in the placebo group on days 2 and 5 and normalized by day 10 . No differences were found for total plasma amino acids levels in both groups on all days, indicating comparable metabolic states between the study groups.

Neutrophil influx was assessed to evaluate the essential inflammatory phase of wound healing. Neutrophils degrade cell debris and extracellular matrix, decontaminate bacteria and produce cytokines, but also generate $\mathrm{NO}^{45-47}$. As mentioned before, $\mathrm{NO}$ is being considered as the central signal molecule in several important processes in wound healing. Several studies have indicated an increased immune response on the administration of arginine ${ }^{6,14,15,22,24,26}$. Others found a decreased infection rate upon arginine supplementation ${ }^{18,25}$. Our results showed no differences in wound neutrophil influx for both groups on all days, suggesting similar wound inflammatory reaction in both groups. In line with this finding, no clinical wound infections were observed in both study groups (data not shown).

Angiogenesis was assessed as a second parameter of clinical wound healing. The process of angiogenesis is mediated by NO, through the induction of VEGF. In vitro studies show that human neutrophils generate $\mathrm{NO}^{46,47}$. Experimental studies have hypothesized that increased arginine levels stimulate local NO production by wound neutrophils, which would enhance NO-dependant processes, such as angiogenesis. Assessment of angiogenesis in our patients, however, shows no differences upon arginine supplementation on all post-operative days.

Reepithelialization, the third and true clinical parameter of wound healing in our study, has been shown to be enhanced by arginine supplementation in several animal studies, but not in human studies ${ }^{24,48,49}$. Results of the present study, however, showed no enhanced reepithelialization in the supplementation group on day 10 of wound healing.

Our results differ from and contradict the findings of other authors. Different explanations can be proposed for our findings. First, most previous human studies evaluate derivatives of wound healing as primary endpoints, looking at wound infection, wound complication or length of hospital stay, whereas we look at more 
specific parameters of wound healing. Interpretation of relations between these different endpoints is difficult. Second, the included subjects in our study population might cause the discrepancy in results. We included relatively healthy subjects, while others included patient groups with extensive (co) morbidities and therefore depleted metabolic states ${ }^{13-22}$. In addition, different types of wounds were studied. Some used small experimental wounds and others chronic wounds, which are not as homogenous as the donor sites of our subjects ${ }^{24,50}$. A third possible explanation might be the differences in species, which makes it difficult to extrapolate the results of experimental studies to human studies. And finally, clinical trials evaluating the effect of arginine, often use a combination of immunonutrients, which makes it impossible to draw any conclusions on the effects of arginine solely ${ }^{25-32}$.

Although the number of subjects of our study is not sufficient to draw firm conclusions, results suggest that intravenous arginine is not beneficial for host immune response, angiogenesis or reepithelialization of skin graft donor sites in relatively healthy humans. Despite a significantly increased plasma arginine level after supplementation and the lack of side effects. We therefore hypothesize that arginine supplementation might only affect wound healing when there is a depletion of arginine, systemically or locally. Future studies are needed to assess the effect of arginine and other amino acid supplementation in different clinical wounds and/or patient groups. 


\section{References}

1. Nirgiotis JG, Hennessey PJ, Andrassy RJ. The effects of an arginine-free enteral diet on wound healing and immune function in the postsurgical rat. J Pediatr Surg 1991;26:936-41.

2. Schaffer MR, Tantry U, Ahrendt GM, Wasserkrug HL, Barbul A. Acute protein-calorie malnutrition impairs wound healing: a possible role of decreased wound nitric oxide synthesis. J Am Coll Surg 1997; 184:37-43.

3. Seifter E, Rettura G, Barbul A, Levenson SM. Arginine: an essential amino acid for injured rats. Surgery 1978;84:224-30.

4. Witte MB, Thornton FJ, Tantry U, Barbul A. L-Arginine supplementation enhances diabetic wound healing: involvement of the nitric oxide synthase and arginase pathways. Metabolism 2002;51:126973.

5. Angele MK, Nitsch SM, Hatz RA, et al. L-arginine: a unique amino acid for improving depressed wound immune function following hemorrhage. Eur Surg Res 2002;34:53-60.

6. Canturk NZ, Vural B, Canturk Z, et al. The role of L-arginine and neutrophils on incisional wound healing. Eur J Emerg Med 2001;8:311-5.

7. Shi HP, Wang SM, Zhang GX, Zhang YJ, Barbul A. Supplemental L-arginine enhances wound healing following trauma/hemorrhagic shock. Wound Repair Regen 2007;15:66-70.

8. Akbarshahi $\mathrm{H}$, Andersson B, Norden M, Andersson R. Perioperative nutrition in elective gastrointestinal surgery--potential for improvement? Dig Surg 2008;25:165-74.

9. Kirk HJ, Heys SD. Immunonutrition. Br J Surg 2003;90:1459-60.

10. Tsuei BJ, Bernard AC, Barksdale AR, Rockich AK, Meier CF, Kearney PA. Supplemental enteral arginine is metabolized to ornithine in injured patients. J Surg Res 2005;123:17-24.

11. de Luis DA, Izaola O, Cuellar L, et al. Effect of c-reactive protein and interleukins blood levels in postsurgery arginine-enhanced enteral nutrition in head and neck cancer patients. Eur J Clin Nutr 2003;57:96-9.

12. de Luis DA, Arranz M, Aller R, Izaola O, Cuellar L, Terroba MC. Immunoenhanced enteral nutrition, effect on inflammatory markers in head and neck cancer patients. Eur J Clin Nutr 2005;59:145-7.

13. Arana V, Paz Y, Gonzalez A, Mendez V, Mendez JD. Healing of diabetic foot ulcers in L-arginine-treated patients. Biomed Pharmacother 2004;58:588-97.

14. Song JX, Qing SH, Huang XC, Qi DL. Effect of parenteral nutrition with L-arginine supplementation on postoperative immune function in patients with colorectal cancer. Di Yi Jun Yi Da Xue Xue Bao 2002;22:545-7.

15. Riso S, Aluffi P, Brugnani M, Farinetti F, Pia F, D'Andrea F. Postoperative enteral immunonutrition in head and neck cancer patients. Clin Nutr 2000;19:407-12.

16. de Luis DA, Izaola O, Cuellar L, Terroba MC, Aller R. Randomized clinical trial with an enteral arginineenhanced formula in early postsurgical head and neck cancer patients. Eur J Clin Nutr 2004;58:1505-8.

17. de Luis DA, Izaola O, Cuellar L, Terroba MC, Martin T, Aller R. Clinical and biochemical outcomes after a randomized trial with a high dose of enteral arginine formula in postsurgical head and neck cancer patients. Eur J Clin Nutr 2007;61:200-4.

18. Casas-Rodera P, Gomez-Candela C, Benitez S, et al. Immunoenhanced enteral nutrition formulas in head and neck cancer surgery: a prospective, randomized clinical trial. Nutr Hosp 2008;23:105-10.

19. de Luis DA, Aller R, Izaola O, Cuellar L, Terroba MC. Postsurgery enteral nutrition in head and neck cancer patients. Eur J Clin Nutr 2002;56:1126-9.

20. Peng X, Yi D, Fan SZ, et al. [Analysis of the influence on the prognosis and safety of arginine in patients with severe trauma and burns--a multi-center randomized double blinded, placebo controlled, clinical trail in 86 patients]. Zhonghua Shao Shang Za Zhi 2006;22:243-6.

21. De Luis DA, Izaola O, Cuellar L, Terroba MC, Martin T, Aller R. High dose of arginine enhanced enteral nutrition in postsurgical head and neck cancer patients. A randomized clinical trial. Eur Rev Med Pharmacol Sci 2009;13:279-83.

22. Marin VB, Rodriguez-Osiac L, Schlessinger L, Villegas J, Lopez M, Castillo-Duran C. Controlled study of enteral arginine supplementation in burned children: impact on immunologic and metabolic status. Nutrition 2006;22:705-12. 
23. Barbul A, Lazarou SA, Efron DT, Wasserkrug HL, Efron G. Arginine enhances wound healing and lymphocyte immune responses in humans. Surgery 1990;108:331-6; discussion 336-7.

24. Kirk SJ, Hurson M, Regan MC, Holt DR, Wasserkrug HL, Barbul A. Arginine stimulates wound healing and immune function in elderly human beings. Surgery 1993;114:155-9; discussion 160.

25. Daly JM, Lieberman MD, Goldfine J, et al. Enteral nutrition with supplemental arginine, RNA, and omega-3 fatty acids in patients after operation: immunologic, metabolic, and clinical outcome. Surgery 1992;112:56-67.

26. Braga M, Gianotti L, Vignali A, Carlo VD. Preoperative oral arginine and n-3 fatty acid supplementation improves the immunometabolic host response and outcome after colorectal resection for cancer. Surgery 2002;132:805-14.

27. Farreras N, Artigas V, Cardona D, Rius X, Trias M, Gonzalez JA. Effect of early postoperative enteral immunonutrition on wound healing in patients undergoing surgery for gastric cancer. Clin Nutr 2005;24:55-65.

28. Sorensen D, McCarthy M, Baumgartner B, Demars S. Perioperative immunonutrition in head and neck cancer. Laryngoscope 2009;119:1358-64.

29. Wibbenmeyer LA, Mitchell MA, Newel IM, et al. Effect of a fish oil and arginine-fortified diet in thermally injured patients. J Burn Care Res 2006;27:694-702.

30. Gunerhan Y, Koksal N, Sahin UY, Uzun MA, Eksioglu-Demiralp E. Effect of preoperative immunonutrition and other nutrition models on cellular immune parameters. World J Gastroenterol 2009;15:467-72.

31. Stableforth WD, Thomas S, Lewis SJ. A systematic review of the role of immunonutrition in patients undergoing surgery for head and neck cancer. Int J Oral Maxillofac Surg 2009;38:103-10.

32. Williams JZ, Abumrad N, Barbul A. Effect of a specialized amino acid mixture on human collagen deposition. Ann Surg 2002;236:369-74; discussion 374-5.

33. Sheridan RL. Burn care: results of technical and organizational progress. Jama 2003;290:719-22.

34. Debats IB, Booi DI, Wehrens KM, et al. Oral arginine supplementation and the effect on skin graft donor sites: a randomized clinical pilot study. J Burn Care Res 2009;30:417-26.

35. Hillen HF, Hak LE, Joosten-Achjanie SR, Arends JW. Microvessel density in unknown primary tumors. Int J Cancer 1997;74:81-5.

36. Baeten $\mathrm{Cl}$, Wagstaff J, Verhoeven IC, Hillen HF, Griffioen AW. Flow cytometric quantification of tumour endothelial cells; an objective alternative for microvessel density assessment. Br J Cancer 2002;87:3447.

37. Van Eijk HM, Dejong CH, Deutz NE, Soeters PB. Influence of storage conditions on normal plasma amino-acid concentrations. Clin Nutr 1994;13:374-80.

38. Castillo L, Beaumier L, Ajami AM, Young VR. Whole body nitric oxide synthesis in healthy men determined from [15N] arginine-to-[15N]citrulline labeling. Proc Natl Acad Sci U S A 1996;93:11460-5.

39. Dejong $\mathrm{CH}$, Welters $\mathrm{CF}$, Deutz NE, Heineman E, Soeters PB. Renal arginine metabolism in fasted rats with subacute short bowel syndrome. Clin Sci (Lond) 1998;95:409-18.

40. Albina JE, Mills CD, Henry WL, Jr., Caldwell MD. Temporal expression of different pathways of 1arginine metabolism in healing wounds. J Immunol 1990;144:3877-80.

41. Lee RH, Efron D, Tantry U, Barbul A. Nitric oxide in the healing wound: a time-course study. J Surg Res 2001;101:104-8.

42. Lo HC, Wu SC, Wang YH, Lee $\mathrm{CH}$. Does pharmacological dose of parenteral arginine have beneficial effect in rats with sub-acute peritonitis? Pediatr Surg Int. 2010; 26(6); 625-32.

43. Wu G, Morris SM, Jr. Arginine metabolism: nitric oxide and beyond. Biochem J 1998;336 ( Pt 1):1-17.

44. Boucher JL, Moali C, Tenu JP. Nitric oxide biosynthesis, nitric oxide synthase inhibitors and arginase competition for L-arginine utilization. Cell Mol Life Sci 1999;55:1015-28.

45. Frank S, Kampfer H, Wetzler C, Pfeilschifter J. Nitric oxide drives skin repair: novel functions of an established mediator. Kidney Int 2002;61:882-8.

46. Wright CD, Mulsch A, Busse R, Osswald H. Generation of nitric oxide by human neutrophils. Biochem Biophys Res Commun 1989;160:813-9.

47. Markert M, Carnal B, Mauel J. Nitric oxide production by activated human neutrophils exposed to sodium azide and hydroxylamine: the role of oxygen radicals. Biochem Biophys Res Commun 1994;199:1245-9. 
48. Chen X, Li Y, Cai X, Xu W, Lu S, Shi J. Dose-effect of dietary L-arginine supplementation on burn wound healing in rats. Chin Med J (Engl) 1999;112:828-31.

49. Naderpour M, Rad JS, Ayat E, et al. Dietary L-arginine and cutaneous wound healing. Ital J Anat Embryol 2008;113:135-42.

50. Frias Soriano L, Lage Vazquez MA, Maristany CP, Xandri Graupera JM, Wouters-Wesseling W, Wagenaar $L$. The effectiveness of oral nutritional supplementation in the healing of pressure ulcers. J Wound Care 2004;13:319-22. 
Summary and conclusions 


\section{Summary and conclusions}

The skin is the most important barrier against hostile attacks from outside our body. However, it also helps us to interact with our environment. When damaged, a complex cascade of repair mechanisms is initiated to restore its function. This is a well-balanced process, influenced by many mediators. Although research has led to new therapeutical interventions in wound healing, delayed wound healing still is a major burden for patients and society. One of the mediators for adequate skin regeneration is nutrition. The main objective of this thesis was to investigate the isolated role of the immunonutrient arginine in the healing of surgical and chronic wounds in men. We hypothesized that arginine supplementation improved human wound healing.

In the first chapter, a review of literature on the current knowledge of the role of arginine in wound healing is presented. Arginine was found to be an important nutrient for skin repair in animal studies and its supplementation significantly improved wound healing. Early results from few studies in men on experimental wounds were promising. As a consequence, arginine supplementation quickly found its way into clinical practice. Clinical studies followed, however they mainly used commercially available nutritional supplements containing, besides arginine, other nutrients such as nucleotides and $\omega-3$ fatty acids. The use of a mixture of nutrients and often the lack of a good control group, supplied with isonitrogenous and/or isocaloric amounts, make it difficult to conclude whether treatments should be attributed to the specific pharmaconutrients or simply to the addition of amino acids and/or calories in general. Furthermore, the parameters used to evaluate wound healing were indirect e.g. infection, or pain free removal of the dressing.

The first step in our thesis was to investigate wether human skin uses arginine for its regeneration, therefore in chapter $\mathbf{2}$ the skin's transorgan metabolic routing of arginine was investigated, an opportunity given to us by free vascularized tissue surgery. Previously, arginine conversion was assessed indirectly. However, the studies presented here used labelled amino acids (isotopes) to study true metabolism. Patients undergoing reconstructive breast surgery received a skin flap named deep inferior epigastric artery (DIEP) flap. During this surgery an arginine tracer $\left({ }^{15} \mathrm{~N}_{2^{-}}\right.$ arginine) was infused and blood was sampled from the DIEP-flap. Significant uptake of ${ }^{15} \mathrm{~N}_{2}$-Arginine $(p<0.05)$ was observed. Although we failed to prove the enzymatic conversion to ${ }^{15} \mathrm{~N}$ citrulline or ${ }^{15} \mathrm{~N}_{2}$ urea, arteriovenous concentration differences of citrulline and ornithine show that the skin produces both amino acids. Since both amino acids are not protein bound they must be generated endogenously within the skin flap by NOS and ASE-activity respectively. Although tracer data clearly show arginine uptake by the skin, net arginine release was observed. In line with the net release of most other amino acids this finding can be ascribed to net protein breakdown in these post-absorptive patients. The sole net uptake of the amino acid glutamate was remarkable. 
Next step was to look at the expression of arginine-metabolic enzymes and argininemetabolites, which were expected to be elevated in surgical wounds compared to normal skin. In chapter $\mathbf{3}$ data are presented of our immunohistological study, in which several biopsies were taken from wounds during a period of ten days post-wounding. We observed that macrophages, polymorphonuclear neutrophils (PMN's), fibroblasts, keratinocytes and endothelial cells showed expression of inducible nitric oxide synthetase (iNOS) compared to no/sparse expression in normal skin. Furthermore, we observed constitutive expression of endothelial nitric oxide synthetase (eNOS) in vessels. After injury an increased number of vessels was observed expressing iNOS. Moreover, both arginase isoforms, arginase-1 (ASE-1) and arginase-2 (ASE2), were expressed during wound healing. ASE1 was uniquely expressed by neutrophils postwounding, while ASE-2 staining was observed in endothelial cells, keratinocytes, fibroblasts, macrophages and PMN's. In addition to immunohistological evaluation of wounds, levels of arginine metabolites were measured. Increased levels of wound fluid citrulline, nitrite/nitrate (NOx) and ornithine were measured compared to plasma, indicating arginine conversion by NOS and ASE. Levels of ASE1 were significantly higher in wound fluid compared to plasma, while levels of ASE2 were higher in plasma. On the basis of our observations we conclude arginine consumption during healing of surgical wounds in men.

In chapter 4 the expression of arginine metabolites/metabolic enzymes in chronic wounds were compared to acute wounds. Because infection complicates the course of wound healing, we related the presence of infection to altered arginine metabolism. Some significant differences were observed. First, infected chronic wounds showed significantly elevated wound fluid levels of citrulline and ornithine in comparison to acute wounds. As these amino acids are not released from protein degradation, this suggests elevated activity of the enzymes NOS and ASE. This is supported by the finding of significantly elevated wound fluid ASE1 in these wounds. In contrast decreased levels of NOx were observed in wound fluid of infected chronic wounds, indicating decreased nitric oxide synthesis. Furthermore, patients with infected chronic wounds showed decreased plasma arginine levels compared to patients with acute or non-infected chronic wounds.

In chapter $\mathbf{5}$ we describe the results of a double blinded randomized clinical pilot study investigating the effect of oral arginine supplementation, as a single nutrient, on the healing of skin autograft donorsites. Wound healing was evaluated by measuring PMNinflux, neovascularisation and reepithelialization. In both groups equal NOS and ASEactivity was observed in the wound environment. Patients receiving arginine, showed no improvement of wound healing.

In chapter 6 we tried to overcome possible shortcomings of the previously conducted pilot study, by enlarging the study population and supplying arginine intravenously. The same wound model and wound healing parameters were studied. Both groups were comparable in age, nutritional/metabolic and inflammatory state. We observed an adequate raise of plasma arginine after supplementation. However, no beneficial 
effect was observed on PMN-influx, infection, angiogenesis or reepithelialization upon arginine supplementation.

\section{Final conclusions and future perspectives}

The expression of NOS-isotypes and arginine metabolites in surgical wounds presented in this thesis supports previous experimental studies indicating the need for arginine in a NO-mediated repair of injured skin. In addition, we observed arginase expression during healing. Previous studies showed elevation of ASE1 in animal wound healing and overexpression of ASE1 in pathological skin conditions in men. However, our results suggest a more prominent role of ASE2 in normal healing in men. It is not unimaginable that different wound types have different needs at different time points. Our study on chronic wounds supports this hypothesis by showing elevated arginine conversion compared to acute wounds. Furthermore, a NO-depleted state was observed in the infected chronic wounds, possibly responsible for defective defense barrier, as NO is used by several inflammatory cells. This deficient NO production might be caused by bacterial arginine consumption. Another explanation might be a process called substrate competition known from in vitro experiments. A disturbance of the delicate balance of NOS and ASE expression, favoring one of both metabolic routes, might affect the availability of arginine. Remarkably, patients with infected chronic wounds had decreased levels of plasma arginine. Lowering of systemic arginine levels is also seen in patients subjected to trauma, burns or surgery and not beneficial for the immune system. As patients had no different systemic inflammatory response, no differences in nutritional state or co-morbidity compared to non-infected chronic wounds, we attributed this finding to a increased metabolic demand caused by the infection present in the wound.

We also conclude that arginine supplementation does not improve wound healing in acute surgical wounds. This is in sharp contrast to experimental studies. We used the donorsite of skin autografting as our model. The advantage of this model is that it is homogeneous and easy to access. Disadvantage can be that it can only be used to study reepithelialization. Although a clinically relevant model, a donor site heals quickly under normal circumstances with few complications. Therefore, differences might be difficult to observe. It could be that arginine supplementation is more effective in other wounds types, like chronic wounds with a NO-depleted state. Sequential activation of the different arginine metabolic pathways is observed in animal models. This might indicate a time course requirement for different arginine metabolites. Moreover, topical application of arginine might be explored, as topical NO-donors have shown beneficial effects on experimental wound healing. Although, arginine plasma levels rose adequately after supplementation, we also observed high levels of plasma ornithine. Bypassing the catabolization of arginine by the gastrointestinal tract should be considered. Citrulline is a natural precursor for L-arginine, it is converted to arginine in many tissues. Therefore it bypasses 
metabolism in the liver and is not a substrate or inducer of arginase. Others already showed increased levels of plasma arginine accompanied by induction of bioactive NO upon citrulline supplementation.

Finally, from our study using stable isotopes we might conclude that arginine consumption by skin is not a substrate driven process. In the future, we should consider exploring the possibilities of manipulating the expression of argininemetabolizing enzymes in wounds. Although the animal experimental data are compelling, there is need for more experimental and clinical trials in order to better define the role of arginine in the care of patients. 
Samenvatting en conclusie 


\section{Samenvatting en conclusie}

De huid is onze belangrijkste barrière tegen schadelijke invloeden van buitenaf. Tevens helpt ze ons in de communicatie met onze omgeving. Wanneer de huid beschadigd is, wordt een complexe cascade van herstelmechanismen in gang gezet om haar functie te herstellen. Dit goed uitgebalanceerde proces wordt beïnvloed door vele mediatoren. Hoewel onderzoek met betrekking tot wondgenezing heeft geleid tot vele nieuwe therapeutische interventies, blijft vertraagde wondgenezing een zware last voor de patiënt en de samenleving. Voeding is van essentieel belang voor een adequate wondgenezing, waarbij aminozuren de bouwstenen zijn. Aminozuren zijn de bouwstenen van onze voeding. Dit proefschrift beschrijft de rol van het aminozuur arginine als immunonutrient, bij de genezing van chirurgische en chronische wonden bij mensen. Onze hypothese is dat arginine suppletie humane wondgenezing zal verbeteren.

In het eerste hoofdstuk wordt een literatuuroverzicht van de huidige kennis over de rol van arginine in de wondgenezing gepresenteerd. Uit dierproeven blijkt dat arginine een belangrijke voedingsstof is voor het herstel van de huid. Als immunonutrient verbetert arginine de wondgenezing aanzienlijk. Ook de resultaten van enkele vroege studies met experimentele humane wonden waren veelbelovend. Naar aanleiding van deze resultaten vond suppletie van arginine al snel haar weg naar de kliniek. De daaropvolgende klinische studies vertoonden echter nogal wat beperkingen. Zo bevatten de toegediende voedingssupplementen naast arginine ook andere bestanddelen zoals nucleotiden en omega-3-vetzuren. Vaak ontbrak een goede controlegroep, gesuppleerd met isonitrogene en/of isocalorische hoeveelheden aminozuren. Moest het effect van deze behandelingen toegeschreven worden aan de specifieke immunonutriënten of aan de toevoeging van aminozuren en/of calorieën in het algemeen? Bovendien werden indirecte parameters gebruikt om de wondgenezing te evalueren zoals infectie of het pijnvrij verwijderen van verbandmiddelen. Deze beperkingen maakten het moeilijk conclusies te trekken uit deze studies.

De eerste stap voor dit proefschrift was het toetsen van de hypothese dat de menselijke huid arginine gebruikt. Hoofdstuk 2 beschrijft te resultaten van de transorgane meting van arginine metabolisme in de huid. Dit werd ons mogelijk gemaakt doordat plastische chirurgie gebruik maakt van zogenaamde vrij gevasculariseerde weefsel transplantatie, waarbij het huidmetabolisme relatief geïsoleerd bestudeerd kan worden. Tot nu toe werd arginine metabolisme indirect beoordeeld. Echter voor onze studie werden gelabelde aminozuren (isotopen) gebruikt. Patiënten die een borstreconstructie ondergingen middels een vrij gevasculariseerde huidlap, genaamd Deep Inferior Epigastric Artery flap (DIEP-lap) werden geïncludeerd. Tijdens deze operatie werd een arginine tracer $\left({ }^{15} \mathrm{~N}_{2}\right.$-arginine) toegediend en tevens werd bloed afgenomen uit de ader en slagader van de DIEP-lap. Een significante opname van ${ }^{15} \mathrm{~N}_{2}$-arginine $(p<0,05)$ werd waargenomen. Hoewel we de enzymatische omzetting naar ${ }^{15} \mathrm{~N}$ citrulline of ${ }^{15} \mathrm{~N}_{2}$ ureum niet konden aantonen, 
kunnen we uit de arterioveneuze concentratieverschillen van citrulline en ornithine opmaken dat de huid deze aminozuren produceert. Omdat geen van beide aminozuren vrijkomt uit eiwitafbraak, moeten deze endogeen gegenereerd zijn in de huid door respectievelijk NOS en ASE-activiteit. Ondanks dat de tracer data duidelijk aantonen dat er arginine opname door de huid plaatsvindt, werd een netto arginine release waargenomen. In lijn met de netto release van de meeste andere aminozuren kan deze bevinding toegeschreven worden aan netto eiwitafbraak in deze katabole patiënten. Een opmerkelijk bevinding was dat het aminozuur glutamaat als enige een netto opname vertoonde.

De volgende stap was het bestuderen van de expressie van enzymen die betrokken zijn bij arginine metabolisme in zowel de normale huid als in de huid met chirurgische wonden. Hierbij werd een verhoogde expressie in chirurgische wonden ten opzichte van normale huid verwacht. Hoofdstuk 3 beschrijft de resultaten van onze immunohistologische studie, waarbij biopten van wonden gedurende een periode van tien dagen na de operatie werden bestudeerd. We constateerden toegenomen expressie van induceerbaar stikstofoxide synthetase (iNOS) in macrofagen, polymorfonucleaire neutrofielen (PMN's), fibroblasten, keratinocyten en endotheelcellen in deze chirurgische wonden vergeleken met normale huid. Verder constateerden we een basale expressie van endotheliale stikstofoxidesynthetase (eNOS) in bloedvaten van de normale huid. In de wonden echter werd een verhoogd aantal bloedvaten waargenomen die tevens iNOS tot expressie brachten. Zowel de arginase isovormen, arginase-1 (ASE1) en arginase-2 (ASE2) bleken tot expressie te komen tijdens de wondgenezing. ASE1 komt alleen tot expressie in neutrofielen na verwonding, terwijl ASE2-aankleuring wordt waargenomen in endotheelcellen, keratinocyten, fibroblasten, macrofagen en PMN's.

In aanvulling op immunohistologische evaluatie van wonden, werden de waarden van arginine metabolieten gemeten in wondvocht en plasma. Hieruit kan men indirect arginine metabolisme afleiden. Er werden verhoogde waarden citrulline, nitriet / nitraat (NOx) en ornithine gemeten in wondvocht ten opzichte van plasma. Waarden van ASE1 waren significant hoger in wondvocht in vergelijking met plasma, terwijl de waarden van ASE2 hoger waren in het plasma. Deze waarnemingen suggereren arginine verbruik tijdens de humane wondgenezing. Om een potentiële verklaring te vinden voor de verstoorde heling van chronische wonden wordt in hoofdstuk 4 de expressie van arginine metabolieten en metaboliserende enzymen in chronische wonden vergeleken met chirurgische wonden. Aangezien infectie het beloop van wondgenezing negatief beïnvloed, werd tevens de relatie tussen de aanwezigheid van een infectie en arginine-omzetting bestudeerd. Derhalve hebben we de chronische wonden in twee subgroepen verdeeld, te weten de niet- geïnfecteerde en de geïnfecteerde. Enkele significante verschillen werden waargenomen. Ten eerste, geïnfecteerde chronische wonden laten significant verhoogde citrulline en ornithine waarden zien in wondvocht ten opzichte van chirurgische wonden. Aangezien deze aminozuren niet uit eiwitafbraak vrijkomen, suggereert deze verhoging een 
toegenomen omzetting van arginine door de enzymen NOS en ASE. Deze suggestie wordt ondersteund door de bevinding dat deze geïnfecteerde wonden significant hogere ASE1 concentratie bevatten. Er werden echter verlaagde waarden van NOx waargenomen in wondvocht van geïnfecteerde chronische wonden, hetgeen kan duiden op een verminderde aanmaak of verhoogd verbruik van stikstofmonoxide. Een NO deficiëntie kan nadelig zijn voor de afweer reactie. In tegenstelling tot de andere twee subgroepen werd er in de groep patiënten met geïnfecteerde chronische wonden verlaagde plasma argininespiegels geconstateerd. Aangezien er geen verschil was in systemische metabole of inflammatoire status tussen de subgroepen patiënten, wijzen deze bevindingen op het feit dat toegenomen lokaal verbruik van arginine in chronisch geïnfecteerde wonden leidt tot een verlaging van systemische arginine spiegels.

In hoofdstuk 5 worden de resultaten van een pilotstudie beschreven. De opzet van de studie was een dubbelblinde gerandomiseerde klinische studie die het effect van orale arginine-suppletie, als mononutriënt, op de genezing van donorsites (van huidtransplantaten) bestudeert. De wondgenezing werd geëvalueerd door het meten van PMN-instroom, neovascularisatie en reëpithelialisatie. In zowel de controle als gesuppleerde groep werd een gelijke NOS en ASE-activiteit waargenomen in het wondmilieu. Patiënten in de arginine-groep, toonden geen verbetering van de wondgenezing.

In hoofdstuk 6 werd gepoogd de mogelijke beperkingen van de eerder uitgevoerde pilotstudie te verbeteren door de studiepopulatie te vergroten en arginine intraveneus toe te dienen. Hetzelfde wondmodel en dezelfde parameters werden bestudeerd. Beide groepen waren vergelijkbaar in leeftijd, nutritiële, metabole en inflammatoire status. Een adequate stijging van het plasma arginine werd na suppletie waargenomen. Een gunstig effect op de wondgenezing bleef echter uit.

\section{Definitieve conclusies en toekomstperspectieven}

De expressie van NOS-isovormen en argininemetabolieten in chirurgische wonden zoals beschreven in dit proefschrift ondersteunt de eerdere experimentele studies waaruit blijkt dat het herstel van beschadigde huid gereguleerd wordt door NO. Daarnaast werd arginase expressie waargenomen tijdens de wondgenezing. Eerdere studies toonden een verhoging van ASE1 in dierlijke wondgenezing en een overexpressie van ASE1 in pathologische huidaandoeningen bij mensen aan. Echter, onze resultaten tonen een meer prominente rol van ASE2 in normale humane wondgenezing. Het is niet ondenkbaar dat verschillende typen wonden verschillende behoeften aan voedingsstoffen hebben op verschillende tijdstippen. Onze studie over chronische wonden ondersteunt deze hypothese door een verhoogde arginine conversie aan te tonen in vergelijking met chirurgische wonden. Verder werd een NOdeficiëntie waargenomen in de geïnfecteerde chronische wonden, mogelijk verantwoordelijk voor de gebrekkige afweer, aangezien NO wordt gebruikt door verschillende inflammatoire cellen. Een tekort aan NO zou ook veroorzaakt kunnen 
worden door bacteriële arginine consumptie. Een andere verklaring kan gezocht worden in een proces genaamd "substraat competitie" en bekend van in-vitro experimenten. Dit is een verstoring van het evenwicht in NOS en ASE expressie, waarbij één van beide metabole routes de overhand krijgt. Deze verstoring kan dan invloed hebben op de beschikbaarheid van arginine. Verder was het opmerkelijk dat patiënten met geïnfecteerde chronische wonden verlaagde plasma arginine spiegels vertoonden. Verlaging van de systemische arginine spiegels wordt ook gezien bij patiënten die zijn blootgesteld aan een trauma, brandwonden of operatie en deze verlaging is niet bevorderlijk voor het immuunsysteem. Onze verschillende subgroepen patiënten lieten geen verschil zien in systemische inflammatoire response, voedingstoestand of comorbiditeit. Derhalve zijn wij van mening dat een verlaagde plasma arginine spiegel toegeschreven kan worden aan een verhoogde lokale metabole behoefte ten gevolge van een infectie.

Een andere belangrijke conclusie van dit proefschrift is dat arginine-suppletie de wondgenezing in acute chirurgische (schaaf)wonden niet verbetert. Dit staat in schril contrast met experimentele studies. Als wondmodel gebruikten we de donorsite van de huidtransplantaten. Het voordeel van dit model is dat het homogeen is en gemakkelijk toegankelijk. Nadeel kan zijn dat deze voornamelijk gebruikt kan worden om reëpithelialisatie te bestuderen. Hoewel het een klinisch relevant wondmodel is, geneest een donorsite snel onder normale omstandigheden, hetgeen een reden kan zijn dat verschillen moeilijk waar te nemen zijn. De bevindingen van deze studie sluiten niet uit dat arginine suppletie potentieel meer effect heeft op andere typen wonden. Mogelijk toekomstig onderzoek kan zich richten op de behoefte aan arginine in de verschillende fasen van wondgenezing. In diermodellen is reeds een sequentiële activering van de verschillende metabole routes van arginine waargenomen. Dit kan duiden op een tijdsafhankelijke behoefte aan verschillende arginine metabolieten. Daarnaast zou lokale applicatie van arginine kunnen worden onderzocht, aangezien het aanbrengen van een NO-donor op wonden in de vorm van een crème een gunstig effect heeft op experimentele wondgenezing. Citrulline suppletie kan eveneens onderzocht worden. Hoewel arginine plasmaspiegels adequaat stegen na suppletie, werden ook hoge plasmaspiegels van ornithine waargenomen. De omzetting van arginine door het gastro-intestinale kanaal dient hiervoor verantwoordelijk te worden gehouden. Citrulline is een natuurlijke precursor voor L-arginine en het wordt omgezet in arginine in vele weefsels. Citrulline omzeilt het metabolisme in de lever en is geen substraat of inductor van arginase. Verhoogde argininespiegels in plasma en tegelijkertijd inductie van het bioactieve NO zijn reeds aangetoond na citrulline suppletie. Tot slot kunnen we van onze studie met stabiele isotopen concluderen dat arginine consumptie door de huid niet een substraatgedreven proces is. Het lijkt daarom meer logisch te focussen op manipulatie van expressie van argininemetaboliserende enzymen in wonden in plaats van substraat te suppleren. Ondanks de positieve experimentele data, is er meer behoefte aan klinische studies om de rol van arginine beter te definiëren in de zorg voor patiënten. 
Dankwoord 
120 


\section{Dankwoord}

Het dankwoord, het laatste hoofdstuk, maar zeker niet onbelangrijk. Want na zo een lange periode onderzoek combineren met opleiding, heb ik heel veel mensen ontmoet die mij gestimuleerd en geholpen hebben. Langs deze weg wil ik dan ook iedereen die op enigerlei wijze betrokken is geweest bij de totstandkoming van mijn proefschrift bedanken. De volgende mensen in het bijzonder:

Prof. dr. van der Hulst, beste René, tijdens je eigen succesvolle promotietraject ontdekte je nog een bijzonder aminozuur; arginine. Een nieuw project voor een promovendus was geboren en zo geschiedde. Nu ongeveer tien jaar later heb ik je leren kennen als een hardwerkende ambitieuze plastisch chirurg. Je carrière van plastisch chirurg in opleiding tot professor heb ik van dichtbij mee mogen maken. Je bent altijd jezelf gebleven, maar nu wel wat serieuzer, tegenwoordig mogen we niet meer zo hard lachen en keten op de stafgang. Dank voor je begeleiding van mijn promotietraject. Op je herhaaldelijke vraag "wanneer is je boekje klaar?" kan ik nu eindelijk antwoorden "het is klaaaar".

Beste professoren Wim Buurman en Mick Deutz, ondanks dat ik niet van de algemene heelkunde was, werd ik warm onthaald in jullie onderzoeksgroepen en laboratoria. Beste Mick, jij bent vanaf het begin betrokken geweest bij aminozuur/isotopen studies, helaas heeft je abrupte vertrek naar Amerika ons contact verwaterd. Beste Wim, onze lange gesprekken over 'die goede oude tijd' en je onuitputtelijke bron van onderzoeksideeën vond ik altijd erg inspirerend. Hartelijk dank voor jullie begeleiding en het reviseren van mijn artikelen.

Leden van de beoordelingscommissie bedankt voor het kritisch lezen van dit proefschrift.

Beste mensen van het metabole en immunologische lab op nivo 5 . Het was iedere keer weer feest om bij jullie binnen te lopen, jullie stonden altijd voor me klaar. De afgelopen jaren heb ik hier zoveel mensen ontmoet, dat het teveel is om op te noemen, toch ga ik een poging wagen. Beste Mo, Joep, Micha, Yvonne, Hans, Yvette, Robert, Trudi, Kim en iedereen die ik vergeten ben, heel erg bedankt voor jullie hulpvaardigheid en gezelligheid. Marcel jou wil ik apart bedanken voor je hulp bij het analyseren en schrijven van het tracerstuk. Tim, 'gouwe', dank voor je weekend-blots en co-auteurschap. Mo, het voorbereiden van promotiepraatjes met jou, zal ik nooit vergeten.

De afdeling Pathologie van het MUMC en met name Jack Cleutjens, Coby, Aniek en Peutz-Kootstra wil ik bedanken voor hun hulp bij het opzetten en uitvoeren van mijn immunohistochemische kleuringen. En in het bijzonder Jack voor het co-auteurschap van verschillende artikelen.

Beste stafleden van de afdeling plastische chirurgie MUMC, jullie leerden mij het vak en daarnaast was er altijd tijd voor heel wat leuke sociale events. René, John, Tom, Stephania, Wouter, velen van jullie heb ik leren kennen als plastisch chirurg in opleiding. De overgang naar staflid was heel natuurlijk. Veel respect heb ik voor jullie, 
want het is niet gemakkelijk om als jonge staf een afdeling weer op te bouwen, desondanks bleef de sfeer goed en heb ik veel van jullie geleerd.

Collegae AIOS, beste Marjoes, Alice, Tom en Darren wat hebben we toch veel meegemaakt de afgelopen jaren: iedere dag intensief samenwerken, samen optreden in een band, geweldige films maken voor afscheid van collega's, verliezen van een professor, het krijgen van een aantal baby's, ongeveer vijf visitaties, en eindelijk inauguratie van een nieuwe professor. Maar we hebben ons erdoorheen geslagen! Bedankt voor jullie collegialiteit en gezelligheid.

Beste poli dames en secretaresses, Claudia, Lilian, Debby, Kim, Antoinette, Karin, Petra, José, Nelly en Marian ook jullie hebben de afdeling in barre tijden gesteund en dit heeft jullie goede humeur nooit verpest. Alle verpleegkundige van A1, Edward en Alfred, jullie ook bedankt voor jullie ondersteuning op de werkvloer en prettige samenwerking. Alle OK-verpleegkundigen, anesthesieverpleegkundigen en anesthesisten, ook jullie wil ik bedanken. Naast het gewone werk was het nooit een probleem voor jullie om mee te werken aan mijn onderzoek, even een buisje bloed of biopt af nemen, een laserdoppler aansluiten of weer een zak tracers aan hangen, hartelijk dank.

De 'oude garde', Prof. Boeckx, Roel, Harm, Marleen, Lloyd, Bas. Als coassistent bij jullie begonnen. Het enthousiasme voor het vak, de harde werkmentaliteit en eindeloze humor, hebben mij alleen maar gesterkt in mijn keuze om plastische chirurg te worden. Harm, jou wil ik nog apart bedanken, jij zorgde voor een door het MEC goedgekeurd onderzoeks-protocol, wat uiteindelijk heeft geleid tot dit proefschrift. Roel, de academie heeft aan jou een goede opleider verloren, bedankt voor je jarenlange persoonlijke coaching.

Mijn perifere stage in Heerlen, was een fijne tijd. Jullie gaven mij de vrijheid en het vertrouwen om mijn vak uit te voeren, beste Theo en Jan-Willem, hartelijk dank hiervoor. De polidames, Kelly, Aylalalana, Jeanny, Jacqueline, Ine alle mensen van de OK, Shayla, Suus, Franka, dank voor jullie humor en altijd ongecompliceerd hard werken.

Beste Tiny, geweldige lay-out! Bedaank.

Mijn lieve vriendinnen Marthe en Boukje, samen geneeskunde gestudeerd en in hetzelfde dispuut gezeten. Bij jullie vond ik altijd een luisterend oor voor mijn promotie en/of opleidingsperikelen en nog zoveel meer! Ondanks de afstand, het drukke gezinsleven maken we toch altijd weer tijd voor elkaar, een vriendschap voor altijd! Haike, ik geniet van je goedlachsheid en energie (die me blijft verbazen vooral bij $45^{\circ} \mathrm{C}$ ). Met jou heb ik er een geweldige vriendin bij gekregen. Verheug me nu al op onze tijd in Amsterdam en wat we in de toekomst nog allemaal mee gaan maken.

Dames van de Junior Kamer, het was een verademing om eens niet tussen 'alleen maar dokters' te zitten. Ik heb genoten van onze activiteiten en vergaderingen. In het bijzonder mijn TGIF-vriendinnen: Beatrice, Lis@ en Ingrid, dames we gaan weer gezellig borrelen als ik terug ben in Maastricht! 
Mijn paranimf en vooral beste vriendin Fleur. We leerden elkaar kennen op 'de sociëteit'. Sindsdien zijn we onafscheidelijk en hebben we bijzonder mooie tijden samen beleefd; onze studententijd, verre reizen, gewoon lekker in Maastricht, je bruiloft en niet te vergeten de komst van Sophie, Anna en Bram. Onze band is heel speciaal en dat houden we lekker zo!

Mijn andere paranimf en tevens broer Georges, nu weet wat het paranimfen in houdt, geweldig hè zo'n promotie!

Mijn familie, lieve mama \& papa, wat is het toch belangrijk om uit een warm nest te komen, waar je vertrouwen en onvoorwaardelijke steun krijgt. Alleen dan kun je grootste dingen bereiken. Jullie hebben er altijd voor gezorgd dat wij niets tekort kwamen. Lieve Georges en lieve Constance, al vanaf onze kindertijd hebben we veel plezier samen en tegenwoordig een hechte band, die veel voor mij betekend. Een betere familie had ik mij niet kunnen wensen. 

125

Curriculum Vitae 


\section{Curriculum Vitae}

Iris Barbara Johanna Gertruda Debats werd geboren op 19 september 1975. Na het afronden van het gymnasium aan de Stedelijke Scholengemeenschap te Maastricht, ging zij geneeskunde studeren. Eerst aan het Limburgs Universitair Centrum, te Diepenbeek (B) en later aan de Universiteit van Maastricht. In augustus 2001 behaalde zij haar arts examen.

Hierna heeft zij gewerkt in Medisch Centrum De Heel, te Zaandam, als ANIOS algemene heelkunde. Om vervolgens in april te starten bij de vakgroep Plastische Chirurgie, te Maastricht. Na een aantal maanden als ANIOS gewerkt te hebben werd zij fulltime onderzoeker voor een periode van twee en een half jaar (opleider Prof. dr. W. Boeckx). De vooropleiding chirurgie volgde zij in het Orbis Medisch Centrum, te Sittard (opleider Dr. A.G.M. Hoofwijk). Haar vervolgopleiding startte zij in januari 2007 in het academisch ziekenhuis te Maastricht. De perifere stage werd gevolgd in het Atrium Medisch Centrum (Th. Van der Kar) en na het behalen van het EBOPRAS examen, rondde zij haar vervolg opleiding succesvol af (opleider Prof. dr. Van der Hulst).

Van 1 juli 2010 tot eind 2011 zal zij werkzaam zijn als fellow in de Hand en Pols chirurgie op de afdelingen Plastische, Reconstructieve en Handchirurgie verbonden aan de volgende ziekenhuizen; in Rotterdam het Erasmus Medisch Centrum (Prof. dr. S.E.R. Hovius); in Den Haag het Haga Ziekenhuis (R. Koch); in Amsterdam het Amsterdams Medisch Centrum (Dr. S. Strackeé )en de Vrije Universiteit ziekenhuis (Prof. M. Ritt); in regio Utrecht het Diakonessenhuis (Dr. T. Moojen/R. Feitz).

\section{Curriculum Vitae}

The author of this thesis, Iris Barbara Johanna Gertruda Debats, was born in Bilzen, Belgium, on September $19^{\text {th }}$ 1975. After graduating the Gymnasium at the Stedelijke Scholengemeenschap Maastricht in 1993, she started her medical education at Limburgs Univeritair Centrum, Diepenbeek (B). After two years she switched to Maastricht University and finished her medical education in august 2001.

After medical university, she decided to leave the Southern part of the Netherlands and worked as a resident surgery at Medical Centre De Heel, Zaandam. This was only for a short period, after half a year she came back to Maastricht, to the department of Plastic, Reconstructive and Handsurgery, University Medical Centre. For 3 years she committed to this department as a resident and fulltime researcher on arginine and wound healing. From January 2005 to 2007 she worked as a resident at the department general surgery in Sittard (Head dr. A.G.M. Hoofwijk). In January 2007 she started her residency Plastic, Reconstructive and Handsurgery at Maastricht University Hospital and Atrium Medical Centre in Heerlen (Head Prof. dr. R. van der Hulst, Drs. Th. Van de Kar). Her residency was completed after she successfully took the EBOPRAS exam. 
From $1^{\text {st }}$ of July 2010 until the end 2011 she will be working as a clinical fellow, specializing in hand and wrist surgery, at the departments of Plastic, Reconstructive and Hand Surgery, at the Erasmus Medical Centre Rotterdam (Prof. dr. S.E.R. Hovius); Haga Hospital in the Hague (R. Koch); Amsterdam Medical Centre (Dr. S. Strackeé) and VU Medical Centre in Amsterdam (Prof. dr. M. Ritt); Diakonessenhuis in Utrecht/Zeist (Dr. T. Moojen/R.Feitz). 